TO:

TEST REVIEW BOARD:

R. E. Branstrom, R. D. Clingman, P. W. Davison

FROM: $\quad$ SPEAR Comittee

SUBJECT: $\quad$ SPEAR Report NEPN-1

ENCLOSURE: (1) through (21) SPEAR Nemoranda (see Table of Contents)

Enclosed is the final SPEAR report for NEPN-1. A summary of all analyses is presented in Memorandum No. 1. A nore detailed sumnary of analyses related to the primary objectives of test ce?l overpressure and oxygen pull-in is presented in Memorandum Vo. 2. The remaining memoranda present detailed analyses of specific problems by individual SPEAR Comittee members.

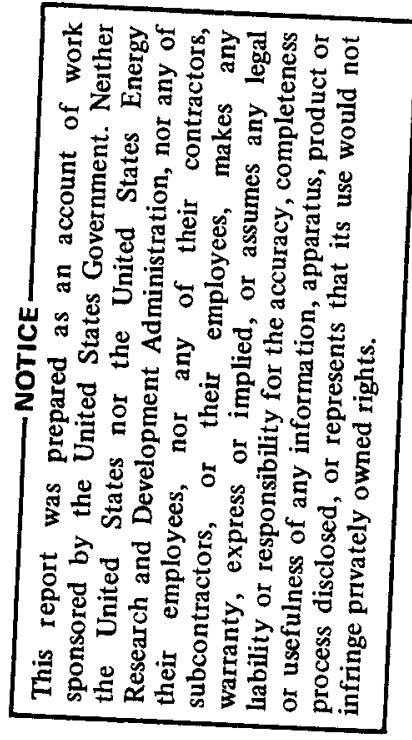

\section{SPEAR COMITTEE}

H. W. Brandt

K. R. Conn

R. G. Cooper

K. D. Cumnings

J. K. Endo

E. J. Fuller

R. J. Gulcie

J. W. Holaday

E. B. Jchnson

C. W. Kensi

M. J. Margetts

D. J. IicCroskey

B. Misra

T. O'Callaghan

J. H. Ransthaler
NTO

NRO

NRO

NRO

$\mathrm{N}+\mathrm{O}$

NTO

NRO

NRO

NTO

NRO

INRO

NTO

NRO

NRO

NRO

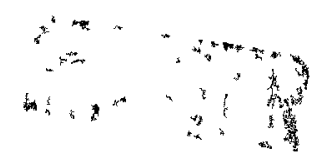

Approved by:

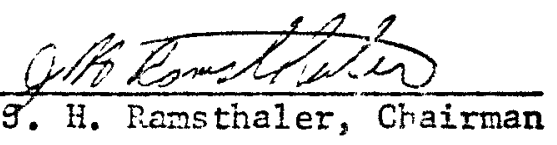

SFEAR Comittee

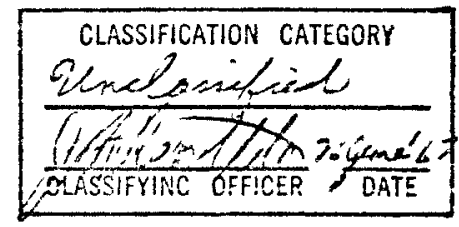




\section{DISCLAIMER}

This report was prepared as an account of work sponsored by an agency of the United States Government. Neither the United States Government nor any agency Thereof, nor any of their employees, makes any warranty, express or implied, or assumes any legal liability or responsibility for the accuracy, completeness, or usefulness of any information, apparatus, product, or process disclosed, or represents that its use would not infringe privately owned rights. Reference herein to any specific commercial product, process, or service by trade name, trademark, manufacturer, or otherwise does not necessarily constitute or imply its endorsement, recommendation, or favoring by the United States Government or any agency thereof. The views and opinions of authors expressed herein do not necessarily state or reflect those of the United States Government or any agency thereof. 


\section{DISCLAIMER}

Portions of this document may be illegible in electronic image products. Images are produced from the best available original document. 


\section{SPEAR REPORT \\ NES Duct Design \\ Demonstration Test \\ NEPN-1}

CONIENTS

SPEAR

Memorandum

(1)

(2)

(3)

(4)

(5)

(6)

(7)

(8)

(9)
Sumary SPEAR Analyses of Test Objectives, Sumary of Anomolies, and Recommendations

Summary SPEAR Analysis of Test Cell Overpressurization and Air Pull-in

Summary of Air Backflow Data (Oxygen Analyzer)

Calculation of Air Backflow Based on NEPN-1 Data

Engine Test Compartment/Duct Aerodynamic Performance

ETC Pressure Oscillations and Overpressure After Shutdown

Seals and Purge System on ETS-I Engine Test Compartment

NEPN-I Test Results on Initial Inerting of ETC, Shield Water Flow Rates, Integrity of the ETC, and ETC Pressure Drop

Evaluation of Primary Gas Blowback
Author

J. H. Ramsthaler

M. J. Margetts

R. J. Gulde

B. Misra

R. J. Gulde/

K. R. Conn

K. R. Conn

K. D. Cummings

J. K. Endo

R. J. Gulde 
SPEAR

Memorandum

(10)

(II)

(12)

(13)

(14)

(15)

(16)

(17)

(19)

(20)
Comparison Permanent and Temporary Oxygen Analyzers

Steam Generator System Operation NEPN-I

Steam Line Condition Analysis

NEPN-I Duct Coolant Water Flow Report

GN Supply System Steady State Performance Characteristics

Results ETC Post Fire Inspection of NEPN-I

Summary Test Description and Chronology of NEPN-1

Evaluation of Strain Gage Data on NES Design Demonstration Test

Minimum Temperature at R045 Outlet

Flare Operation

PT-906A Malfunction During NEPN-I Test No. 4 (PCV-449 Closure)

Data Systems Evaluation
Author

R. J. Gulde

C. W. Kensi

E. J. Fuller

J. W. Holaday

H. W. Brandt

D. J. McCroskey

H. W. Brandt

T. O'Callaghan

J. K. Endo

J. K. Endo

H. W. Brandt

R. G. Cooper/

E. B. Johnson 
SPEAR MEMORANDUM No. 1

24 June 1967

TO: TEST REVIEW BOARD:

K. E. Branstrom, R. D. Clingman, P. W. Davison

FROM: $\quad$ J. H. Rams thaler

SUBJECT: SPEAR Report INEN-1

SPEAR analyses have been completed for NEPIN-1. The following summarizes the SPEAR analyses of test objectives, anomalies noted during investigation, and reconmendations as a result of the studies.

\section{Test Objectives}

1. Determine the effect of steam generator and primary flow shutdown on engine test compartment repressurization and oxygen content

The primary test objective for NEPli-1 was to determine if an unsafe condition could be created by a malfunction of the stean generators which resulted in a loss of duct pumping if hydrogen were in the system. The tests showed that oxygen would enter the test cell if the steam generators were shut down singly or together with no primary flow. $30 \mathrm{Ib} / \mathrm{sec}$ of purge nitrogen reduced the orygen pull-in but did not eliminate it. There were no significant test compartment overpressures produced with the steam generator shutiowns.

When primary flow was terminated at an extreme rate (252 psi/sec) without the steam generators, oxygen was pulled into the engine test compartment. Lower decay rates (78. psi/sec. and 9.7 psi $7 \mathrm{sec}$ ) gave no evidence of oxygen pull-in. Overpressure of the engine test compartment was induced in all cases where the primary flow vas terminated without the steam generators in operation. A 1.6 psi overpressure was produced at a $252 \mathrm{psi} / \mathrm{sec}$ decay rate and $0.2 \mathrm{psi}$ overpressure at. $9.7 \mathrm{psi} / \mathrm{sec}$ decay rate.

The pull-in of oxygen was an indicated possibility from sub-scale tests but the overpressure was not predicted. However, there vere no directly applicable tests conducted in sub-scale. The rapid primary flow shutdowns were conducted without purge in sub-scale and the NEPli-l primary flow shutdowns were always conducted with a high purge flow $\cong 301 \mathrm{~b} / \mathrm{sec}$.

Mass balances using NEPl-1 data indicate higher oxygen content than measured and indicate air backflow during all shutdowns except the final shutdown of Test 5. Both the calculations and measured oxygen contents indicate decreasing backflow with decreasing pressure decay rate and increasing purge rate. These suggest a combination might be found to eliminate the problem. 


\section{Evaluate engine test compartment performance vith steam generators and simulated ergine flow.}

The pull-down of the engine test compartment was close to that predicted. With one steam generator operating, the test compartment pressure was 10.3 psia $( \pm 0.1)$ compared to a 10.2 psia prediction. With two steam generators operating, the test compartment pressure vas $7.9 \pm 0.05$ psia at $1400^{\circ} \mathrm{R}$ steam temperature in four of the five runs, compared to a predicted value of 7.5 psia. In the fifth run the test cell pressure was 7.2 psia $\left(1400^{\circ} \mathrm{R}\right)$. This variance requires additional investigation.

Varying the steam temperature from $800^{\circ} \mathrm{R}$ to $1400^{\circ} \mathrm{R}$ dropped the test compartment pressure $=0.6 \mathrm{psia}$ and the addition of $30 \mathrm{1b} / \mathrm{sec}$ purge flow raised the pressure about $0.4 \mathrm{psi}$. The test compartment pressure generally followed the predicted change with primary flow, but a distinct hysteresis was noted. The test compartment pressure lagged the steady-state value in both increasing and decreasing primary flow rates. During the malfunction of PCV-449 when primary flow vas terminated at $252 \mathrm{psi} / \mathrm{sec}$ the actual test compartment was as much as $40 \%$ belor its steady-state value for the corresponding primary chamber pressure. A similar hysteresis was noted when the steam generators were started up or shut down.

\section{Evaluate engine test compartment seal system}

The engine test compartment seal system performed satisfactorily except for the S-1 bottom seal blade purge. This seal had a leals which persisted throughout the test series. The leak rate was not excessive ( .1 汭/sec) but when the engine test compartment pressure reached 2 psia the $S-1$ bottom seal blade purge pressure dropped below ambient (12.6 psia). In this condition it is possible for air to enter the test cell although none was observed in NEPi- 1 .

A pre-test leak check indicated the leaking seal was suspected and it is felt a basis has been established for developing a control procedure.

4. Evaluation of engine test compartment vater flor

The side-shield water flow was calculated to be slightly below the requirement (1085 computed, 1475 desired). The calculations were performed using YEPI- 1 pressure data and relating it to prior tests where water flows were measured. The NEPN-1 instrumentation location was changed from the previous test and a recomnendation has been made to relocate a pressure tap to increase the confidence in the vater flow calculation. An NRO investigation is required to determine if $1085 \mathrm{lb} / \mathrm{sec}$ is satisfactory.

5. Evaluation of engine test compartment initial inerting

The engine test compartment was inerted to below $3.5 \%$ oxygen in less than one minute. It is concluded that the inerting time and procedure is satisfactory. 
6. Evaluate halo ring nitrogen purge system in engine test compartment

The nitrogen purge systen performed satisfactorily. There were no excessive pressure drops in the system and the control valve was $50 \%$ open at $30 \mathrm{Ib} / \mathrm{sec} \mathrm{flow}$.

\section{Evaluate pressure drop across the intermediate shield in the engine test compartment}

The malfunction of PCV-449 enabled this paraneter to be studied under an extreme condition. There vas no neasurable pressure drop across the intermediate shield at any time, demonstrating that this is no problem.

\section{Evaluate steam generator operation}

The steam generator operation was very successful. The units operated for a total of 1955 minutes and a total of 10 individual startups and shutdowns were logged.

In Test 3 the pumping characteristics were about 10\% better than in the other four tests and the shutdown was slower, 3.5 seconds versus 2 seconds for the others. These items require additional investigation.

\section{Evaluate steam line performance}

The steam Iine showed evidence of considerable movement and high dynamic loads. The water dam appeared only partially successful in keeping water out of the line. It appears that the line nay have been loaded past its yield point and follor-on analys is of the wide-band data is required. to assess the magnitude of this problem.

\section{Duct water flow}

The modification to increase flow to the bottom 8 tubes of section 3 was successful and $1120 \mathrm{gpm}$ were obtained, compared to an $810 \mathrm{gpm}$ requirement.

\section{Nozzle exhaust recirculation}

Thermocouples were located in the nozzle area to determine if gas recirculates into the engine test compartment during primary flow operation. All gases floring were ambient in ITEPiT-1 and no meaningful conclusions could be drawn. Recommendations are included for alternate instrumentation to better assess this item in future tests.

\section{Overcooling of transducers in the upper thrust structure for X-engine testing}

It is planned to locate transducers in the upper thrust structure area which cannot withstand temperatures below $480^{\circ} \mathrm{R}$. The temperature dropped below this minimum for periods of 6 to 18 seconds when nitrogen purge vas terminated. This information must be studied by cognizant instrumentation engineers to determine if corrective action need be taken. 


\section{Duct plume}

Calorimeter radiometers and anemoneters vere placed in the vicinity of the duct plume to determine if the plume could be accurately studied for future hydrogen tests. The data channels have been checked by SPEAR and found to be recording. A detailed follow-on analysis is required to determine that the measurements are satisfactory for the hydrogen tests.

\section{Stress analysis duct}

A quick look was made of limited strain gage data and no overloads were noted. No pre-test predictions were available for comparison and a follow on analysis is required to better assess the observed loads.

\section{Dynamic analysis}

Accelerometer and noise measuring channels have been checked and found to be recording. A detailed follow-on study is needed to determine if there are potential noise or vibration problems with the system.

\section{Flare operation}

The flare successfully operated for the entire test series without an unplanned flare-out. In Test 4 the flare was intentionaliy extinguished during the highest primary flow and failed to ignite in one try. The malfunction of PCV -449 prevented additional attempts. The flare normally requires several attempts for ignition and the test result is not unexpected.

The flare flame-out problem observed in previous tests appears to have been corrected, but there is always the chance of a malfunction which causes a flame-out. A follow-on study to determine the advisability of a redundant system or an improved ignitor appears advisable.

\section{Performance primary nitrogen system lines and valves}

The system supplying nitrogen for the primary flow performed better than anticipated. The pressure drop was lower than predicted and the control valve had a much more linear $C_{v}$ in the low range than anticipated. This gave good control characteristics at low pressure.

\section{Data acquisition}

NEPN- I was used as a try-out for the data reduction programs to be used for X-engine analysis both at NTO and at NRO. The NRO facilities were not used because of budget limitations. However, the NTO procedures were checked.

In general, the NTO data acquisition and reduction system performed satisfactorily. There were thinned data available on $R+1$ and a large percentage of the digital listings were available on $R+2$. An eight-hour computer malfunction prevented the acquisition of all data by $R+2$. The remaining data were available on the morning of $R+3$. The EU tape was 
transmitted to $\mathbb{N R O}$ on $R+I$ per schedule but the wide-band tape dupes were not transmitted until several days later due to IRo budget problems which negated their need. They could have been duped by $R+1$. The ability to produce plots of the data and return them to NTO by $R+2$ was not denonstrated.

A total of 235 channels were used in NEPN-1 and 232 gave valid data in the first data pass. Of the initial discrepancies, 41 vere correctable data reduction errors, giving 12 lost data channels or $96 \%$ efficiency.

An equipment problem vas noted when a combination of problems resulted in the loss of 37 seconds of digital data. Correction of this problem is under investigation by NTO.

\section{Comparison of temporary and permanent gas analyzers}

A preliminary comparison between the permanent and temporary oxygen analyzers indicated that they vere in good agreement. The permanent analyzers gave corresponding readings but they were delayed by about 3 seconds (behind the temporaries) during rapid ramps. Additional study is required on this preliminary analysis.

\section{Summary of Anomalies}

\section{Malfunction of PCV-449}

PCV-449 ramped shut at its maximum rate then PT905 malfunctioned in Test 4. No test objectives were lost.

\section{Engine test compartment overpressure}

Engine test compartment overpressure occurred after each primary flow shutdorn without the stean generators.

\section{Oxygen in the engine test compartment}

An increase in oxygen content was detected in the engine test compartment after the shutdom of one and two steam generators when the primary engine flow was zero. An increase was also detected when primary flow was rapidly terminated without the steam generator operating.

\section{Variations of test cel1 pressure from predictions}

The pre-test prediction report indicated that the test cell pressure would be a fixed function of primary engine flov and steam generator operation. It has been established that there is a dynamic factor which gives a variable relationship depending on ramp rate.

\section{Variation of test cell pressure vith stean generator operation}

In four of the five tests the stean generators produced an engine test compartment pressure reproducible within \pm 0.1 psi. In the third test, the engine test compartment pressure was $10 \%$ Ioser than in the other tests for reasons not yet established. 


\section{S-1 bottom seal blade purge leakage}

The S-I bottom seal blade purge leaked during the entire test series. No problems resulted but a condition which could be dangerous with hydrozen in the system arose when the seal pressure dropped belor ambient.

\section{Low convolute seal pressure}

The convolute seal pressure is designed to be 6 psig. The seal pressure vas 3 psigduring IIEPi-1. ITO is investigating an alternate pressure control valve to eliminate this problem.

8. Convolute seal buffer purge overpressure

The convolute seal buffer purge had an overpressure of 2.4 psigshortly after initiation of seal purge flow. The pressure peaked at 4.4 psig compared to $2.0 \mathrm{psi}$ normal. This resulted in a negative pressure differential of 1.4 in the convolute seals which were at 3 psig. An investigation is required to find means to reduce this transient phenomenon.

9. Side-Shield vater flow

The side-shield water flow was 1285 gpm compared to 1475 desired. A study is necessary to determine if this should be modified.

10. Steam line movement

The steam line again showed deformation. An investigation is required to resolve this phenomenon.

11. Overcooling in the upper thrust structure

The temperature in the upper thrust structure dropped below $480^{\circ} \mathrm{R}$ which is the minimum for transducers which are to be located there in $X$-engine tests

\section{Flare ignition}

The flare railed to ignite in one attempt after a deliberate shutoff during Test 4.

\section{Data acquisition}

The major anomaly in this area was the 37 seconds of digital. data lost during Test 4, due to the tape errors. Twelve transducer malfunctions were obtained. 


\section{RECONMENDATIONS}

1. A study should be conducted to find an improved means for measuring if backflow of air into the duct has occurred (Reference Memos $2 \& 3$ ).

2. Studies should be continued to develop improved means to compute the air backflow into the duct and to develop analytical techniques to predict test cell overpressurization. Use of a computer model is recommended (Reference Memos $2 \& 6$ ).

3. Data analysis should be continued, integrating test results from previous NES duct tests with the NEPN-1 data to develop a more complete understanding of duct operation. (Reference Memos $5 \& 6$ ).

4. Wide-band data should be reduced for the folloving: (Ref. Memos $1,12 \& 17$ )

a. Evaluation of noise levels

b. Study of duct plume

c. Study of duct vibration

d. Study of steam line vibration.

5. A study should be made of the response characteristics of the accelerometers used on the duct in conjunction with the data reduction. (Ref. Memo 17)

6. A follow-on study should be conducted on Test 3 to determine why the steam generators were more efficient than in other runs, and why the shutdowns and startups varied from run to run. (Ref. Memos $5 \& 11$ )

7. A study should be conducted to determine if the low water flow in the side-shield is adequate. (Reference Memo 8)

8. The duct water flow system should be operated at full flow in the next test series to demonstrate all systems are satisfactory. The section 3-B outlet should be checked for vibration during full-flow operation. One of the outlet valves should be closed and the system checked again for vibration. (Reference Memo 13)

9. The side shields and top shields should be instrumented to measure deflections and movement. (Reference lemo 17)

10. A pre-test stress prediction report should be made. (Reference Memo 17)

11. An investigation should be made to determine if the short periods of time below $480^{\circ} \mathrm{R}$ in the UTS area observed in $\mathrm{NEPN}-1$ would harm XE instrumentation. (Reference Memo 18)

12. An alternate means should be studied to evaluate recirculation in the engine test compartment. (Reference liemo 9) 
13. A study should be made on flare ignition. (Reference Memo 19)

14. The permanent oxygen analyzers should not be switched from one tap to another unless an 8-second delay is acceptable. Additional studies should be conducted on the analyzers. (Reference Memos 8 \& 10)

15. The study on the validity of the oxygen analyzer data should be continued. (Reference Memo 10)

16. The pre-test leak check on the test compartment seals should be used as a basis for a control test for future test cell use.

17. A more detailed investigation should be made into the cause of the leakage in the S-1 bottom seal blade purge. (Reference Memo 7)

18. Action should be taken to prevent the lower-than-design pressure problem in the convolute seals from occurring again. (Ref. Memo 7)

19. A study should be made of the cause of the overpressurization of the convolute seal buffer purges. (Reference Memo 7)

20. The range on the seal gas flow transducer should be changed so it is more sensitive in detecting a change in leak rate. (Ref. Memo 7)

21. Steam line measurements should be made as soon as possible. (Ref. Memo 12)

22. Investigate need for water after SGS has been shut down or make it mandatory to cooldown steam in NEP-IV and V before shutdown to prevent the large shutdown $\triangle \mathrm{T}$. (Reference Memo 12)

23. The production of cathode ray tube plots for SPEAR use should be demonstrated as soon as possible. (Reference Memo 21)

24. An investigation should be initiated to determine what can be done to prevent the loss of data as occurred in NEPN-1. (Ref. Memo 21)

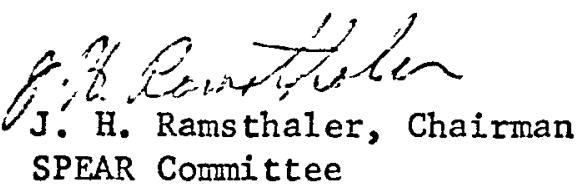




\begin{tabular}{lll} 
TO: & J. H. Ramsthaler & 26 June 1967 \\
FROM: & M. J. Margetts & \\
SUBJECT: & $\begin{array}{l}\text { Summary SPEAR Analysis of Test Cell Overpressurization } \\
\text { and Air Pull-in }\end{array}$ \\
REFERENCE: & (a) Memo B. Mandell from W. L. . Inegar, dated 6 June 67, \\
& \multicolumn{2}{l}{ Subject: ETS-1 Scale Model Testing }
\end{tabular}

\section{INTRODUCTION}

One of the primary purposes of the NEP-N I testing was to demonstrate whether or not (1) overpressurization of the ETC and/or (2) air induction into the NES occur during normal or malfunction shutdown operations. Tests 1 through 3 were designed primarily to investigate steam generator shutdowns while Tests 4 and 5 were to investigate primary flow termination without steam generator flow. More specifically, Test 1 was to define shutdown phenomenon during a normal mode shutdown; i.e., first one generator to idle, then the other. Test 2 was a malfunction case where both steam generators were brought to idle simultaneously. Test 3 was similar to Test 2 with the exception of an increase of purge flow into the ETC to $30 \mathrm{lb} / \mathrm{sec}$. Test 4 was intended to investigate steam generator shutdown with primary chamber pressure of 120 psia and primary flow termination at a normal rate without the steam generators. A failure occurred, however, causing the nozzle pressure decay rate to be much greater than originally programmed ( 252 \#/sec actual rate). Test 5 was to investigate steam generator malfunction with chamber pressure at 60 psia followed by a normal flow termination. This test went as planned.

\section{SUMMARY}

A. Significant findings are as follows:

The important findings of NEPN-I, regarding NES performance,

1. Overpressurization of the ETC does not occur as the steam generators are either independently or simultaneously brought to idle without primery on high purge flow.

2. Overpressurization of the ETC does occur with the termination of primary flow without the steam generators in operation and with relatively large amounts of $\mathrm{GN}_{2}$ purge flow $(30 \mathrm{lb} / \mathrm{sec})$. The overpressurization varies with the rate of primary flow decay. 
3. "Ringing" or pressure oscillations occurred for all cases where (I) steam generators were brought to idle without primary flow and where (2) primary flow vas normally terminated without steam generator flow.

4. Reverse flow (and therefore air induction into the NES) occurs in all cases of steam generator shutdown without primary flow. However, $\mathrm{GN}_{2}$ purge flow does aid in reducing its effect in the ETC.

5. Calculations indicate air backflow when one steam generator is shutdown with the second running but none was measured.

6. Oxygen was measured and computed to be in the test compartment when primary flow was terminated at a rapid rate without the steam generators, but with a high purge flow (252 psi/sec). At lower flow rate terminations $78-9.7 \mathrm{psi} / \mathrm{sec}$ no oxygen was neasured in the test compartment with the high purge flow. Calculations indicated air backflow at $78 \mathrm{psi} / \mathrm{sec}$ but not at $9.7 \mathrm{psi} / \mathrm{sec}$.

7. The shutdown of one steam generator with the second running and the simulteneous shutdown of two steam generators gave two steam pressure decay rates over the initial portion of the shutdown ramp. Quick look calculations on the response of the test compartment pressure to the different rates indicate they may form a basis for computing the decay rate which would result in no oxygen backflow.

8. The pumping effectiveness of the secondary ejectors varied between tests with no appreciable changes in steam conditions (pressure or temperature). This appears to indicate some change in the operation of the steam generators.

\section{B. Instrumentation}

Two close-coupled pressure transducers were located in the engine compartment to record any overpressurization. These appeared to work satisfactorily. Four close-coupled temporary $\mathrm{O}_{2}$ analyzers were also located in the E'TC to identify the presence of air due to reverse flow. These gave $\mathrm{O}_{2}$ readings but there is some question as to their peak readings because of their response time. Smoke bombs were located at the duct exit to visually demonstrate reversal of flow into the duct and a burning tire was placed at the duct exit. These were grossly ineffective and little can be said regarding the visual documentation of air backflow for the NEP N-I tests. A break in steam flow was noted on some tests but no backflow. Pressure transducers were available in the steam line to measure pressure decay, one close to the duct and the second close to the steam generators. The transducer close to the duct malfunctioned in Test il making it necessary to use the transducer close to the steam generators for comparison with other runs. 
III. DISCUSSION

A summary of pertinent information relating to each of the shutdowns during NEP N-I is shown on Table of these tests were the fact that (1) reverse flow occurs in all shutdown modes of the steam generators without primary flow and (2) significant overpressurization occurs during relatively slow primary flow termination without steam generators.

The primary indication of reverse flow were from presents of oxygen noted on the $\mathrm{O}_{2}$ analyzer in the ETC. These gave definite indication of $\mathrm{O}_{2}$ present in Test $7 I$ during shutdown of the second steam generator, in Test $\# 2$, in Test $\$ 3$, and also in Test $\# 4$ in which the failure occurred. The indications were that air was being pulled up into the ETC very shortly after the steam flow termination began. A typical example of this occurrance is shown in Figure 1. Here we see that at approximately $0.7-0.8$ seconds after steam decay starts $O_{2}$ is apparently indicated in the ETC. This occurs even though steam pressure has decayed to a level of only 44 psia. The implication here is that the secondary ejector pumping capability must fail causing the steam availabile in the duct during the $.7 \mathrm{sec}$. increment plus air to flow back into the duct. It has been computed ( (first pressure peak) not enough steam and $\mathrm{GN}_{2}$ are available in the duct to pressurize the system. It is therefore concluded that the remainder of the mass must be air. The $\mathrm{O}_{2}$ analysers tended to corroborate this inplication.

The only case where air induction was definitely ruled out was in Test $\$ 5$ where primary flow was slowly terminated $(9.7 \mathrm{psi} / \mathrm{sec})$ with no steam generators on but with $25 \mathrm{lb} / \mathrm{sec}$ of $\mathrm{GN}_{2}$ purge flow. Here both experimental data and analytical efforts agreed. However, during the time period when the nozzle pressure was at 60.1 psia steady state and both steam generators were brought to idle simultaneously, experimental data indicate no presents of $\mathrm{O}_{2}$ whereas the analytical model indicates this to be marginal.

A cross plot of pressure decay rate versus the average measured test cell oxygen content is snown on Figure \#2. This plot while showing considerable scatter indicates the lower pressure decay rates tend to pull less oxygen into the test cell. There are also indications that the purge might raise the maximum allowable pressure decay rate.

Negligible overpressurization occurred during the shutdown of the steam generators (Tests 1,2 and 3 ). However overpressurizations occurred in all cases when primary flow was terminated without steam generators. The overpressures were not predicted, but the subscale tests, which were the basis for the predictions did not include the high purge. flow rates which were present during all of the shutdowns iñ which overpressurization occurred. The relation of pressure decay rate and overpressure is plotted on Figure 3. 
It is interesting to note that overpressure of the ETC can occur without experiencing any reverse flow. This was demonstrated in Test \#5. Equally noteworthy is the fact that severe reverse flow can exist with no overpressurization. This was demonstrated in Test $\# 2$ and also in scale model work.

\section{Recommendations}

1. Although the systems appeared to withstand the overpressurization generated during Test $\mathbb{\# 4}$ a better understanding of the overpressurization and "ringing" (pressure oscillations) phenomena is indeed necessary in light of the obvious consequences. It is therefore recommended that further analysis be made of the NEP N-I data to give this understanding. A theoretical model also, should be developed that can (I) account for the subscale and full scale differences regarding ETC overpressurization and (2) fully explain and define the mechanisin of ETC overpressurization and pressure oscillation so that any full scale occurrence can be anticipated and predicted with confidence.

2. It was experimentally demonstrated (analytical efforts concurred) that air backflow into the ETC can be reduced and possibly prevented with increasing purge flow and slower decay rates. It is therefore recommended that the time-dependent-mass-inventory model be (see vemo 4) sophisticated and computerized such that an optimum combination of decay rate and purge flow can be defined which will prevent air back flow. This model should be tested with experimental data from the scale model test such that confidence in its ability to arrive at a solution is established.

3. In the next $\mathrm{DDT}(\mathrm{NEP}-5)$ it is felt imperitive that the following be documented:

(a) Static pressure at a point near the steam injection plane on the secondary ejectors. This will positively define the pressure/time relation at that point which is important in calculating secondary ejector pumping capability on an instantaneous basis and in relation to steam flow and ETC repressurization.

(b) Visual evidence of air inductions into the duct. Sufficient smoke should be made available to adequately document this occurrence. Also high speed movie cameras operating at no less than 400 frames per sec should be used instead of the 16 to 24 frames/sec ones that were used.

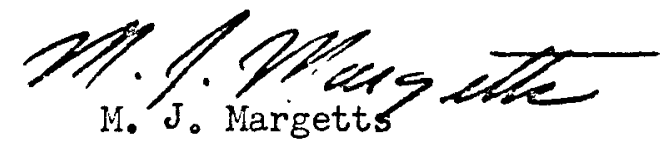




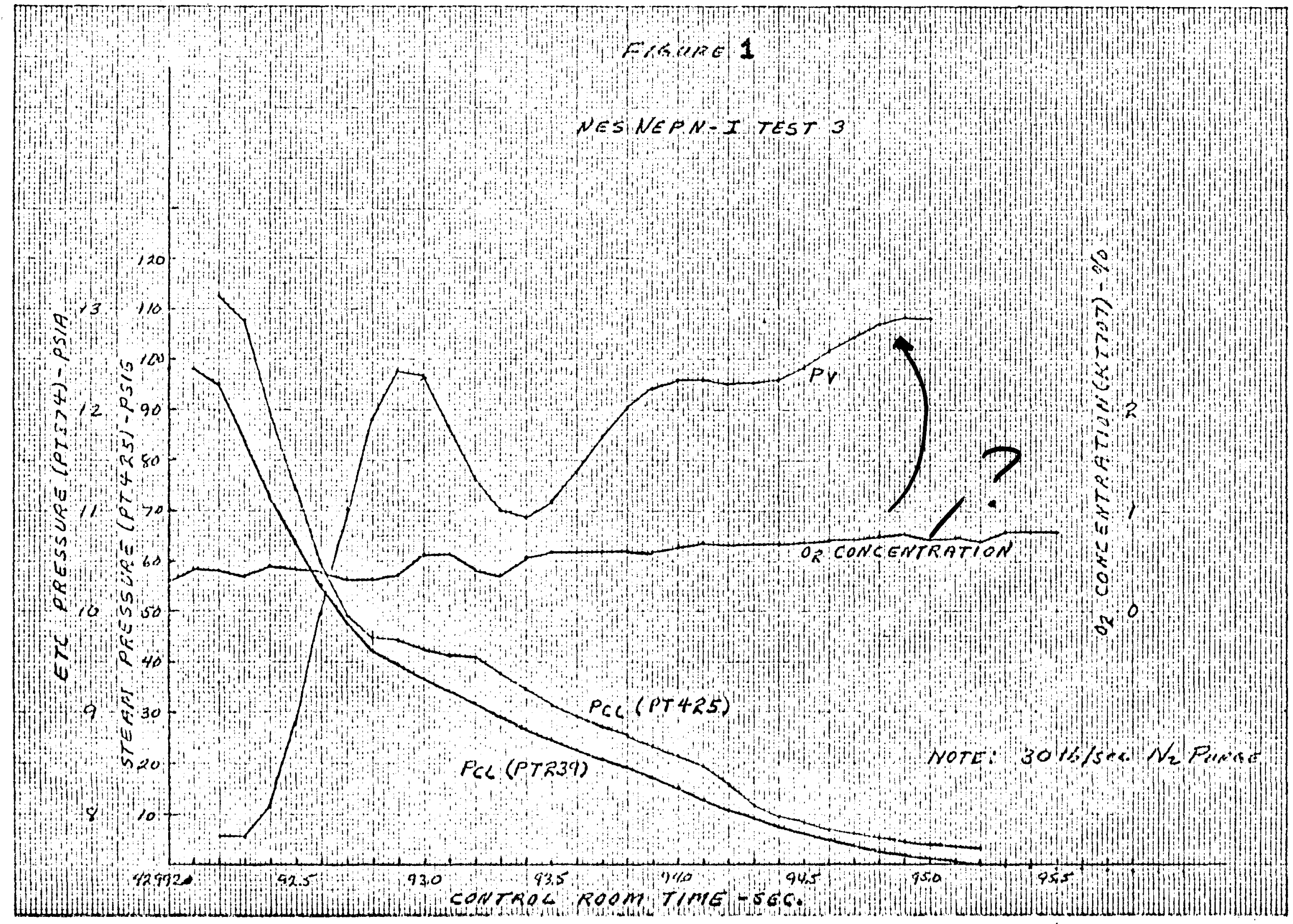




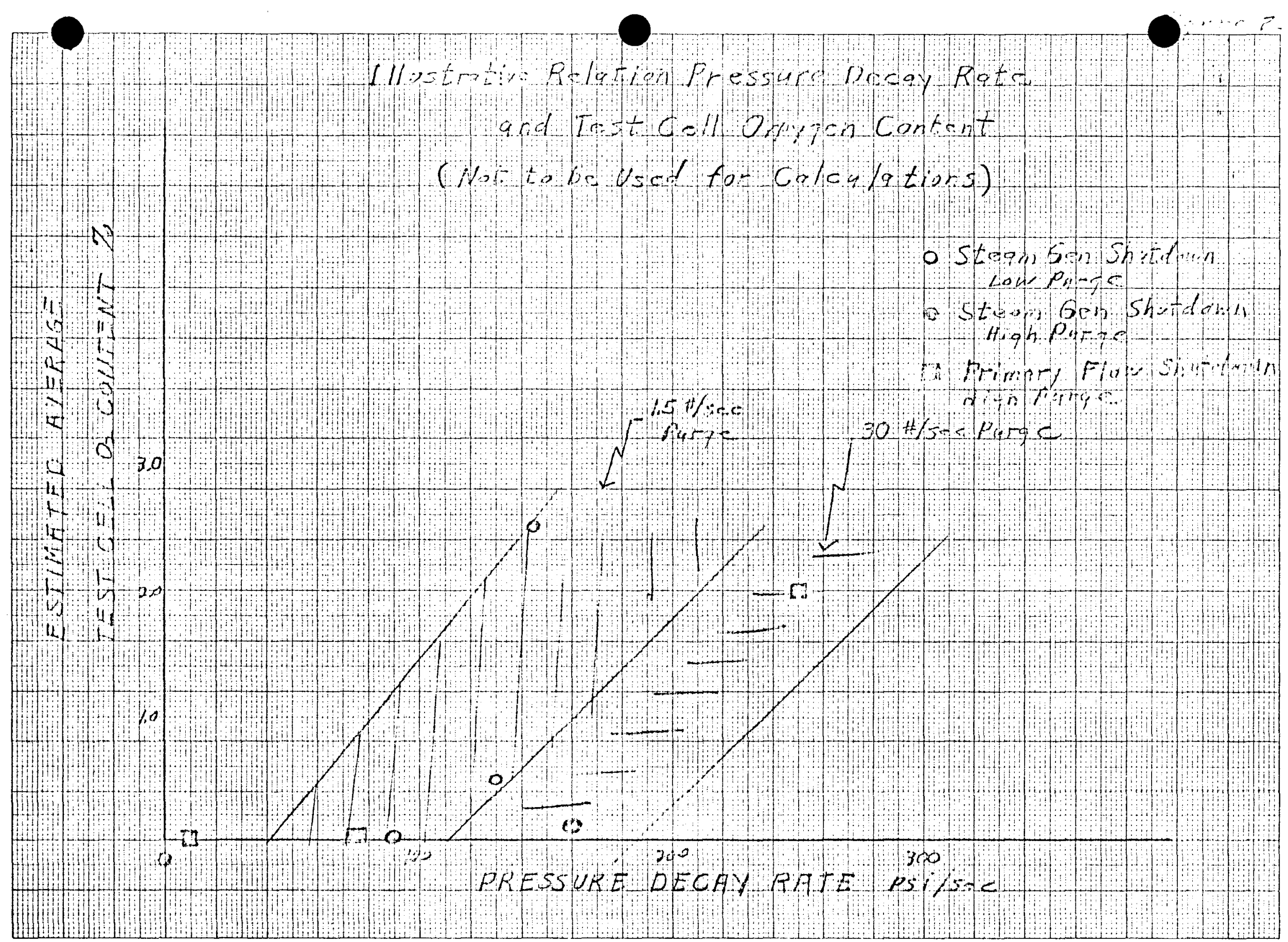




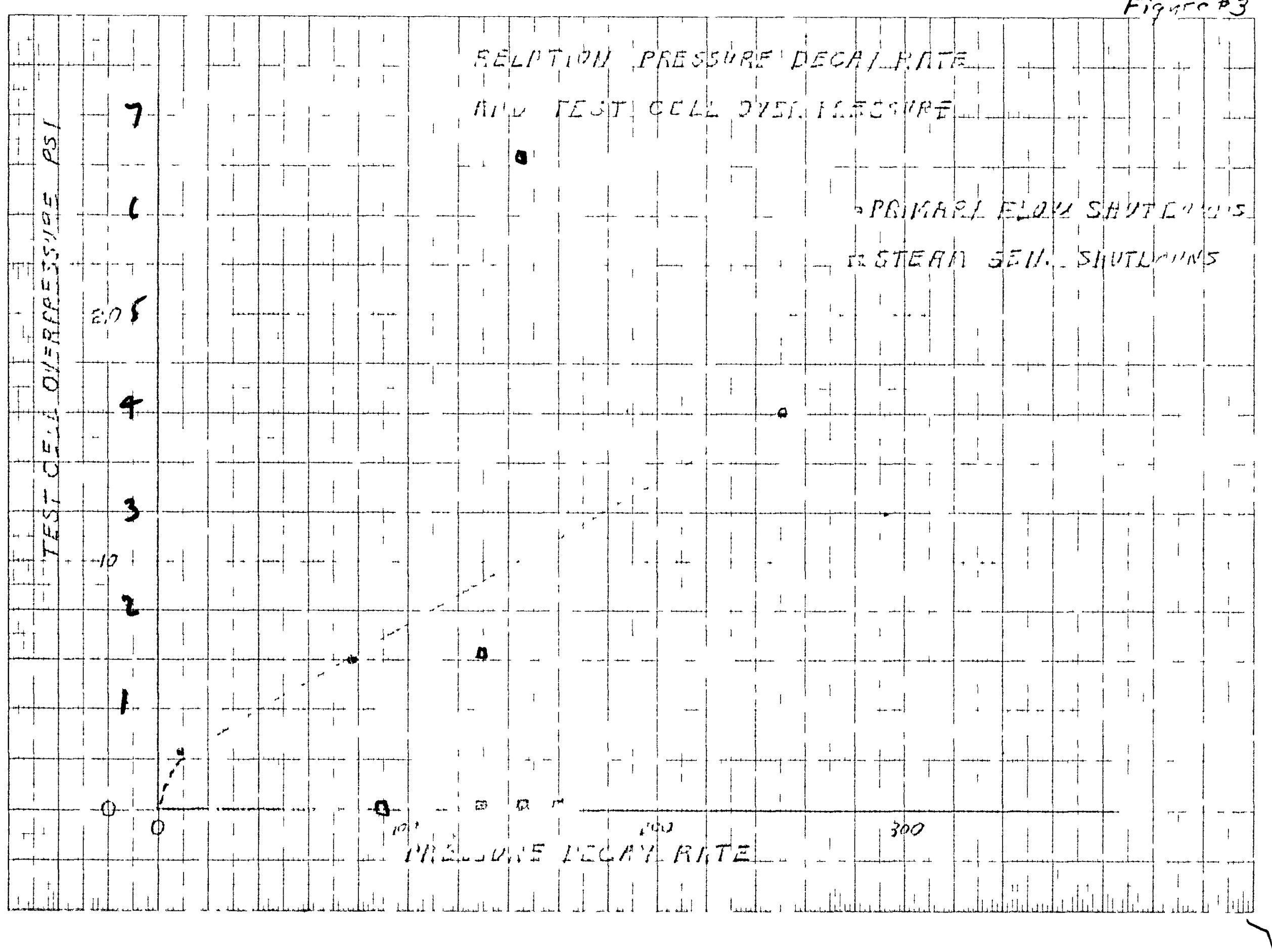


SUMMARY SHUTDOWNS NEP N-1

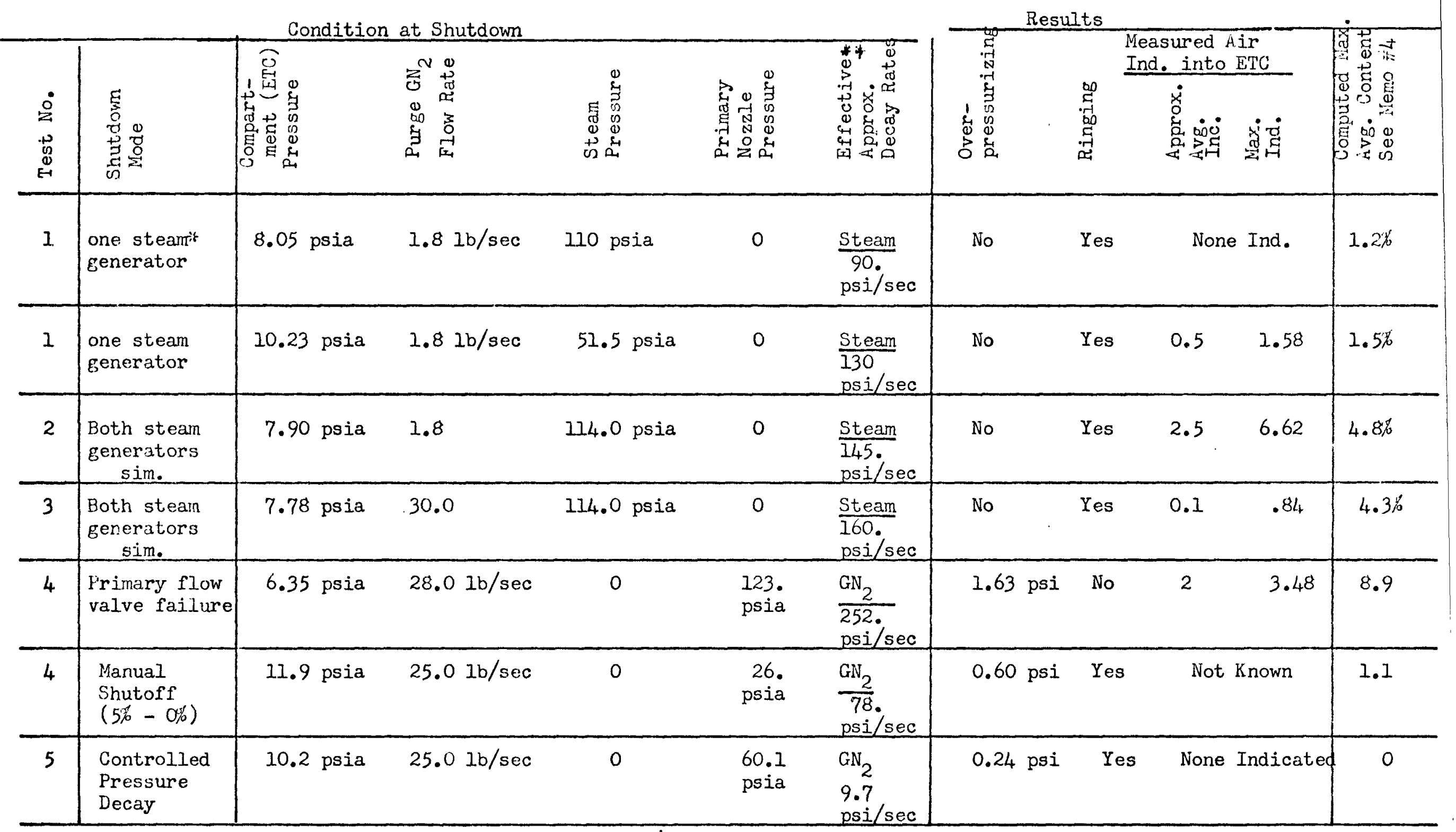

* One steam generator down to idle while other was held at full steam.

* Main portion of shutdown ramp which was relatively linear. Steam decay rates are based on PT 4 \& 5 which was available for all runs (see memo \#6 for details) 
SPEAR MEMORAITUM NO. 3

\author{
TO: J. H. Ramsthaler 23 June 1967 \\ FROM: $\quad$ R. J. GuIde \\ SUBJECT: Summary of Air Backflow Data (Oxygen Analyzers) \\ ENCLS: (1) Figure 1, Location of Oxygen Analyzers \\ (2) Table 1, Oxygen Concentration Data
}

To evaluate backflow of air into the duct and ETC when steam or primary flow is terminated, temporary, fast response oxygen analyzers were installed in the ETC and smoke bombs were located at the duct exit. A burning rubber tire was also provided at the duct exit to supplement the smoke bombs.

The location of the oxygen analyzers in the ETC are shown in Figure 1. Data from KTTO4, KT7O5, KT706 and KT7OT were used to analyze air backflow. Analyzers KTOOL and KTOO2 vere not used since the calibration data indicated an error and response time was longer in comparison to the other analyzers.

It was not possible to determine from a review of rilm of the duct exit whether reverse flow was obtained. A break in the steam plume vas noted at the time of shutdown, but reverse flow could not be detected. Of the two smoke bombs provided, one did not ignite, and the rubber tire was not burning at the time of the test.

During Test No. I the steam generators were shutdow normally by returning one generator at a time to idle. After shutdown of the second generator, the oxygen analyzers indicated a relatively small amount of air backflow. As shown in Table 1 , the oxygen concentration increased from 0.30 to $1.58{ }^{\prime} \circ$ maximum.

The steam generators vere shutdom at the same time during Test No. 2 simulating a malfunction. The oxygen analyzers indicated a large amount of air backflow. At the bottom of the ETC, the oxygen concentration increased from 0.50 to 5.620 maximum. Other analyzers also showed an increase but to a lesser extent. A gradient in oxygen concentration was seen within the ETC. The oxygen concentration decreased from $6.6 x^{\prime \prime}$ at the bottom to $1.33 \%$ at the top of the ETC.

In Test No. 3 the steam generators were shutdown at the same time as in Test No. 2 except that the nitrogen purge was $30 \mathrm{lbs} / \mathrm{sec}$ instead of 1.8 $\mathrm{lbs} / \mathrm{sec}$ at the time of shutdom. The oxygen analyzers showed only a slight increase in concentration which demonstrates that $30 \mathrm{lbs} / \mathrm{sec}$ of nitrogen purge greatiy reduces backflow of air into the ETC. 
During Test No. 4 a malfunction occurred which caused a very rapid shutdown of primary flow. At this time both steam generators were at idle, the ETC pressure was 6.3 psia, and nitrogen purge was about $26 \mathrm{lbs} / \mathrm{sec}$. After the malfunction, the oxygen concentration in the ETC increased from 0 to $3.48 \%$ maximum indicating air backflo w. With rapid termination of primary flow (PC rampdown of $250 \mathrm{psi} / \mathrm{sec}$ ), nitrogen purge of $26 \mathrm{lbs} / \mathrm{sec}$ was apparently insufficient to prevent backflow of air.

Primary flow was shutdown with the steam generators at idle and with nitrogen purge of $25 \mathrm{lbs} / \mathrm{sec}$ during Test No. 5. The oxygen analyzers showed no increase in oxygen concentration after shutdown. This demonstrates that with a normal rampdown of primary flow ( $9.7 \mathrm{psi} / \mathrm{sec})$, a $25 \mathrm{lbs} / \mathrm{sec}$ nitrogen purge will prevent air backflow into the ETC.

Since the oxygen analyzers were located only in the ETC, the level of concentration in the duct after shutdown was not measured. The oxygen concentration in the duct will be higher than in the ETC during periods of air backflow and, therefore, has the greatest potential for dangerous oxygen concentration levels. It has been recommended to Test site personnel that oxygen analyzers be located in the duct during subseguent test muns.

In summery, the results of these tests show that oxygen will enter the test compartment when the steam generators are shutdown and when primary flow is shutdown at a rapid rate. A nitrogen purge of $301 \mathrm{bs} / \mathrm{sec}$ will help prevent backflow of air into the test compartment when the steam generators are shutdown and with rapid termination of primary flow.

Even with purge, it is not known whether air has entered part of the duct. The test results also indicate that an unsafe condition could be created with hydrogen if a combination of malfunctions occurred which resulted in a complete duct shutdown in a hydrogen environment.

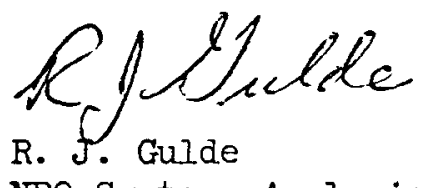

NRO Systems Analysis Department 
TABIE I

Test 1

OXYGEN CONCINTRATION DATA

$\begin{array}{rrrrrr}\text { Time } & \text { KT704 } & \text { KT705 } & \text { KT706 } & \text { KT707 } & \text { Remarks } \\ 42480.9 & .93 & .29 & .34 & .30 & \text { NoI S.G. to idle (42476) } \\ 81.9 & .95 & .38 & .29 & .29 & 1.8 \mathrm{~N}_{2} \text { Purge } \\ 82.9 & .98 & .37 & .27 & .40 & \\ 83.9 & 1.04 & .42 & .37 & .47 & \\ 84.9 & .98 & .41 & .35 & .47 & \\ 85.9 & 1.02 & .40 & .18 & .38 & \\ 86.9 & 1.07 & .38 & .24 & .40 & \\ 87.9 & 1.02 & .46 & .29 & .35 & \text { No.2 S. G. to idle (42488) } \\ 88.9 & 1.06 & .45 & .47 & .47 & \\ 89.9 & 1.08 & .81 & .92 & .77 & \\ 90.9 & 1.09 & 1.13 & 1.16 & .98 & \\ 91.9 & 1.09 & 1.33 & 1.42 & 1.13 & \\ 92.9 & 1.03 & 1.37 & 1.50 & 1.26 & \\ 93.9 & .97 & 1.45 & 1.47 & 1.38 & \\ 94.9 & .96 & 1.49 & 1.37 & 1.48 & \\ 95.9 & .94 & 1.47 & 1.35 & 1.48 & \\ 96.9 & .93 & 1.41 & 1.38 & 1.49 & \\ 97.9 & .95 & 1.46 & 1.37 & 1.53 & \\ 98.9 & .92 & 1.49 & 1.33 & 1.55 & \\ 99.9 & .94 & 1.54 & 1.39 & 1.58 & \\ 500.9 & .97 & 1.54 & 1.37 & 1.53 & \\ 01.9 & .98 & 1.53 & 1.42 & 1.51 & \\ 02.9 & .99 & 1.51 & 1.45 & 1.48 & \end{array}$

Test 2

$\begin{array}{rrrrrr}42780.2 & 1.01 & .47 & .34 & .50 & 1.8 \mathrm{~N}_{2} \text { Purge } \\ 81.7 & 1.06 & .51 & .35 & .45 & \text { Both S.G. to idle (42782) } \\ 82.7 & 1.18 & .55 & .13 & .49 & \\ 83.7 & 1.16 & .63 & .92 & 1.40 & \\ 84.7 & 1.25 & 1.04 & 1.40 & 2.35 & \\ 85.7 & 1.31 & 1.69 & 1.84 & 4.18 & \\ 85.7 & 1.33 & 2.02 & 2.20 & 4.93 & \\ 87.7 & 1.24 & 2.26 & 2.43 & 5.02 & \\ 88.7 & 1.20 & 2.42 & 2.71 & 5.57 & \\ 89.7 & 1.16 & 2.42 & 2.59 & 6.24 & \\ 90.7 & 1.16 & 2.43 & 2.57 & 6.62 & \\ 91.7 & 1.16 & 2.29 & 2.51 & 6.46 & \\ 92.7 & 1.17 & 2.23 & 2.45 & 5.84 & \\ 93.7 & 1.19 & 2.34 & 2.31 & 5.25 & \\ 94.7 & 1.23 & 2.39 & 2.46 & 4.53 & \\ 95.7 & 1.23 & 2.61 & 2.49 & 3.94 & \end{array}$


$\underline{\text { Time }} \underline{\text { KT704 }} \underline{\text { KT7C5 }} \underline{\text { KT706 }} \underline{\text { Kt707 }} \underline{\text { Remarks }}$

Test No. 3

\begin{tabular}{|c|c|c|c|c|c|}
\hline $\begin{array}{r}42985.5 \\
86.5 \\
87.5 \\
88.5 \\
89.5 \\
90.5 \\
91.5 \\
92.5 \\
93.5 \\
94.5 \\
95.5 \\
96.5 \\
97.5 \\
98.5 \\
96.5 \\
43000.5 \\
01.5\end{array}$ & $\begin{array}{l}.78 \\
.66 \\
.66 \\
.47 \\
.47 \\
.57 \\
.42 \\
.12 \\
.14 \\
.24 \\
.20 \\
.25 \\
.14 \\
.18 \\
.15 \\
.09 \\
.08\end{array}$ & $\begin{array}{l}.37 \\
.42 \\
.33 \\
.27 \\
.25 \\
.17 \\
.20 \\
.14 \\
.20 \\
.27 \\
.37 \\
.43 \\
.40 \\
.37 \\
.37 \\
.31 \\
.28\end{array}$ & $\begin{array}{l}.56 \\
.49 \\
.40 \\
.51 \\
.39 \\
.25 \\
.28 \\
.57 \\
.44 \\
.53 \\
.57 \\
.57 \\
.48 \\
.43 \\
.47 \\
.43 \\
.35\end{array}$ & $\begin{array}{l}.51 \\
.49 \\
.50 \\
.49 \\
.44 \\
.43 \\
.45 \\
.42 \\
.58 \\
.69 \\
.78 \\
.83 \\
.84 \\
.71 \\
.58 \\
.55 \\
.49\end{array}$ & Both S.G. to idle (42992) \\
\hline
\end{tabular}

Test No. 4

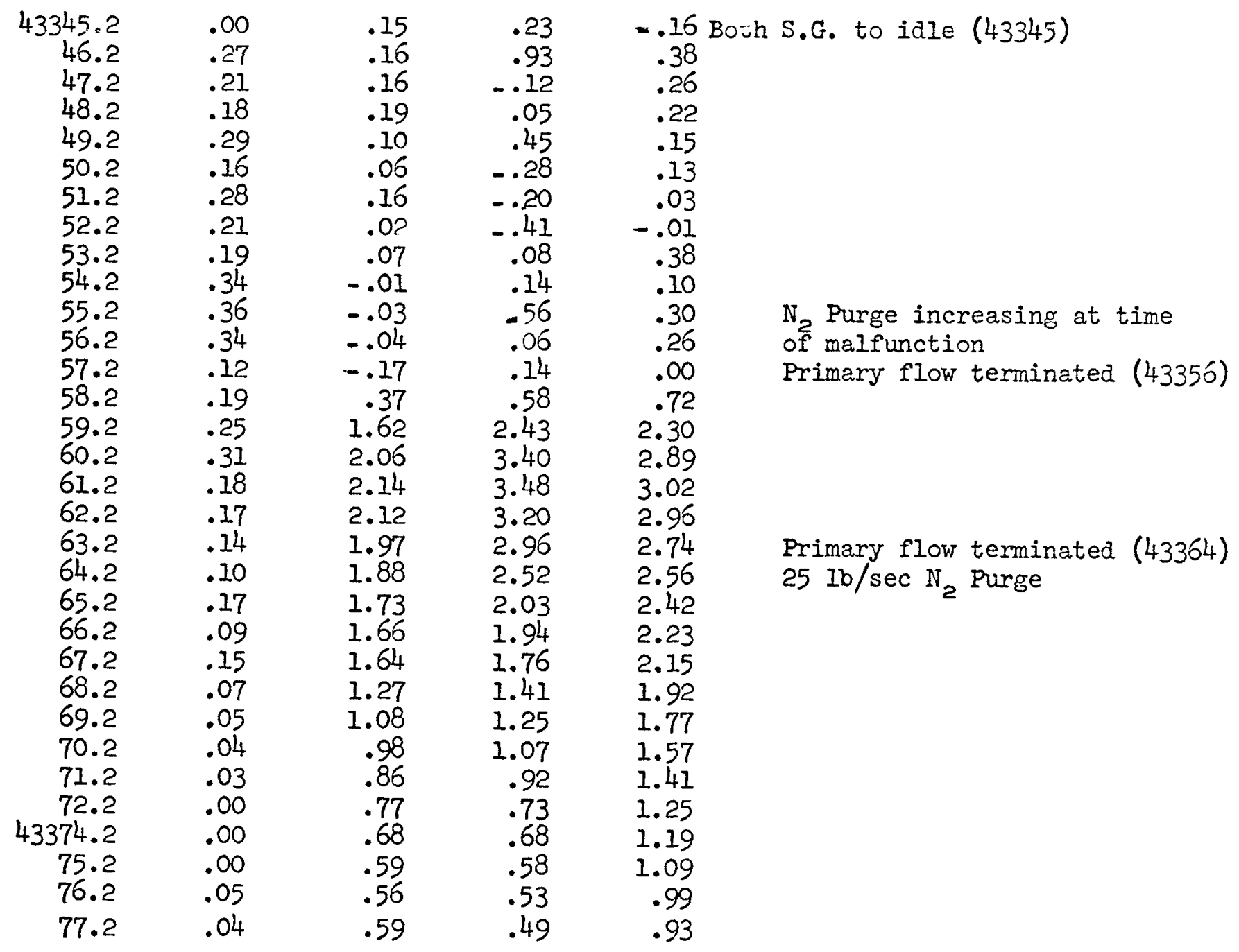


$\underline{\text { Time }} \underline{\text { KT704 KT705 KT706 KT707 }} \underline{\underline{\text { Remarks }}}$

\section{Test No. 5}

$\begin{array}{rrrrr}44170.1 & .84 & .39 & .03 & .83 \\ 71.1 & .81 & .23 & .34 & .81 \\ 72.1 & .77 & .24 & .34 & 1.08 \\ 73.1 & 1.03 & .29 & .41 & .85 \\ 74.1 & .88 & .26 & -.02 & .82 \\ 75.1 & .99 & .23 & -.14 & .96 \\ 76.1 & 1.09 & .20 & .20 & .87 \\ 77.1 & .96 & & -.16 & 1.03 \\ 78.1 & .91 & .22 & .05 & .83 \\ 79.1 & .91 & .12 & .05 & .83 \\ 80.1 & .91 & .06 & -.17 & .88 \\ 81.1 & 1.00 & .01 & .20 & .74 \\ 82.1 & 1.04 & .20 & -.43 & .75 \\ 83.1 & 1.05 & & -.27 & .99 \\ 84.1 & .99 & & -.14 & .75 \\ 85.1 & .86 & & .20 & .90 \\ 85.1 & .84 & .32 & .16 & .78 \\ 87.1 & .77 & .23 & .11 & .85 \\ 88.1 & .61 & .19 & .27 & .85 \\ 91.1 & .43 & .30 & .22 & .89 \\ 92.1 & .40 & .28 & .15 & .90 \\ 93.1 & .35 & .29 & .19 & .89 \\ 94.1 & .30 & .30 & .23 & .82\end{array}$

Both S.G. to idle (44171)

$25 \mathrm{lb} / \mathrm{sec} \mathrm{N}_{2}$ Purge

Primary flcw shutdown (44186) 


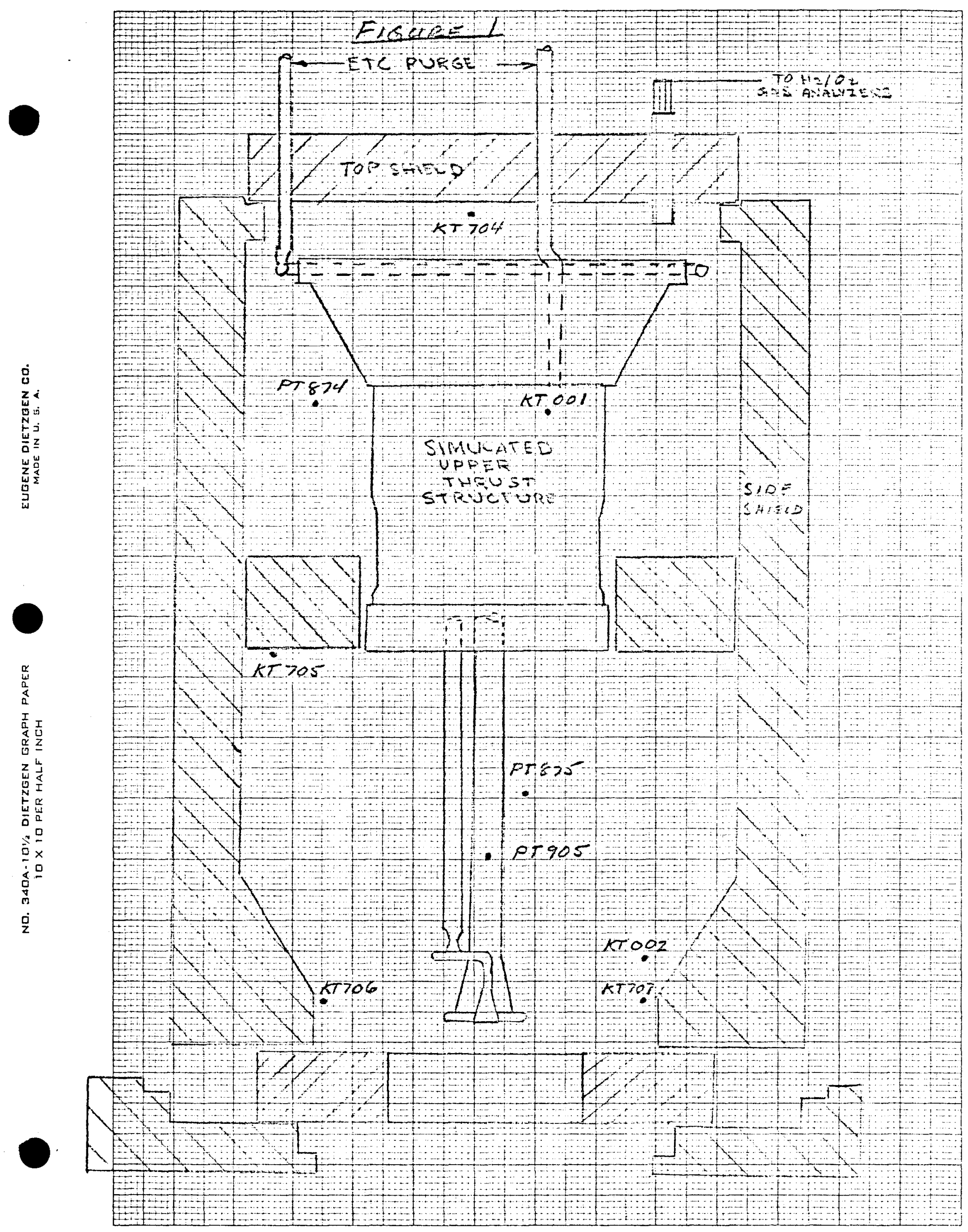


SPEAR MEMORANDUM NO. 4

26 June 1967

TO:

J. H. Rams thaler

FROM:

B. Misra

SUBJECT:

Flow Transients and Air Backflow in ETS-I Duct

Enclosures:

Transient Plots

The behaviors of ETS-I duct under transient conditions as represented by the flow rates, temperatures, pressures and oxygen concentration for the various runs are summarized in Figures $1-8$. To understand the dynamic behavior of the system, such as pressure surges, reverse flow, etc., it would require an extensive analysis of the three-dimensional flow field produced by the complex geometrical configuration of the system. However, a purely empirical approach to the complex flow problem was made based on mass balances alone to try to understand the gross behavior of the system and, if possible, to establish the operating conditions under which air back flow may occur. It may be noted that pressure surges cannot be studied on mass balances alone without taking the ineritial effects of the fluid into account.

Due to lack of adequate data, as well as sufficient time for data analysis, it was assumed that the primary duct and the entire cell attain the same temperature and pressure instantaneously. It was further assumed that the fluids involved are the same and obey the perfect gas laws. The indicated temperatures in the test compartment were used where necessary, although the temperatures seemed to be low.

From the experimental data, the change in mass of the fluid in the cell, the primary, secondary and the purge fluid flow during each 0.1 second of operating time were calculated. The difference in the change in mass of the cell fluid and the combined mass flow of the primary, secondary and the purge fluid was assumed to be air. Thus, from these data one can establish the time at which air black flow may occur. Similarly, the concentration of oxygen in the cell may be calculated assuming perfect mixing of the fluids. The calculated data up to the time when the first pressure peak was observed during Run No. 1, 2, 3 and 4, and the first 1-second of operation for Run No. 5 are summarized in Table 1 . The experimental data on the oxygen concentration do not correspond to the same time as the calculated data. This could be due to the appreciable lag in the oxygen analyzer on to the inherent uncertainties in the mass balances as shown. 
The examination of the calculation shows that air back-flow occurred during all experiments except Run No. 5. There is poor agreement between the absolute values of the calculated and the measured concentration of oxygen due to lag in the response of the oxygen analyzer as reasons mentioned above. There was relative agreement between the two, however, the tendency towards increasing and decreasing levels agreeing. A cursory examination of the results shows that by decreasing the rate of repressurization of the cell, which may be accomplished either by (1) more purge gas flow, (2) primary fluid flow or (3) decreasing the rate of pressure decay of the secondary fluid, it appears as though the $\mathrm{O}_{2}$ back flow can be eliminated. By establishing the proper relation between the cell repressurization rate and the secondary fluid pressure decay under a set of transient conditions which prevents air black flow, the volume of the secondary fluid (accumulation) may be established.

B. Misra

B. Misra

$\mathrm{BM}: \mathrm{mk}$ 


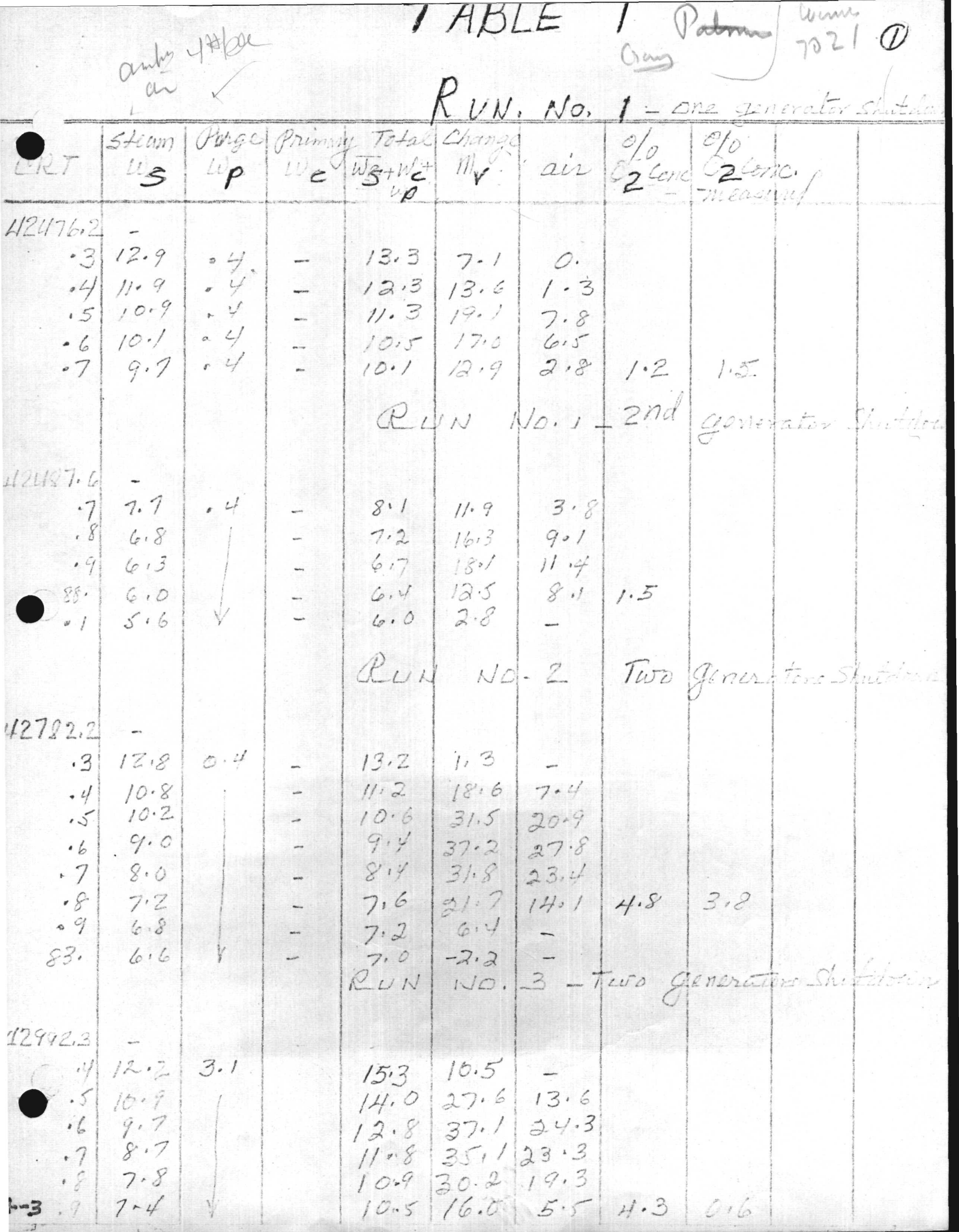




$$
\text { TABLE / (Cont'A) }
$$

(3) 


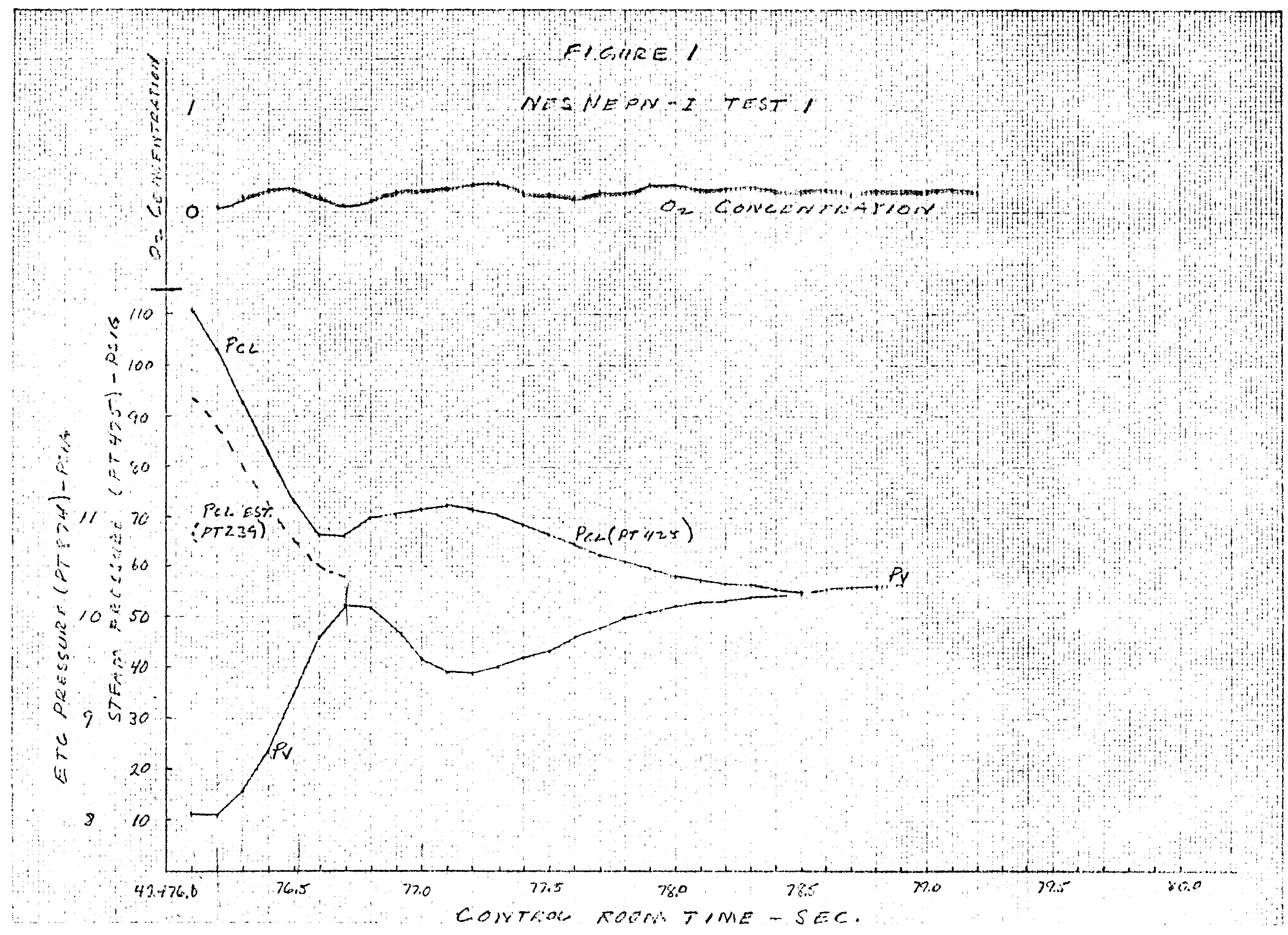




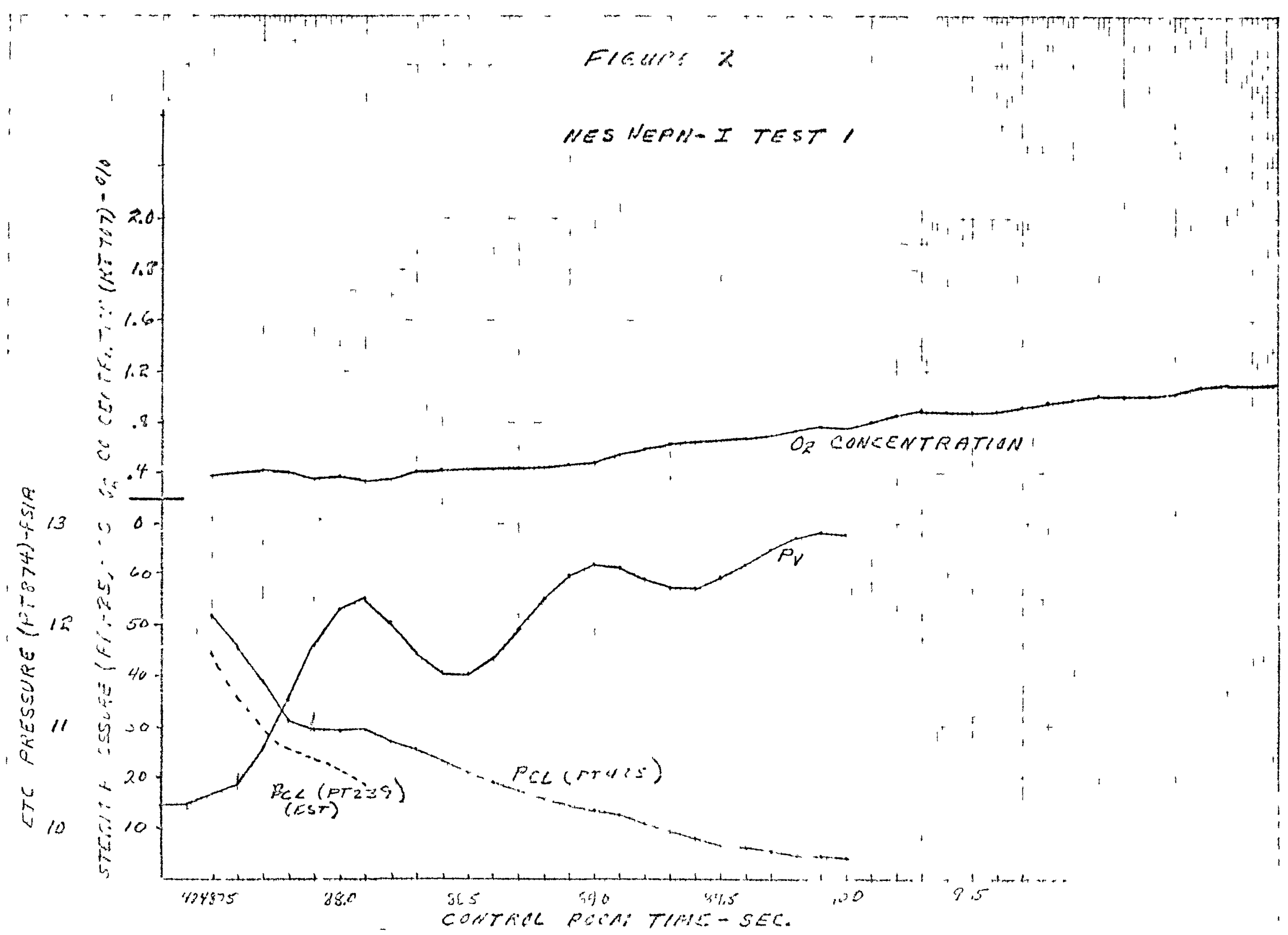


Vur Ganah shaddom

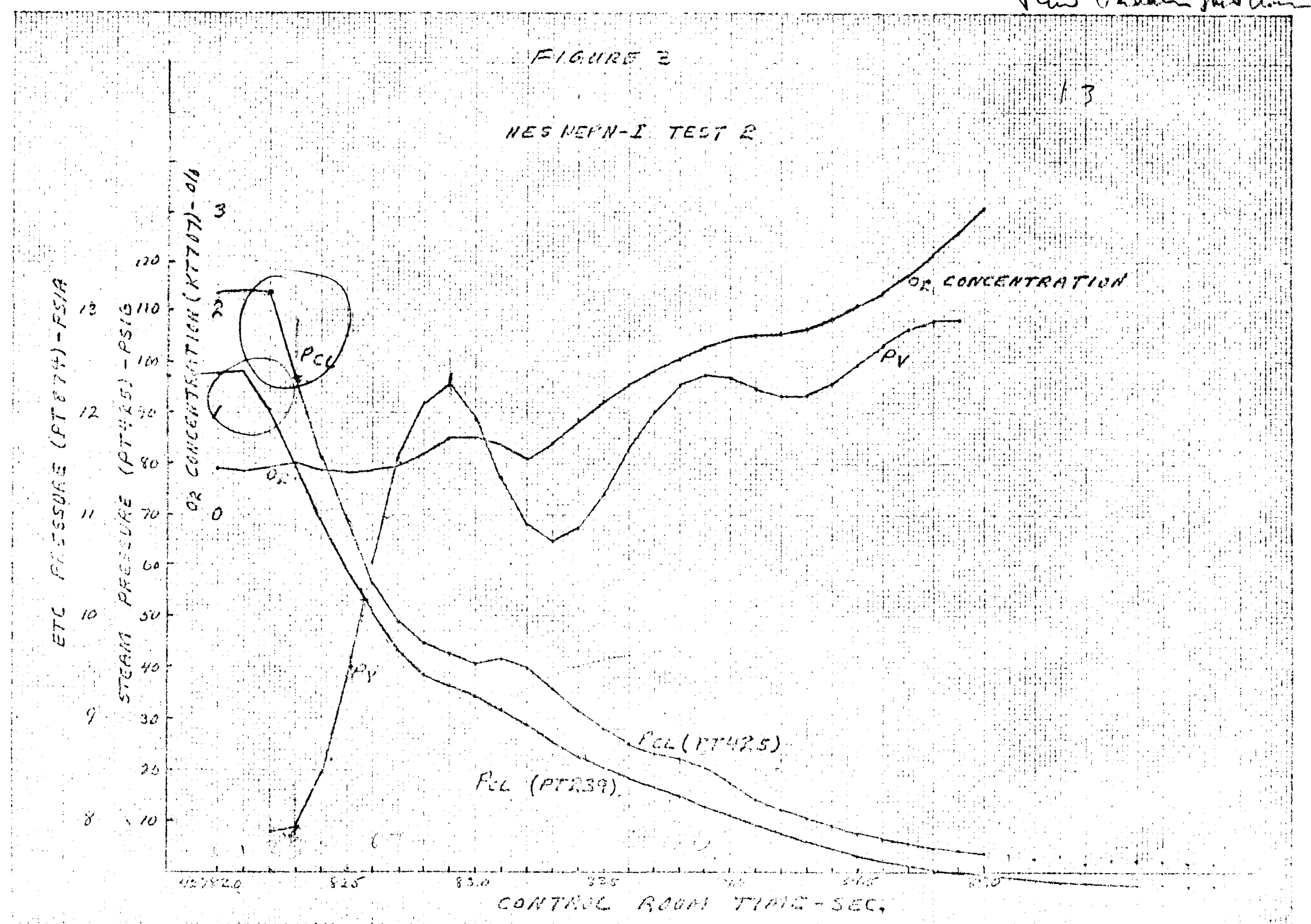


frene 4

NES NEPN-I TEST 3

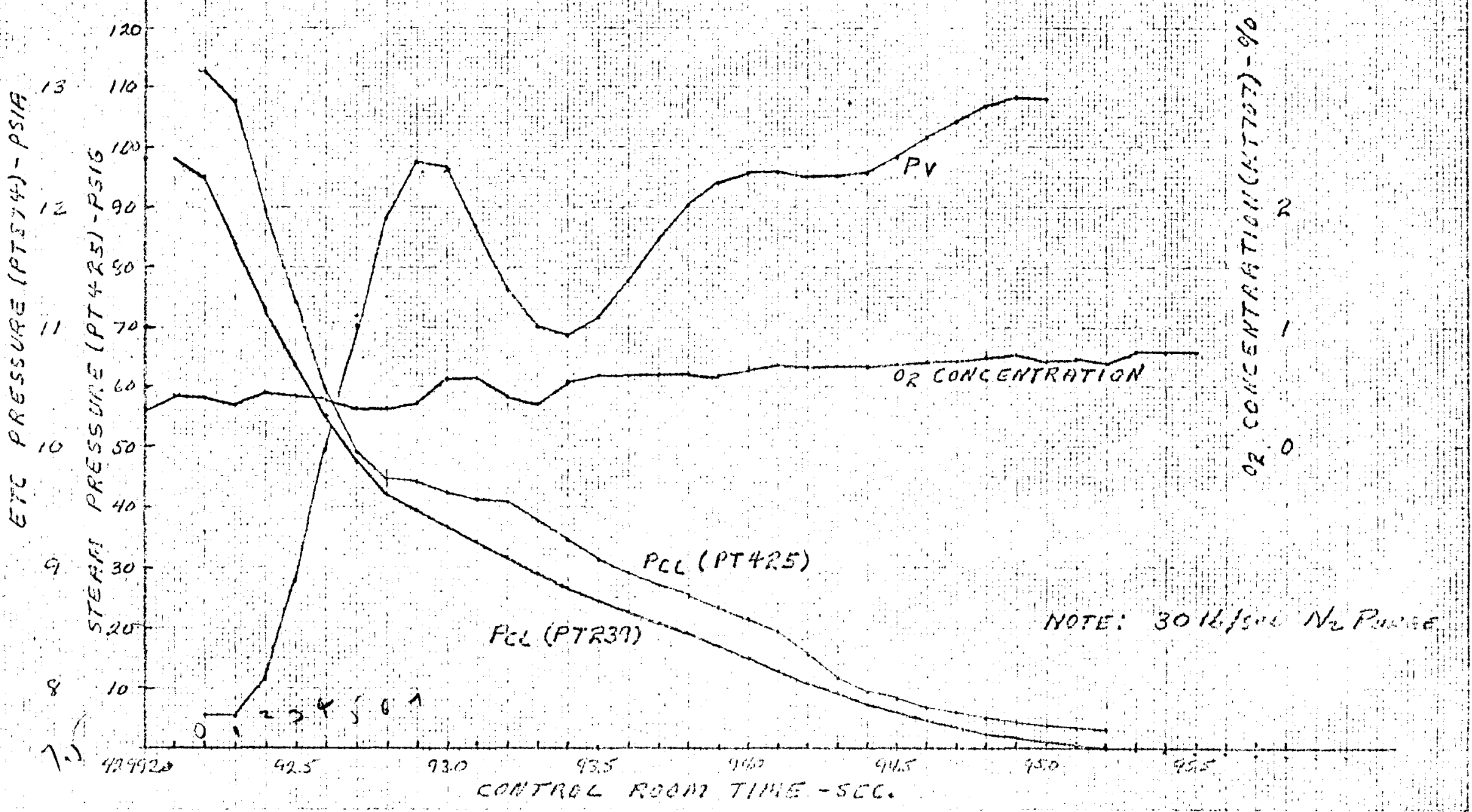




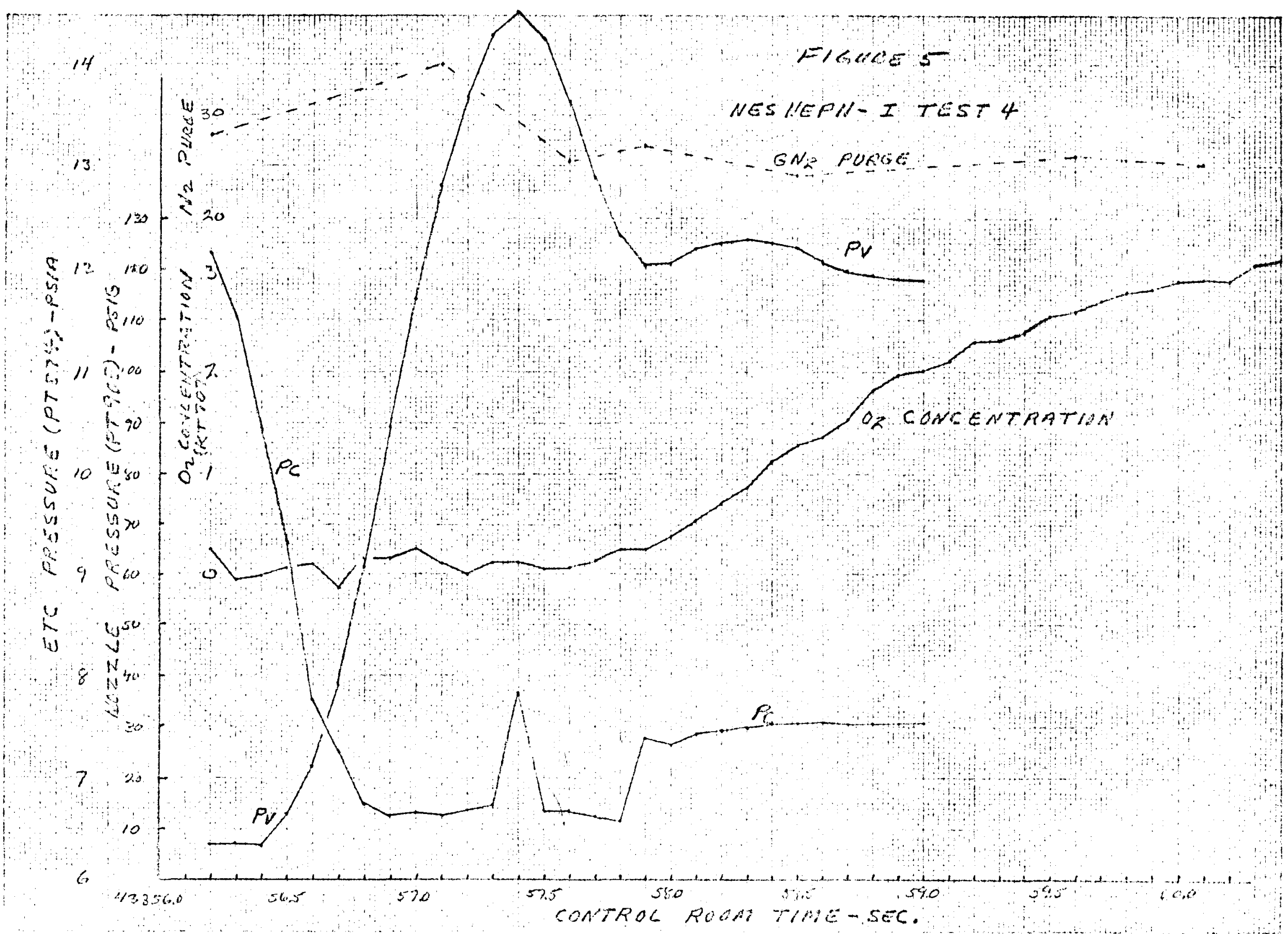




\section{*}

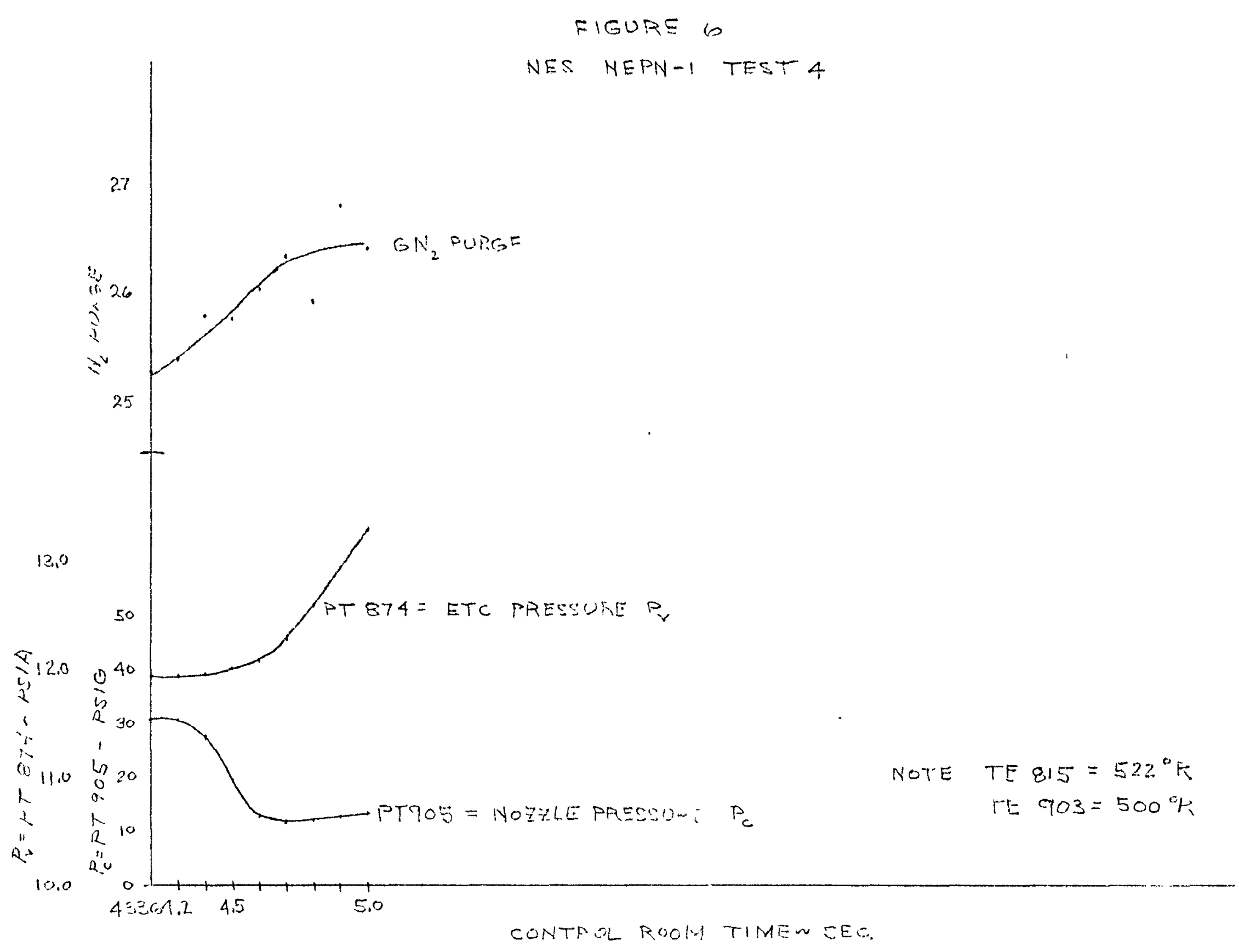




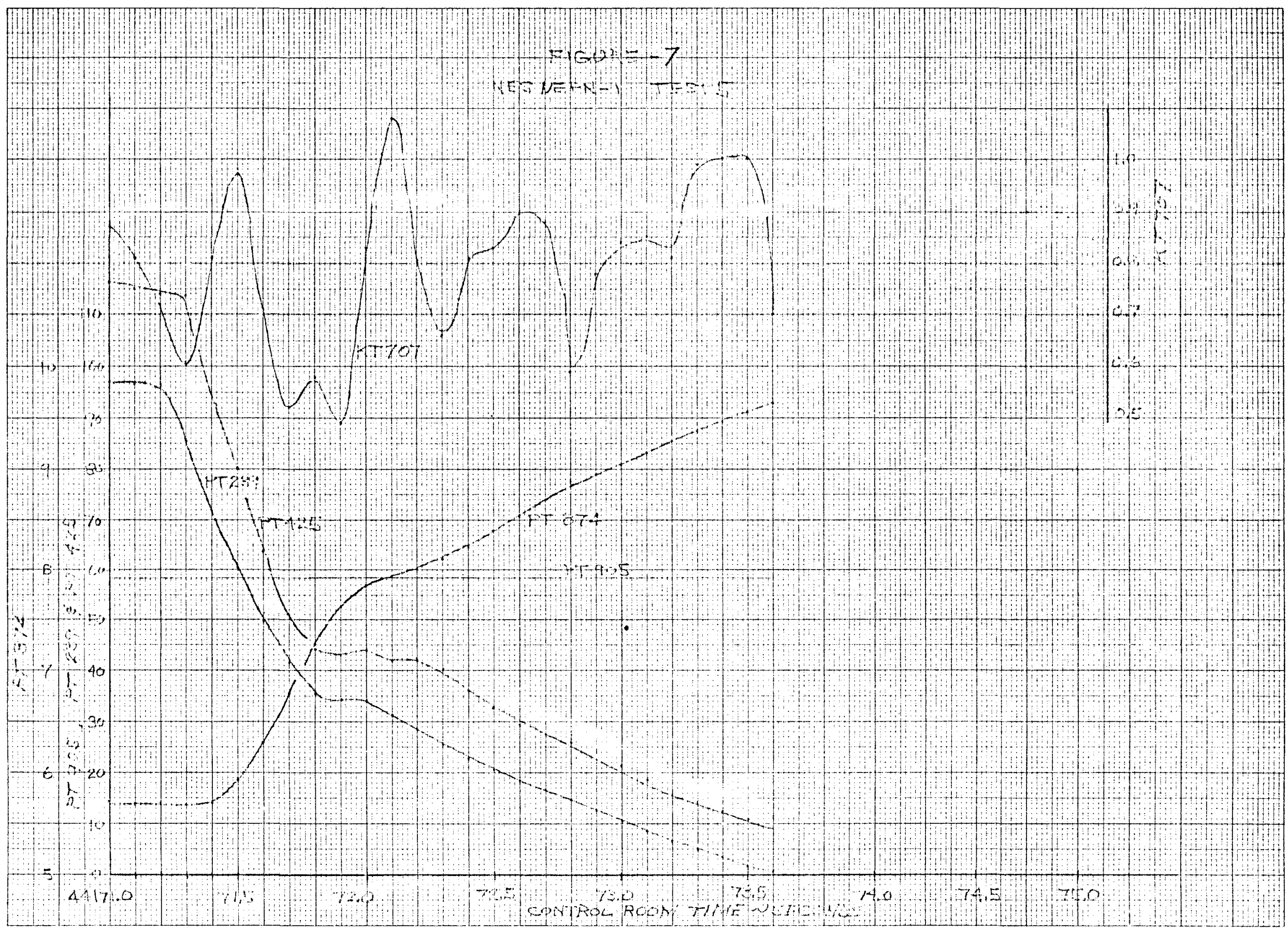




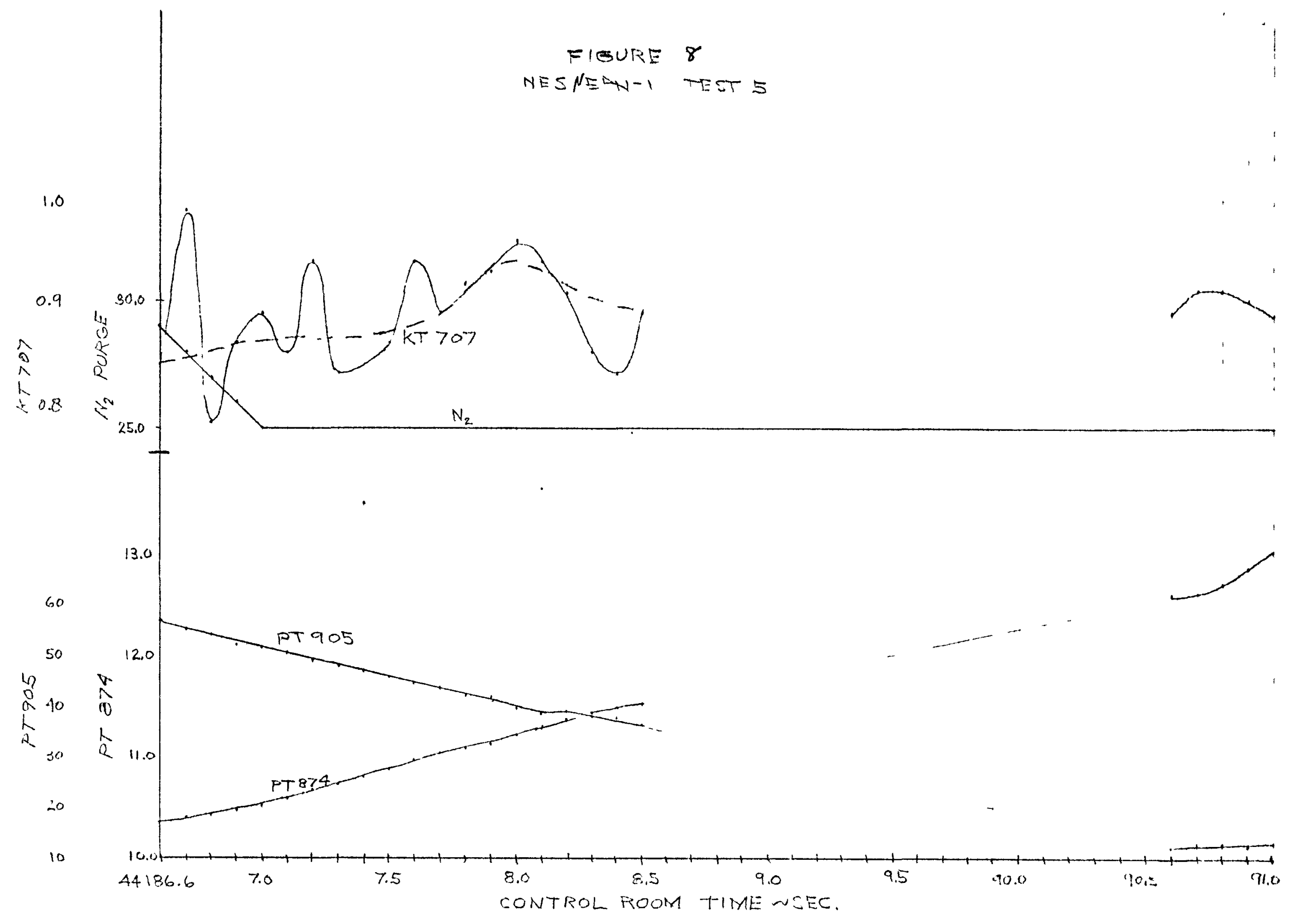


TO: J. H. Rams thaler

FROM: $\quad$ R. J. Gulde/K. R. Conn

SUBJECT: $\quad$ Engine Test Compartment/Duct Aerodynamic Performance

REFEREICE: (a) ETC-Pc Predicted Operating Map, issued 13 June 1967 by TRB No. 4

\section{SUMARY}

In general, the pull-down performance of the ETC vas normal, very repeatable, and followed the predicted data reasonably well during the NES EPN-I Tests. With one and two generators at full power the ETC pulled down to about 10.3 psia and 7.7 psia, respectively. Primary nozzle pressures of 60 and 123 psia were attained with a minimum pull-down pressure of 2.0 psia in the latter case. The effect of gaseous nitrogen purge flow into the ETC was smali with flow rates of 25 to $35 \mathrm{lb} / \mathrm{sec}$ resulting in an increase in ETC pressure of only about 0.4 psi.

The only major anomalies discovered in the performance were: (1) The ETC pressure with both generators on line was about 0.8 psi lover during Test 3 than during the other tests. A more detailed evaluation is necessary to determine the cause of this difference and its possible significance on steam and ETC performance repeatability. (2) The ETC pressure lags the primary nozzle pressure during the ramp up in nozzle pressure. (3) Significant overpressures vere experienced during a malfunction shutdown as well as a normal programmed shutdoun of primary nozzle flow without steam generator operation. A discussion of the overpressures is given in another memorandum within this report.

The agreement of the EPIT-I test results with the Phase I DDT Test was fair. However, a detailed data analysis of the Phase I tests are necessary before firm comparisons and conclusions should be made relative to the results of the EPN-I tests.

\section{DISCUSSION}

\section{Instrumentation}

The following data channels were used in the evaluation of the ETC performance during IJES EPI-I:

$\begin{array}{ll}\text { ETC Pressure } & \text { - PT } 874 \\ \text { Nozzle Pressure } & - \text { PT } 905 \\ \text { Steam Temperature } & - \text { TE } 159 \\ \text { Steam Pressure } & - \text { PT } 425 \\ \text { GN } & \begin{array}{l}\text { Purge Flow } \\ \text { used for the higher flows and the latter for low flows.) }\end{array}\end{array}$


Pressure channels PT874 and PT875 were close-coupled transducers. Of the two, PT874 was used because (1) on the dynagraph PT875 was recording too low at the smaller ETC pressure ranges, and (2) when the ETC pressure went to the minimum level of about 2 psia in Test 4 there was a calibration shift of 0.1 psi in the digital data of PT875. Otherwise, the correlation of the digital data between the two pressures was good.

The nozzle pressure channel, PT906, malfunctioned in Test 4 causing the unscheduled shutdown. From this point the data from PT906 is invalid; therefore, PT905 was used for the nozzle pressure in all tests. The ternperature channel TE534 was not operating, therefore TE159 gave the only value of steam temperature. The downstrean steam pressure channe1, PT239, was not responding properly in Test 1 and was indicating negative ambient psig values of up to about 2 psig in the latter tests with idle steam conditions. The upstream channels PT425 and PT 426 appeared to operate normally; therefore, PT425 was selected as representation of steam pressure.

\section{ENGINE TEST CONPARTMEIT PULL-DONN PERFORMAITCE}

\section{ETC Pull-Down Performance with Steam Generator Operation}

The ETC pressures with one and both steam generators operating at full steam conditions are summarized in Figure 1, while chronological histories of the startup of the generators to full steam and the stable operating conditions are shown in Figures 2, 3, 4, 5 and 6 . With only the No. 1 steam generator operating at full steam, the average ETC pressure for all tests was 10.62 psia with a maximum deviation from this average of 0.14 psia or 1.4\%. During this series of tests the repeatability of the one generator pul1-down pressure was thus very good. The predicted pull-down pressure with one steam generator (Reference a) was 10.2 psi or an increment from ambient of $2.60 \mathrm{psi}$. The average increment of pull-down during the test was 2.29 (the PT874 ambient pressure reading was $12.91 \mathrm{psia}$ ) which is approximately $12 \%$ less than predicted. As operation with one generator. is considered only a transient phase in bringing the generators "on line" and the ETC pressure will depend also on the untrimned steam temperature, the ETC pressure with one generator is considered somewhat irrelevant.

The operating procedure is to bring both generators up to full steam operation with the steam temperature at a low level of approximately $800^{\circ} \mathrm{R}$ and then trim the temperature and pressure up to the design operating range of $1460 \pm 50 \mathrm{R}$. The ETC pressure gradually decreases as the steam conditions are increased to the design range. The variations of ETC pressure with temperature during the five tests are shown in Figure 1. The ETC pressure and steam temperature correlation vas very repeatable during Tests $1,2,4$ and 5 with a variation from a nominal of less than $2 \%$. Test 3, on the other hand, demonstrated an ETC pressure which was approximately 0.7 to $0.8 \mathrm{psi}$ lower over the complete range of temperatures. The correlation of steam pressure with steam temperature is shown in Figure 7 for all five tests. Considerable variation occurs in this correlation; however, it is not evident that the steam temperature-pressure relationship was appreciably different during Test 3. 
It was not possible during the SPEAR efforts to deternine an explanation of the lower ETC pressure exhibited during Test 3. During Tests 3, 4 and 5, $\mathrm{GN}_{2}$ purge flows of 25 to $30 \mathrm{lb} / \mathrm{sec}$ were introduced into the ETC. These resulted in an ETC pressure increment of only about $0.4 \mathrm{psi}$. Thus, the possibility of difference in compartment leakage or purge flow conditions is not a realistic answer. A review of the primary nozzle pressure data disclosed similar data during the two-steam-generator phase of all tests indicating that there was no erroneous flow of primary gas during this phase of Test 3. Since there was no evidence of abnormal operation of or within the ETC that could explain the lover pressure during Test 3 , it would appear that the probable cause of the difference in ETC pressure resulted from a difference in the steam ejector conditions, such as an increased mass flow or change in molecular weight. This could result from a higher-than-normal generator mixture ratio (higher generator combustion temperature) which would then require more water than normal to establish a corresponding steam temperature. A variation is evident in the steam temperature after the second generator is brought up to full power. During this time period (prior to trimming the temperature up to the design range of $1460^{\circ} \mathrm{p}$ ) in Tests $1,2,4$ and 5 the temperature (TE159) was fairly stable at about $750^{\circ} \mathrm{R}$ with generator $\|_{1} 1$ at full power and $787^{\circ} \mathrm{R}$ with both generators at full pover. During Test 3 the steam tempexature was very erratic after the second generator was brought to full power with the temperature primarily above $800^{\circ} \mathrm{R}$ with a peak to $830^{\circ} \mathrm{R}$ (see Figures 2, 3, 4, 5 and 6 ). The secona generator in Test 3 was generator ${ }^{*} 3$. This generator was also used in Test 1 and Test 5. If there was an abnormality in the operation of this generator during Test 3 it was not evident during Test 5 .

A more detailed evaluation of the steam generator operations during these five tests should be made to determine if and why they may have been different during Test 3 and to evaluate the possible effect on the ETC pull-dom pressure repeatability in future tests.

At the design operating temperature of $1460^{\circ} \mathrm{R}$ the average ETC pressures extrapolated from Figure 1 are 7.7 psia for Tests 1, 2, 4 and 5 and 7.0 psia for Test 3 .

2. ETC Pul1-Down Performance with Steam Generator Operation, Primary F1ow and $\mathrm{GN}_{2}$ Purge

During Tests 3, 4 and 5 large purge flows of the order of 25 to $351 \mathrm{~b} / \mathrm{sec}$ of $\mathrm{GN}_{2}$ were introduced into the ETC. Purge flows of 1.5 to $4.0 \mathrm{lb} / \mathrm{sec}$ were also used during all tests with negligible effects. During Tests 4 and 5 primary flows $\left(\mathrm{GN}_{2}\right)$ producing nozzle pressures of approximately 123 psia and 60 psia, respectively, were introduced. The time histories, Figures 4, 5 and 6 , show the operating conditions at the introduction of the purge and primary flows and the effect of these flows on the ETC pressure. In Test 3 the high purge flon was introduced with steam generator operation only and the ETC pressure at about 7.4 psia. During Tests 4 and 5 the high purge flow was introduced after the shutdorn of the generators and with the primary flow on. In Test 4 the ETC pressure vas about 2 psia and in Test 5 it was about 10 psia when the purge flow was introduced. In al1 three cases the ETC pressure increased approximately $0.4 \mathrm{psi}$ due to the 25 to $35 \mathrm{lb} / \mathrm{sec}$ purge flow. 
Operating maps showing the variations of ETC pressure and nozzle pressure with comparisons to the prediction data are shown in Figures 8 and 9. It is seen that the decrease in ETC pressure with the buildup of nozzle pressure follors the predicted constant offset. However, as seen in Figures 5 and 6 the steam pressure and temperature vere less than the design levels which would result in a higher ETC pressure. In both Test 4 and Test 5 it vas noted that the ETC pressure continued to decrease somewhat after the nozzle pressure became steady. This illustrates that there is a slight lag between ETC pressure and nozzle pressure during the transient phase, because the ETC pressuredrifts to a loter level as a steady level of primary pressure is attained.

During the "drift" phase the ETC pressure decreases below the predicted data (Reference a). However, the predicted data is based on transient Pc through "pull in" and therefore constant primary flow was not considered in this operating regime.

As shown in Figures 8 and 9 the ETC repressurizes to approximately the predicted level for operation with primary flow and without steam generators. In Test 4 it repressurized to about 6 psia compared to a predicted pressure of $6.4 \mathrm{psia}$. The repressurized pressure vas thus about $6.3 \%$ 1over than predicted. During Test 5 the ETC repressurized to about 10.0 psia which is about $1 \%$ lower than the predicted level of 10.1 psia. Thus, in both cases the pull-dom pressure vas lover or better than predicted. During the malfunction shutdown of nozzle flov in Test 4, in which the nozzle pressure ramped dorm at a maximum ramp rate of about $252 \mathrm{psi} / \mathrm{sec}$, the ETC pressure increase lagged the nozzle pressure decay by a considerable degree (see Figure 8 ). However, in Test 5 , in which the primary flow was shutdown at a programed rate of $9.7 \mathrm{psi} / \mathrm{sec}$, the repressurization of the ETC with nozzle pressure follows the predicted data quite well (see Figure 9). The hysteresis with SG startup is shown in Fig. 11.

Overpressurization of the ETC occurred during the shutdown of primary flow without steam generator flow in both Test 4 and Test 5 . In Test 4 the flow shutoff resulted from a malfunction closure of the control valve PCV-449. In Test 5 the shutdown was normal. A discussion of the repressurization of the ETC during steam and primary system shutdowns is presented in another memorandum of this report.

\section{Comparison of NES EPN-I Pull-Down Performance with Phase I NES Test}

The following temporary Test Compartment pull-down pressures were reported in the SPEAR Test reports for Phase 1 NES DDT Tests 3, 4, and 5 with one and two steam generators only operating.

NES DDT 3

1 S.G. TEC $=10.8$ psia

2 S.G. $\quad$ TEC $=7.7$ psia 
NES DDT 4

1 S.G. TEC $=10.3$ psia

2 S.G. $\quad$ TEC $=7.4 \mathrm{psia}$

NES DDT 5

1 S.G. $\quad$ TEC $=9.5$ psia

2 S.G. $\quad$ TEC $=7.0$ psia

This data is also indicated on Figure 1.

The agreement of this data with the EPN-I test results is only fair. However, this data is considered only preliminary and nceds to be verified and evaluated. Also the steam and test conditions are not known. Considerable variation occurs between the data from the three tests with Test DDT 5 indicating low TEC pressures in a manner similar to EPN-I Test 3. Therefore, it is considered important that a detailed evaluation of the data from these tests be made in conjunction with the follow-up evaluation of the occurrance of the low ETC pressure on EPN-I Test 3.

The pulI-down of the TEC pressure with nozzle flow during NES DDT 4, DDT 5 and DDT 6 are shown in Figure 10 along with the data from NES EPN-I Tests 4 and 5 and the prediction data considered during the NES DDT tests and the prediction data prepared for the NES EPN-I tests. NES DDT 5 indicates a correspondingly lover TEC pressure than any of the other tests or the predictions. This test was conducted with a slow nozzle flow ramp (30 seconds to $550 \mathrm{psia}$ ) which apparently resulted in a minimum lag of the TEC pressure with the transient value equivalent to the steady-state value.

However, again the DDT test data must be considered preliminary and a detailed analysis of the data should be made prior to the draving of firm conclusions about the results of those tests. At least a minimum analysis should be made to provide a more complete documentation of the tests and the results.

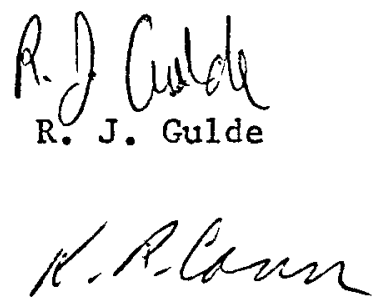

K. R. Conn 



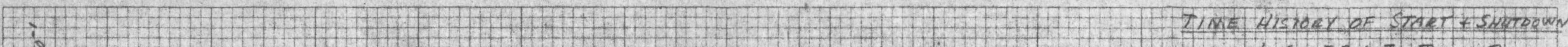

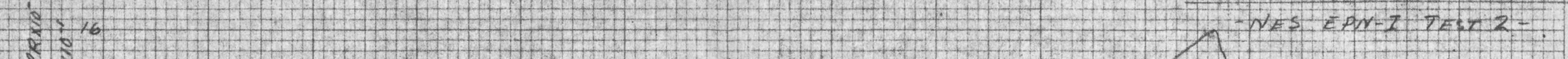

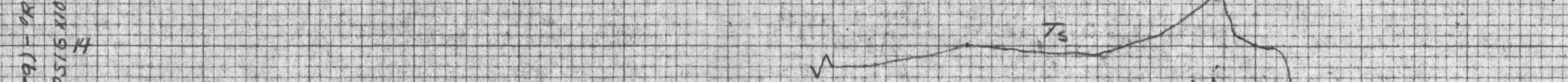

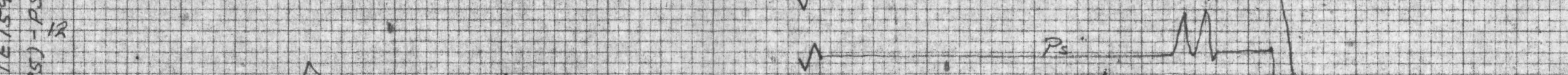

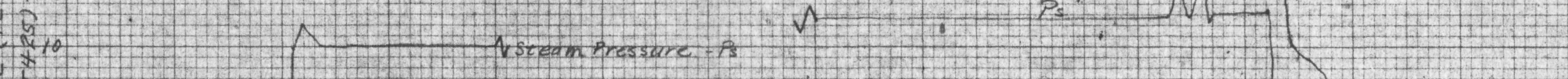

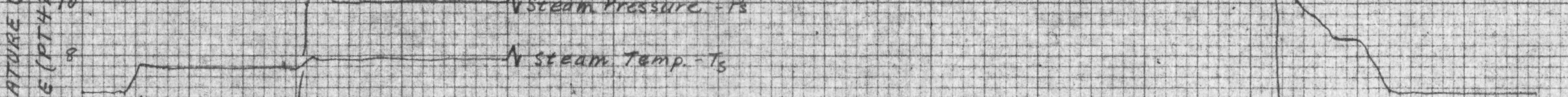

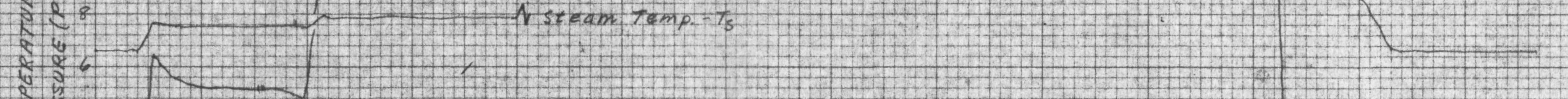

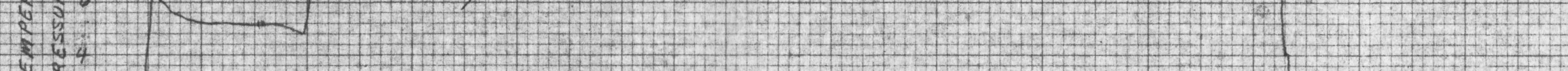
$\mathrm{L}_{\mathrm{L}}^{\mathrm{R}} \mathrm{e}_{2}^{4}$

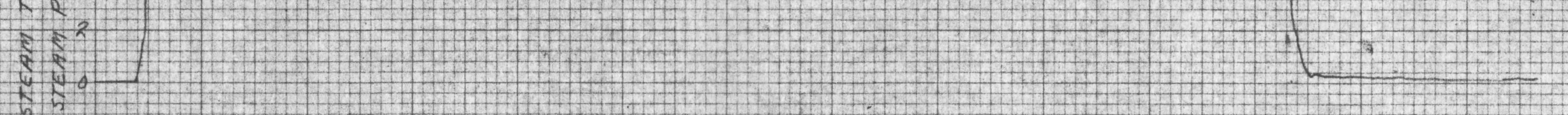
2

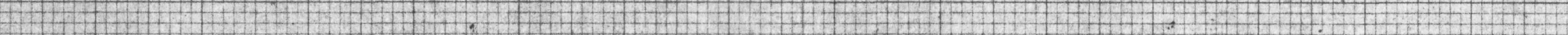

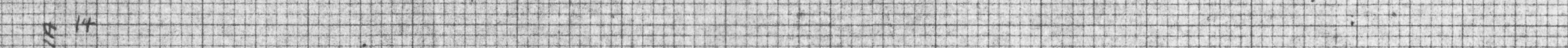

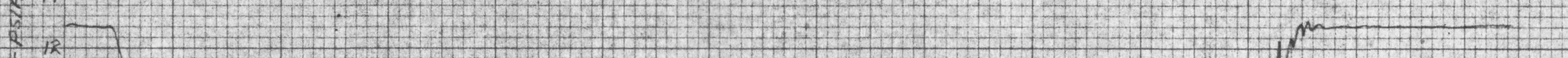

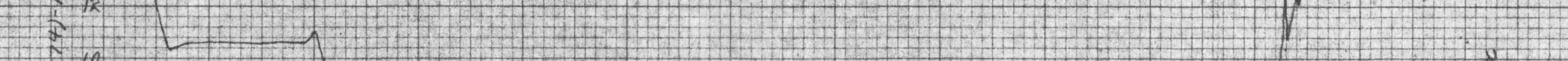

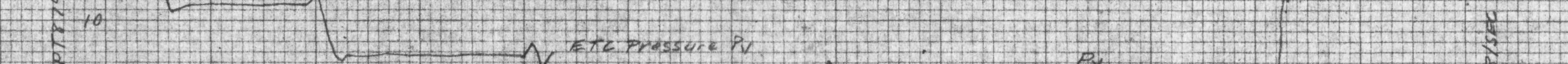

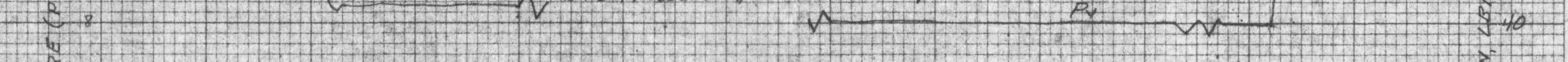
$\int_{6}^{8} 6$

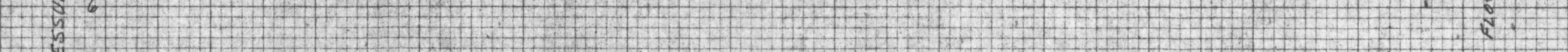

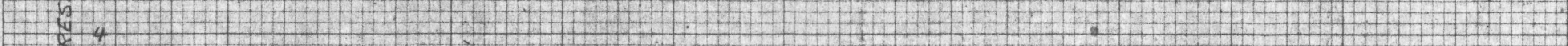

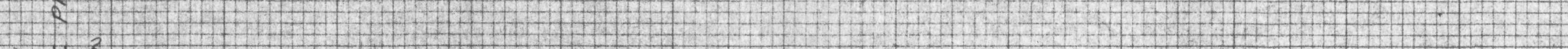

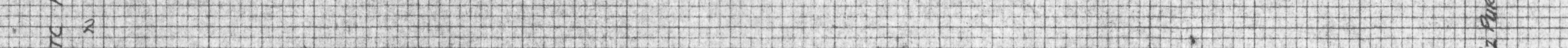

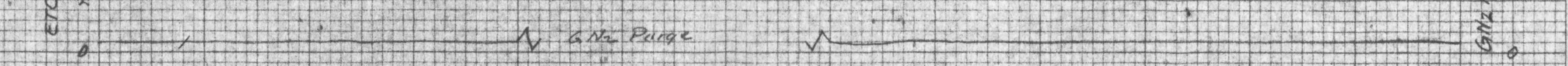

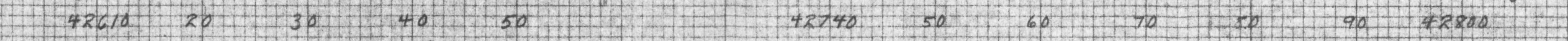
[- :

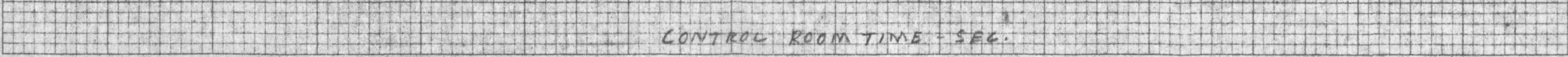





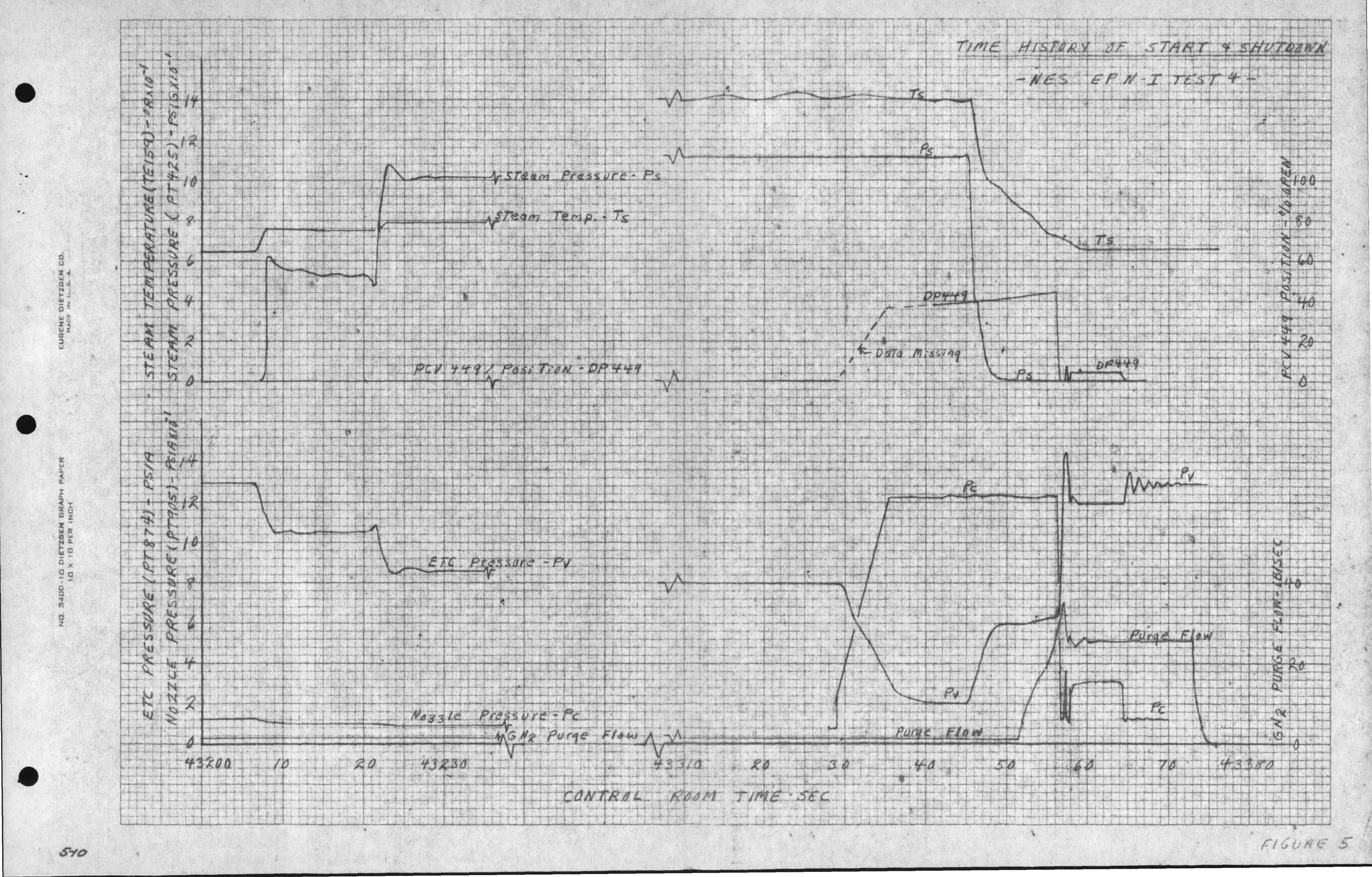





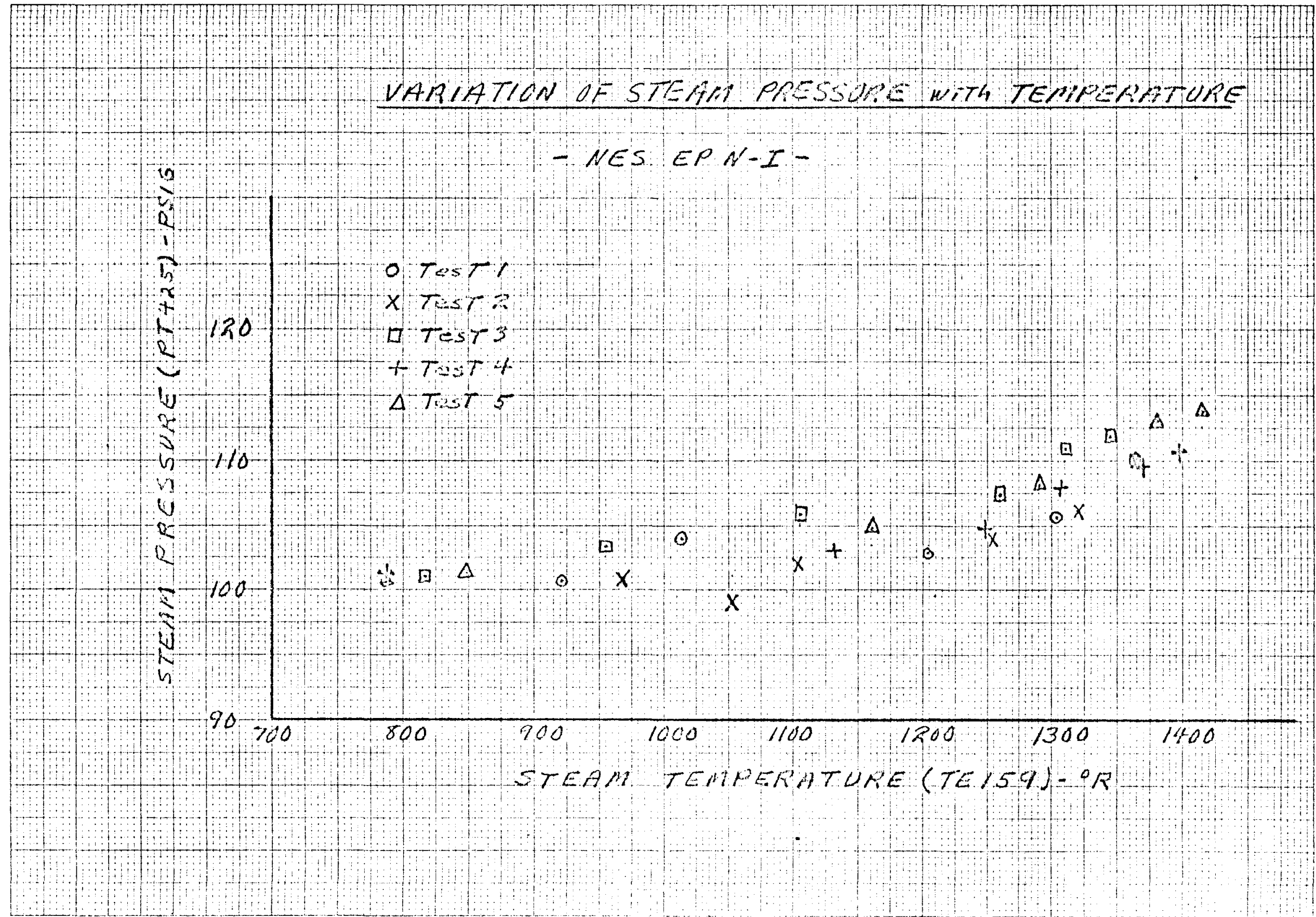


$\frac{\text { WES LETC OPERATWG MAP }}{\text {-HES EPW-I TEST T - }}$

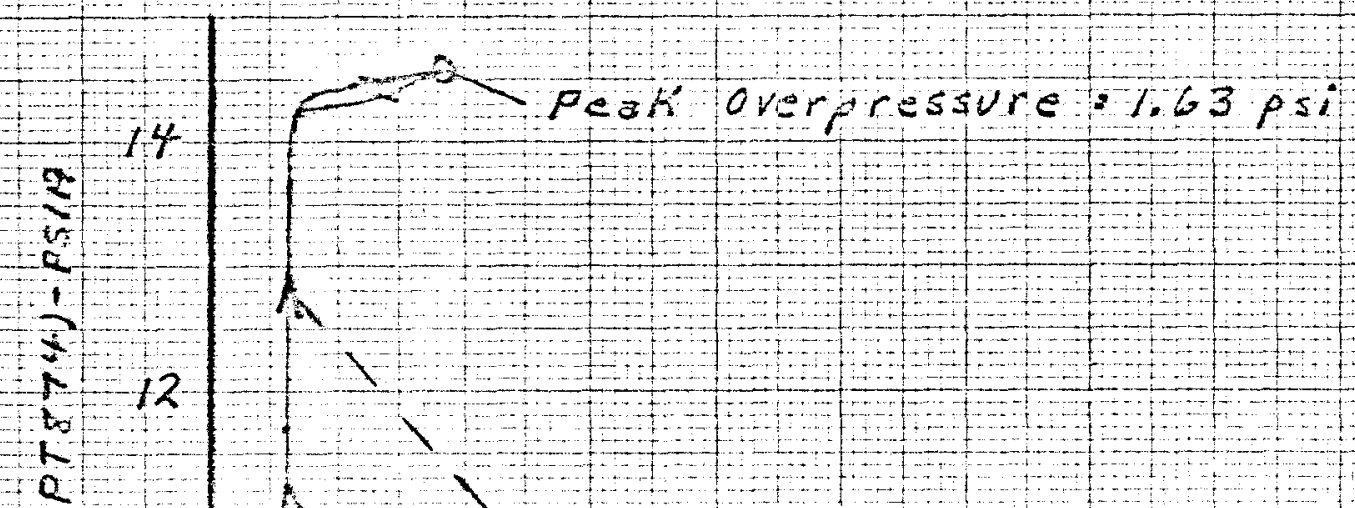

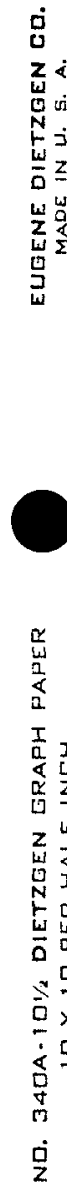

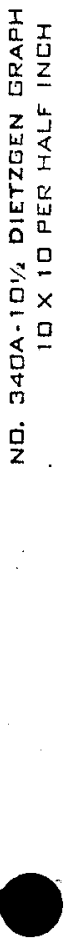

8

(t) 150 ax fun stem
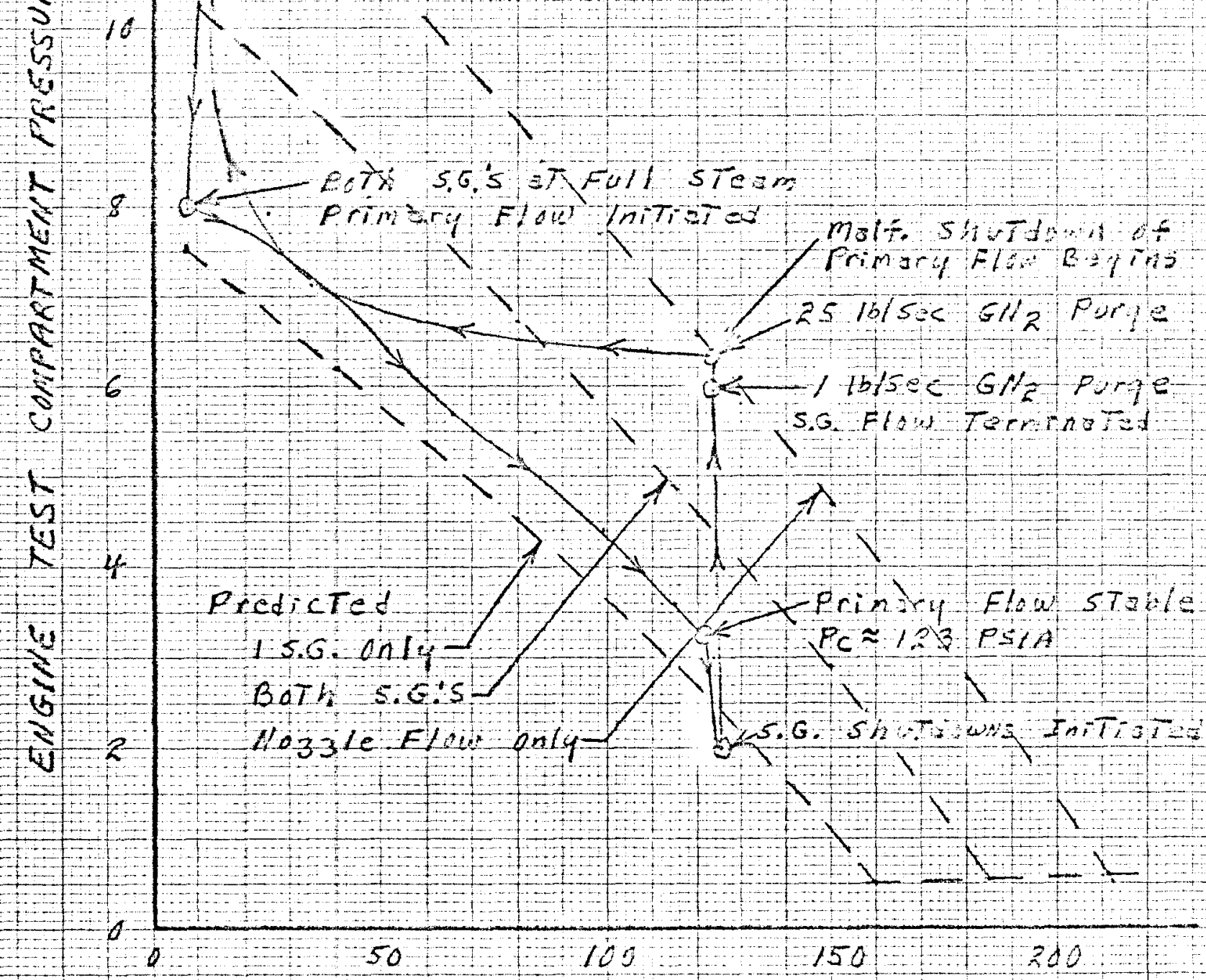

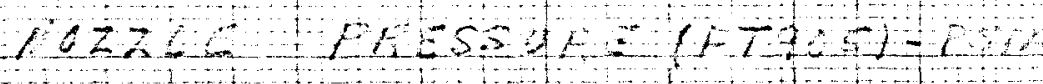

$5-13$ 


\section{NESLETC OPERATISS MAP}

- IES EPH-I TEST S -

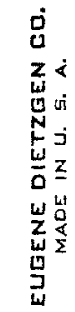

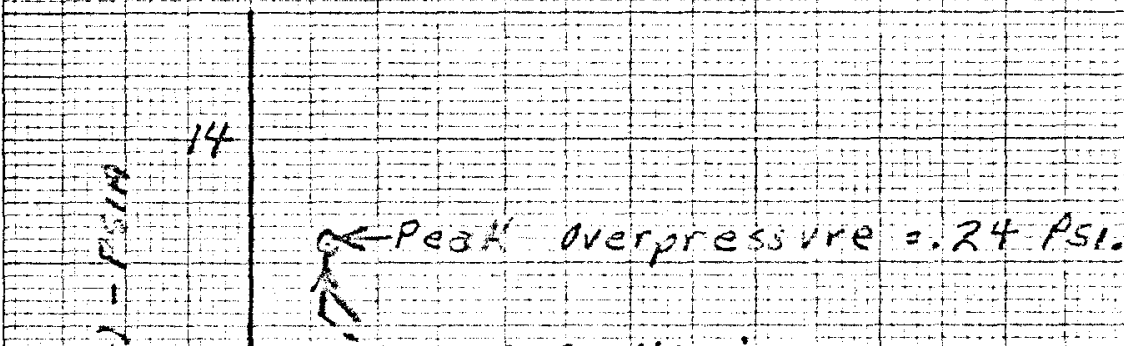

$x$ Deta pissing

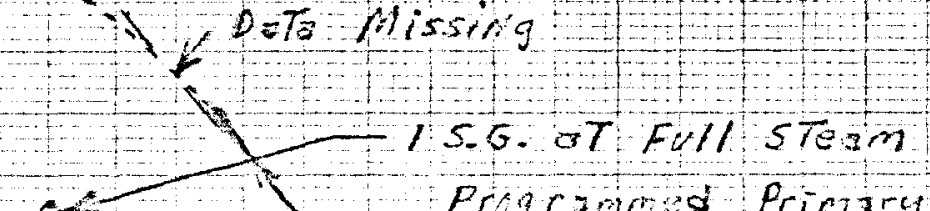

.

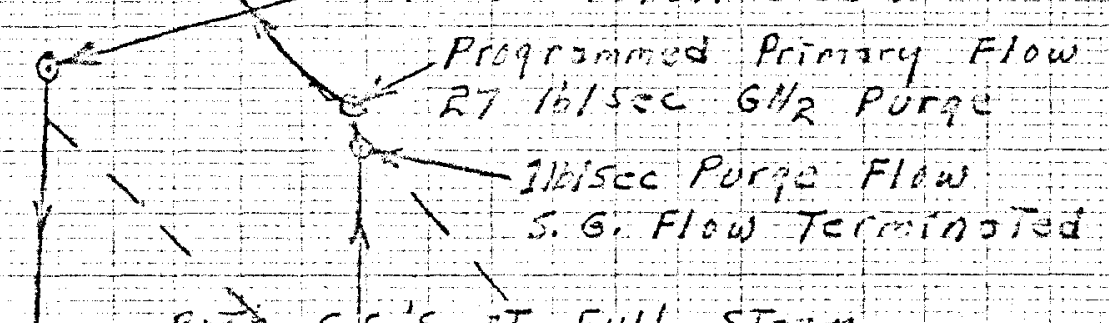
Ean S.GS IT Full STEM

\section{Pranory flow ynitiatad}

(i) $x$

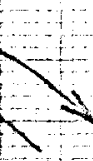

6

$x+4$

u

Preartool is $\operatorname{sent}$ both 5.6 .5 10331
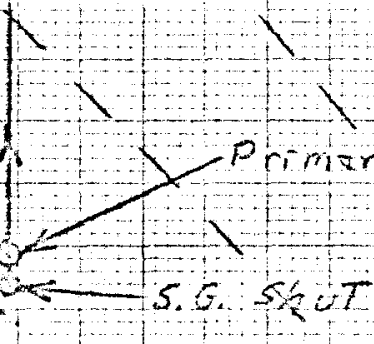

$+7$

$+x=3$

$+4$
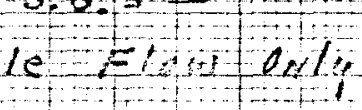


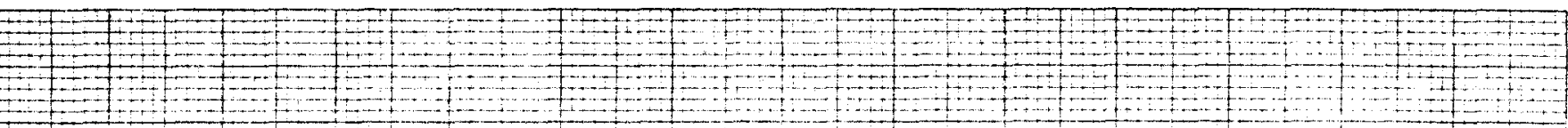

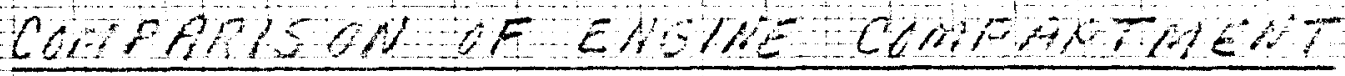

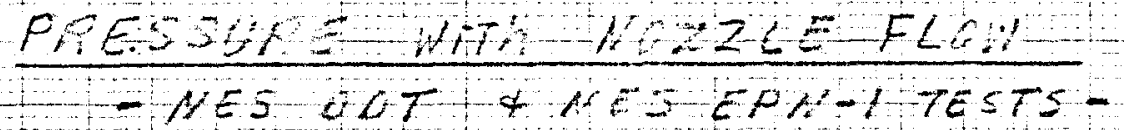

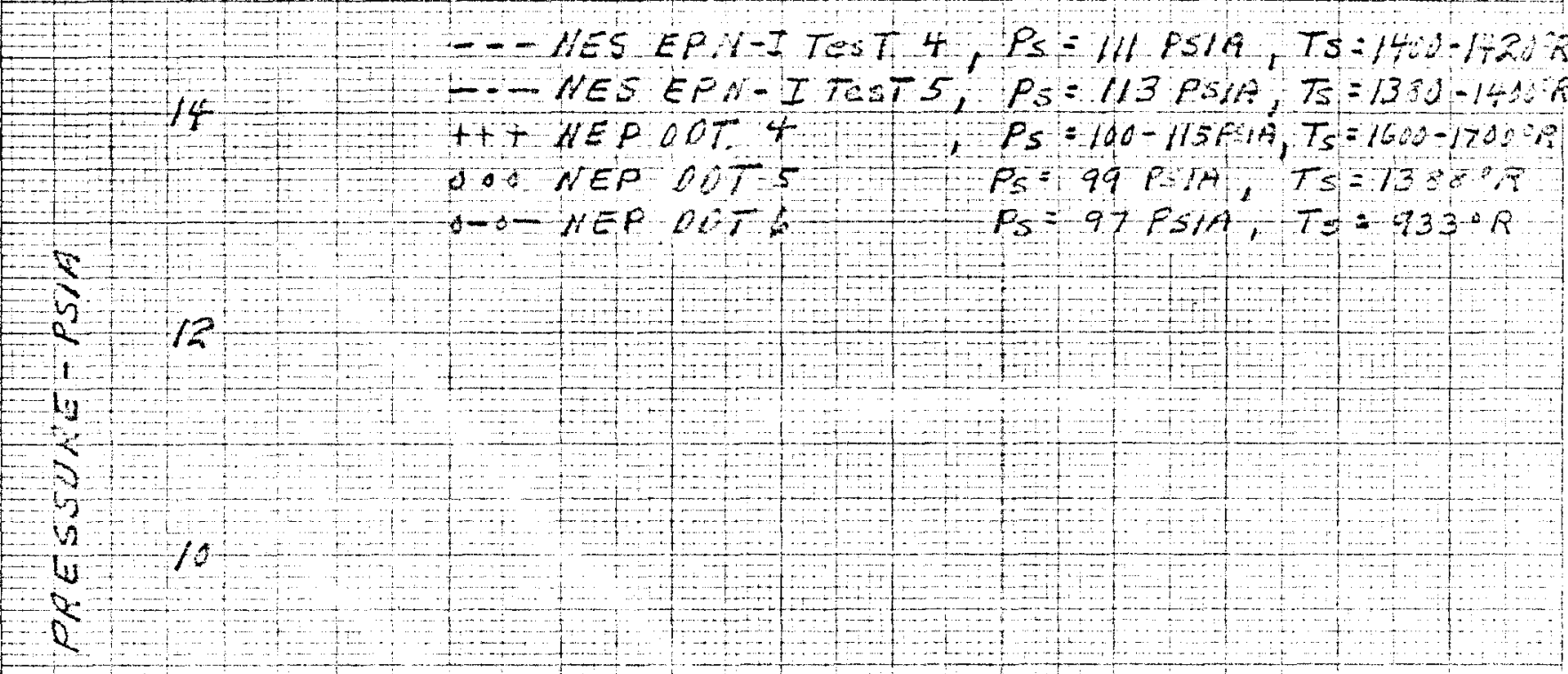

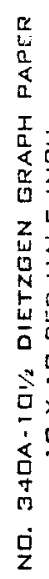

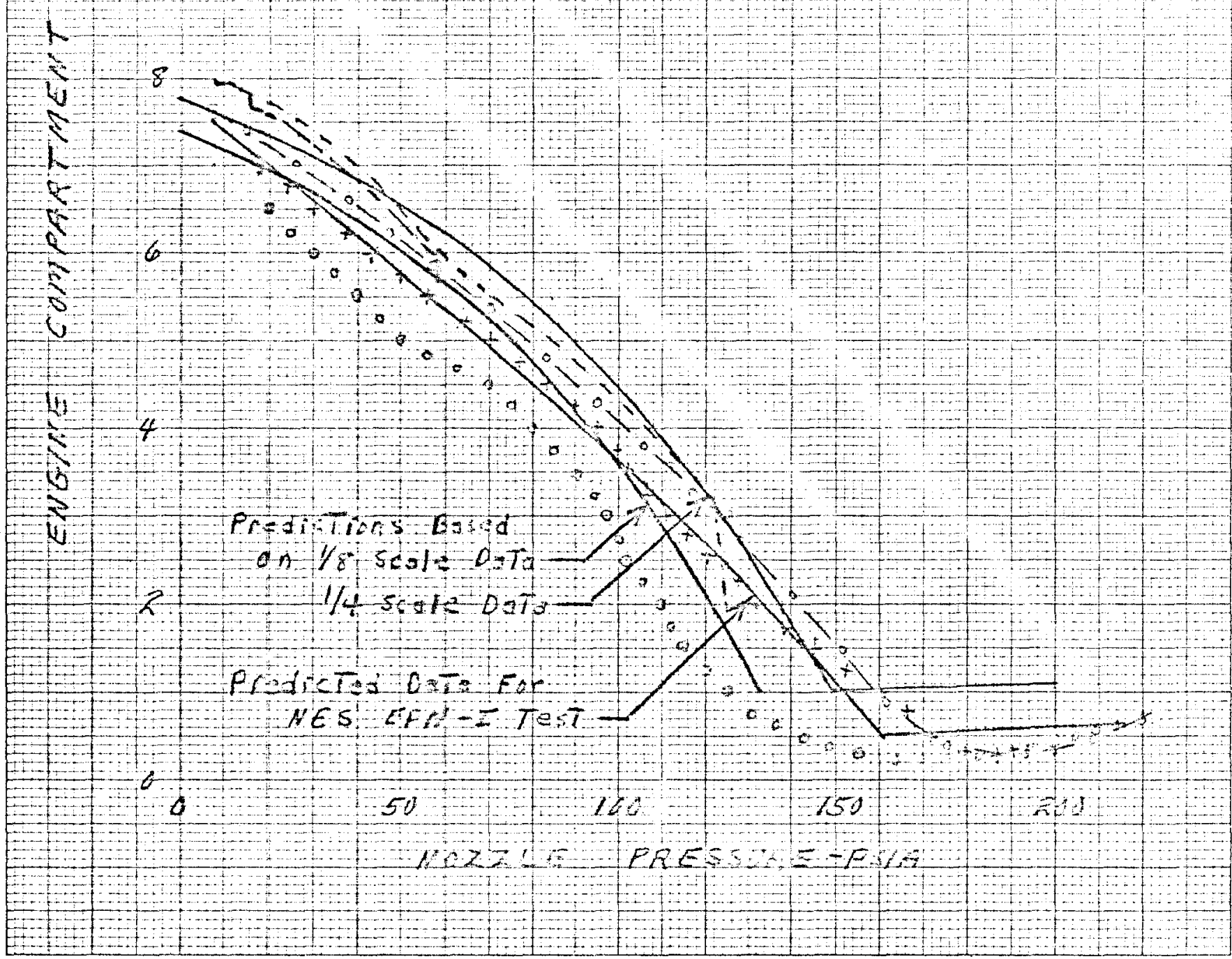




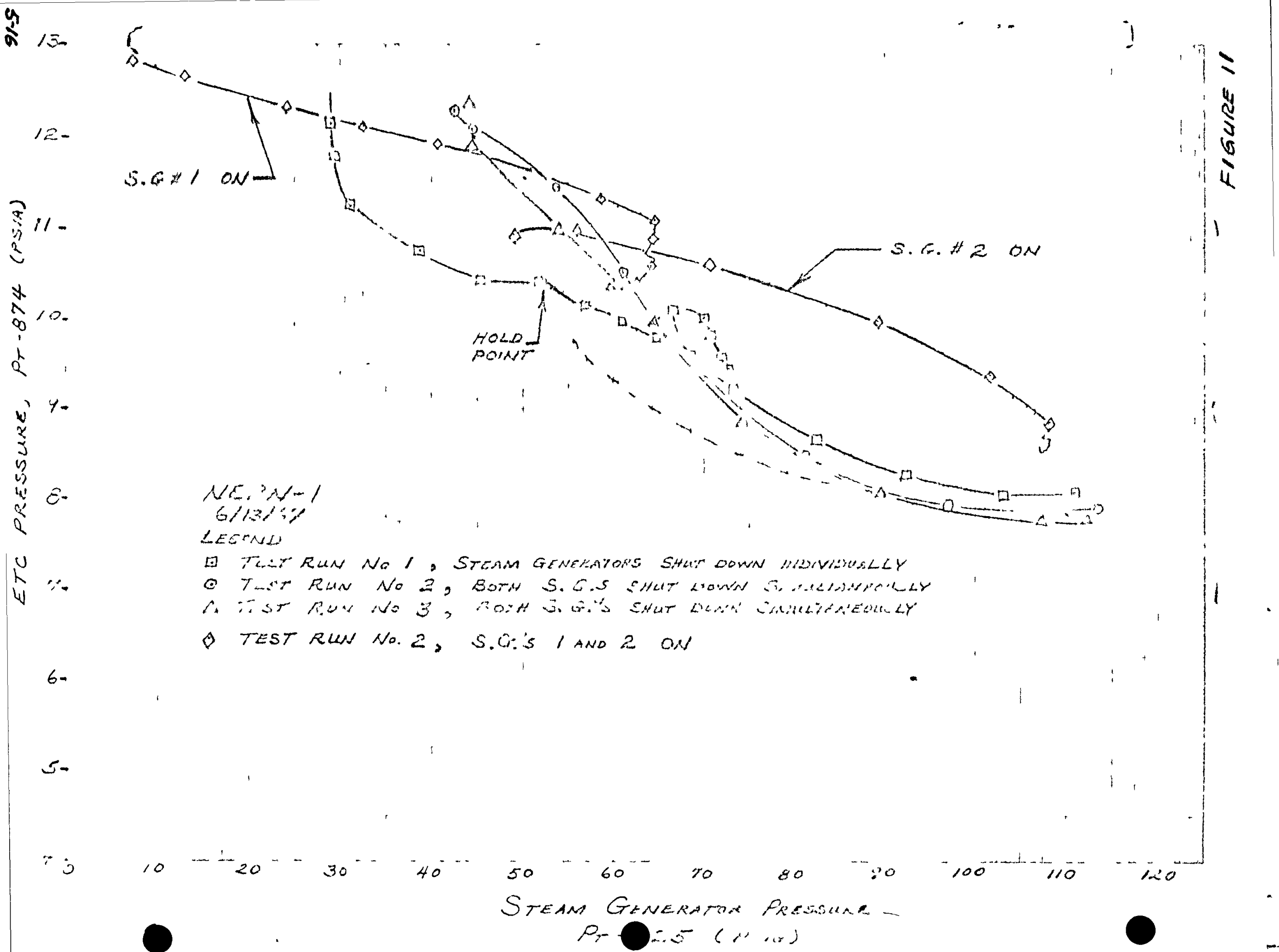


SPEAR MEAIORAIDUM No. 6

TO:

J. H. Ramsthaier

23 June 1967

FROM: $\quad$ K. R. Conn

SUBJECT: Pressure Oscillations and Overpressurization during Engine Test Compartment Repressurization

A. Pressure Oscillation ("Ringing")

The repressurization of the engine test compartment, ETC, to ambient during the shutdowns of all five NES EPN-I tests are shown in Figure 1. It is seen that the ETC pressure exhibits an oscillating characteristic as it seeks an equilibrium level at ambient pressure. In all tests the frequency of the oscillations was approximately I cycle/sec. These oscillations dampened to a negligible amplitude in about 5 cycles.

In shutdowns with stean generators only (Tests 1, 2 and 3), the peak pressure increases with each cycle, although the amplitude of the oscillations are decreasing. This pattern appears reversed in Tests 4 and 5, which had shutdowns of primary flow only. Here the maximum peak pressure occurs on the first cycle and decreases with successive cycles. It should be noted that in Tests 3,4 and 5,25 to $35 \mathrm{lb} / \mathrm{sec}$ of $\mathrm{GN}_{2}$ purge flow was added to the ETC.

\section{B. Overpressurization}

Overpressures were noticed to a significant degree only during the repressurization phase of the ETC-to-ambient for Tests 4 and 5 . This appears to indicate that no ETC overpressurization will occur during shutdown of the steam generators. During Test 4, a malfunction occurred giving a rapid shutdown of Giv primary flow and causing the ETC to pressurize 1.63 psi over ambient. ${ }^{2}$ Folloving the malfunction (rapid closing of PCV-449) the primary flow control valve reopened to approximately $5 \%$ providing a nozzle pressure of 26 psia. The valve was then closed from this position by manual control with a resultant overpressure of 0.63 psi.

C. Discussion and Recomendations

In Test 4 the decay rate of $G N_{2}$ primary flow, due to the malfunction, was approximately $252 \mathrm{psi} / \mathrm{sec}$. The decay rate resulting from the manual closing of the valve was 73 psi/sec. In Test 5 the programed decay rate was $9.7 \mathrm{psi} / \mathrm{sec}$. It is important to note that in all of these cases, considering the wide range of $\mathrm{GN}_{2}$ decay rates, significant overpressurizations occurred. It should also be noted that large amounts of $\mathrm{GN}_{2}$ purge flows (25 to $35 \mathrm{lb} / \mathrm{sec}$ ) occurred during these tests.

Scale model studies indicated, in the range of decay rates discussed above, that no possibility of overpressurization existed. The decay rate at which the possibility of an overpressurization exists, was defined from scale model tests to be something greater than $500 \mathrm{psi} / \mathrm{sec}$. However, no 
purge flow was used during the scale model testing while primary flow decay rates vere studied. The implication here is that $\mathrm{GN}_{2}$ purge flow into the ETC may adversely affect the degree of overpressurization. This implication can be somevhat backed up from data in both scale model and EPN-I tests. Two scale model tests with identical steam generator decay rates (very rapid) were run; one with no purge flow in the ETC and the other with a scaled flow simulating approximately $40 \mathrm{lb} / \mathrm{sec}$ of full-scale purge flow. The first case had an overpressurization of $1.4 \mathrm{psi}$ and the second had an overpressurization of 1.7 psi. The EPN-I tests which tend to support this are Tests 2 and 3. The main difference between these tests was purge flow rates of about $4 \mathrm{lb} / \mathrm{sec}$ and $30 \mathrm{lb} / \mathrm{sec}$, respectively. Maximum peak pressure in Test 2 was 12.29 psia and in Test 3 was 12.38 psia. The steam decay rates were about $90 \mathrm{psi} / \mathrm{sec}$ in both tests. However, these rates were obtained from the PT-239 pressure data which should provide the most valid effect of steam decay on ETC performance since the measurement location is the nearest to the duct end of the steam line. The pressure data from PT-425, located near the generator end of the steam line, did indicate a faster decay rate on Test 3 (160 psi/sec compared to $145 \mathrm{psi} / \mathrm{sec}$ ) which could have caused the greater overpressure. In light of abnormalities noted in the data from PT-239, i.e., no valid data in Test 1 and negative ambient gage pressure data on the other tests, the steam decay data based on it must be considered conditional and it is felt that further evaluation would be necessary to establish a conclusion that overpressure is definitely adversely affected by purge flow.

Post-test investigation indicated that although an overpressurization of 1.63 psi occurred, no damage to the facility was evident.

Recomendations are that further analysis be made of the EPN-1 data to give better understanding to the overpressurization and oscillation phenomena. A1so, theoretical models should be developed that can (1) account for the subscale and full-scale differences regarding ETC overpressurization, and (2) fully explain and define the mechanism of ETC overpressurization and pressure oscillations so that full-scale occurrences can be anticipated and predicted.

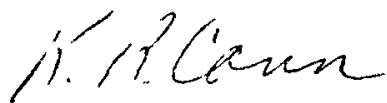

K. R. Conn 


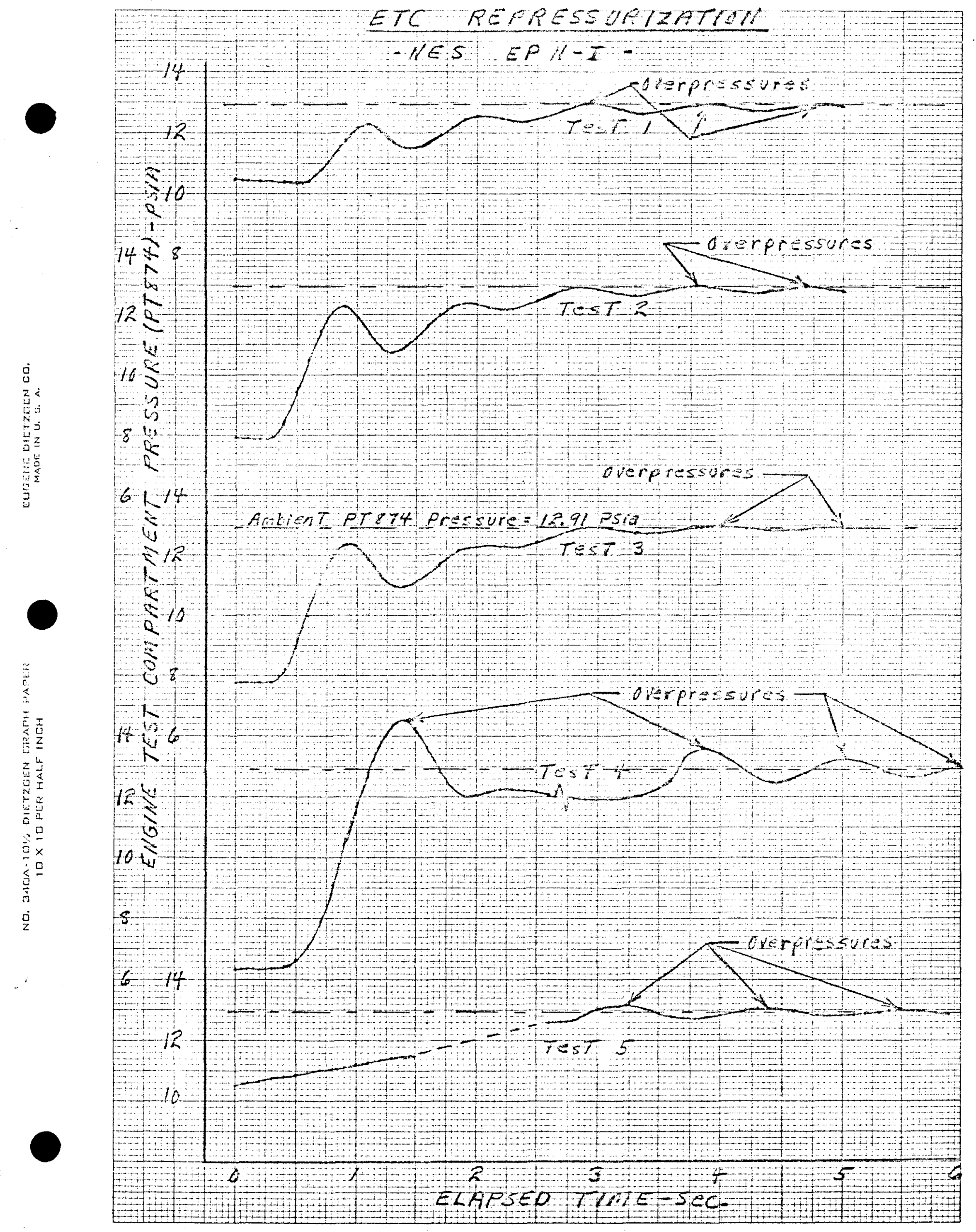


TO: J. H. Ramsthaler

FROM: $\quad$ K. D. Cummings

SUBJECT: Seals and Purge System on ETS-1 Engine Test Compartment

\section{SUMMARY}

The seals and seal purges of the engine test compartment performed satisfactorily with the exception of the leakage in the S-I bottom seal blade purge. Although the convolute seal buffer purges apparently performed satisfactorily during the test, the rapid pressure decay rates during pre- and post-test checks raise some questions as to their reliability.

The seal and purges checked during the SPEAR team effort on NEPN-1 were as follows (see Figure I):

(PT 625), gasket cavity-west

(PT 626), gasket cavity-east

(PT 627), convolute seal buffer purge-outboard

(PT 628), convolute seal buffer purge-inboard

(PT 629), convolute seal pressure-inboard

(PT 630), convolute seal pressure-inboard

(PT 631), bottom seal purge

(PT 632), S-I bottom seal purge

(PT 633), S-2 bottom seal purge

(PT 634), top seal purge

(PT 636), top bellows pressure

The seals and purges anomalies are tabulated as follows:

A. Failure to achieve design pressure (5 psig) in convolute seals.

B. Overpressurization of convolute seal buffer purge.

C. Failure to attempt complete evaluation of "ETC seal leakage under various operating conditions by shutting off the seal activator and buffer gas GIT supply." (SORD-INTO-I-O223, May 1967, Section 2.1.2.) 
Seals and Furge System On ETS-1 Engine Test Compartment (Cont'd)

D. Failure to maintain above atmospheric pressure in $\mathrm{S}-1$ bottom seal purge.

The compartment purge system (halo) performed satisfactorily although some dependence of flow rate on engine test compartment pressure was noted.

It is recommended that:

a. Corrective action be taken on the $S-1$ bottom seal blade purge leakage problem,

b. a more detailed study be made on the correlation of pre-test seal and purge pressure decay checks $\mathrm{vs}$ seal and purge integrity,

c. action be taken to prevent the lower-than-design pressure problem (convolute seal) that occurred in NEPN-I from occurring again,

d. a study be made on the cause of the overpressurization of the convolute seal buffer purges,

e. the pressure range chosen for transducer FT 750 which measures total purge and seal $\mathrm{GN}_{2}$ leakage should be re-evaluated for maximum information recovery.

II. DISCUSSION OF SEAL AND PURGE ANOMALIES

A. Failure to Achive Design Pressure in Seals

Although the dome loaded regulating valves in the seal pressure line were set at 5 psig before the test, a pressure of only 2.6 psig was achieved during the test. This discrepancy apparently was due to a "typical" fault of this type of regulating valve. If the valve is set at a given pressure, uncharged, and then charged again, it is not unusual to find that the downstream pressure has changed. It is recommended that these regulators be modified to hand loaded type which will allow better accuracy from pre-test calibrations.

B. Overpressurization of Convolute Seal Buffer Purge

Data indicated that when the convolute seal buffer purge was activated there was a pressure overshoot of 2.4 pounds over the design pressure of around 2 psig. The overshoot was likely due to dynamic pressure responses which could possibly become larger on future tests.

It is recommended that a detailed study be made to determine cause and recommend modifications to prevent future overpressurization problems. 
Seals and Purge System On ETS-1 Engine Test Compartment (Cont'd)

B. Overpressurization of Convolute Seal Buffer Purge (Cont'd)

In NEPN-1, this situation caused a problem when coupled with the less-than-design pressure discussed in Section $A$. The pressure surge caused a $\Delta \mathrm{P}$ of 2.4 psid across the corvolute seals. An increase in the convolute seal pressure at the time the convolute buffer purge pressure was activated indicated that there was a momentary deflection of the convolutes. This deflection is undesirable since the convolutes are not designed to take an inward pressure.

C. Failure to Attempt Complete Evaluation of "ETC Seal Leakage Under Various Operating Conditions by Shutting Off The Seal Actuator and Buffer Gas GNb Supply."

ETC seal leakage tests were performed for the top and bottom blade purges, and for the gasket purges.

Because of the problem discussed in Section B, the above tests were not performed for the convolute seals and convolute seal purges. Since the $S-I$ and $S-2$ side shield bottom blade purges are connected to the convolute seal purge line, these were not run either. This was the only objective of seals and purges testing that was not attempted.

D. Failure to Maintain Above Atmospheric Pressure in S-I Bottom Seal Purge

The only seal or purge pressure that had a significant leak was the S-1 bottom seal purge. The engine test compartment pressure reached a low of 2 psia during test 4 of NEPN-1. At this point the pressure in the $\mathrm{S}-1$ bottom seal purge was less than atmospheric ( $12.6 \mathrm{psia}$ ).

E. Summary of Purge and Seal Pressure Changes

A summary of all seals and purges that varied from initial pressure is listed below. This table lists the purge or seal pressures (by transducer number) for every period of time where there was a pressure change in a seal or purge. Figures (II-V) are presented for four of the pressure change periods listed below:

\begin{tabular}{|c|c|c|c|c|c|}
\hline 1. PT 632 & - & 43200 & -43390 & (Time & Period) \\
\hline 2. PT 631 & - & 43300 & -43390 & $"$ & $"$ \\
\hline PT 634 & - & 43320 & -43360 & " & " \\
\hline PT 632 & - & 44010 & -44200 & $n$ & $"$ \\
\hline PT 632 & - & 42360 & -42500 & $"$ & " \\
\hline PT 631 & - & 42600 & -42790 & $n$ & $"$ \\
\hline
\end{tabular}


Seals and Purge System On ETS-1 Engine Test Compartment (Cont'd)

E. Summary of Purge and Seal Pressure Changes (Cont'd)

7. PT 634 - $42640-42780$ (Time Period)

8. PT 632 - $42600-42790 "$ "

9. PT 625 - $42640-42780 "$ "

10. PT 632 - $42880-43000$ " "

11. PT 626 - $42640-42780 "$ "

The following comments concern the cases listed above:

1. PT 632: (See Figure II) S-1 bottom shield purge is the only obvious seal leakage. The figure shows the purge pressure drops below atmospheric (12.8 psia). The pressure drop is consistently a function of ETC pressure until ETC pressure reaches about 6 psia. At that point, the purge pressure levels off down to 2 psia indicating choke flow through the leaks occurs at about $6 \mathrm{psia}$. This is the lowest seal or purge pressure experienced during NEPN-I.

2. PT 631: (See Figure III) Bottom seal purge. The figure indicates a small drop of from 15.25 psia to 14.50 psia during ETC compartment depressurization. The seal is operating satisfactorily, nevertheless.

3. PT 634: (See Figure IV) Similar to PT 631.

4. \& 5. PT 632: These data show pressure drop (leakage) very similar to Figure II for different time periods.

6. PT 631: (See Figure V) Seal operating satisfactorily. The discontinuity indicates the time period that the pressure to the purge was shut off. During the period the purge pressure dropped to 12.8 psia (approximately atmospheric) but did not drop below indicating good seal performance. Some pressure drop is noted with ETC pressure decrease as in Figure III.

7. PT 634: The data shows the purge pressure shut off test was satisfactory.

8. PT 632: Same as 4. and 5.

9. PT 625: Same as 7. for PT 625.

10. PT 632: Same as 4., 5. and 8 .

11. PT 626: Same as 7. for PT 626. 
Seals and Furge System On ETS-I Engine Test Compartment (Cont'd)

Although the pressure shutoff to seal and purge test (Part C) was not performed for all seals and purges, the above data indicates the seals and purges (except for the $S-1$ bottom were purge) performed satisfactory for NEPN-I and can be expected to operate satisfactorily down to 0.5 psia ETC pressure.

III. TOTAL GN ${ }_{2}$ SEAL PURGE AND SEAL PRESSURE FLOW RATE

FT-750 measures total $\mathrm{GN}_{2}$ flow rate to all seal purges and seal pressures. Unfortunately, the transducer that measures the orifice $\Delta P$ was ranged too high to measure the small flow rate through the orifice. The flow rate was less than $0.1 \mathrm{lb} / \mathrm{sec}$, and is of the same magnitude as the data from FT-750 obtained during the mechanical seal and leak test.

\section{NITROGEN PURGE SYSTEM}

The compartment nitrogen purge system (halo) behaved normally and no malfunctions were noted. There were several $\mathrm{N}_{2}$ purge flow decays during the five tests. These are attributed to two factors. First, $\mathbb{N}_{2}$ purge flow rate varied with changes in primary $N_{2}$ flow rate since the purge flow and primary flow were fed from the same line. The purge flow rate is, of course, a function of pressure upstream of the orifice. In this case, the upstream pressure is affected by the primary flow rate. Secondly, it is apparent that the purge flow rate does vary with ETC pressure to a small extent. The flow through the sharp edged orifices is somewhat dependent on downstream pressure. This dependence is not sufficient enough to cause any change requirement, however. The $\mathrm{N}_{2}$ supply to the halo is sufficient. The purge valve was open only 50\% during the 30 pound per second purge flow.

\section{PRE- AND POST-TEST SEAL LEAKAGES AS MEASURED BY PRESSURE DECAY RATES}

A leak check was performed on the seals before and after the test to determine if leakage could be detected. Each seal or purge cavity was pressurized and then allowed to decay by closing the supply valve. The data recorded for this test was somewhat incomplete and a more detailed test would be necessary for a complete analysis.

The results are shown on Table $I$. In all cases the pressure decay (leak rate) was the same or lower after the test than before the test indicating there might have been a favorable seal adjustment during the test. One of the seal purges which had immediate pressure decay during the inspection (PT 632) was subsequently verified to have leaks during the test series. The other seal purges did not show indications of leaking at any time during the test series. In the post-test leak check these seal purges appeared to be holding pressure better than pre-test which could account for the difference in performance. 
Seals and Purge System On ETS-I Engine Test Compartment (Cont'd)

V. Pre- and Post-Test Seal Leakages As Measured By Pressure Decay Rates (Cont'd)

It is concluded that the pre-test leak check can be a valuable tool for pre-determining discrepant seals. It is recommended that a minimum leak criteria should be established and a test procedure written for checking seal leakage.

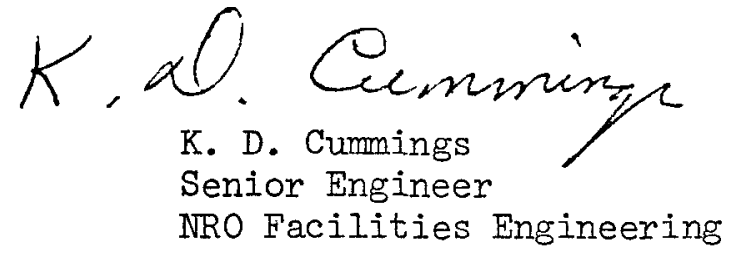




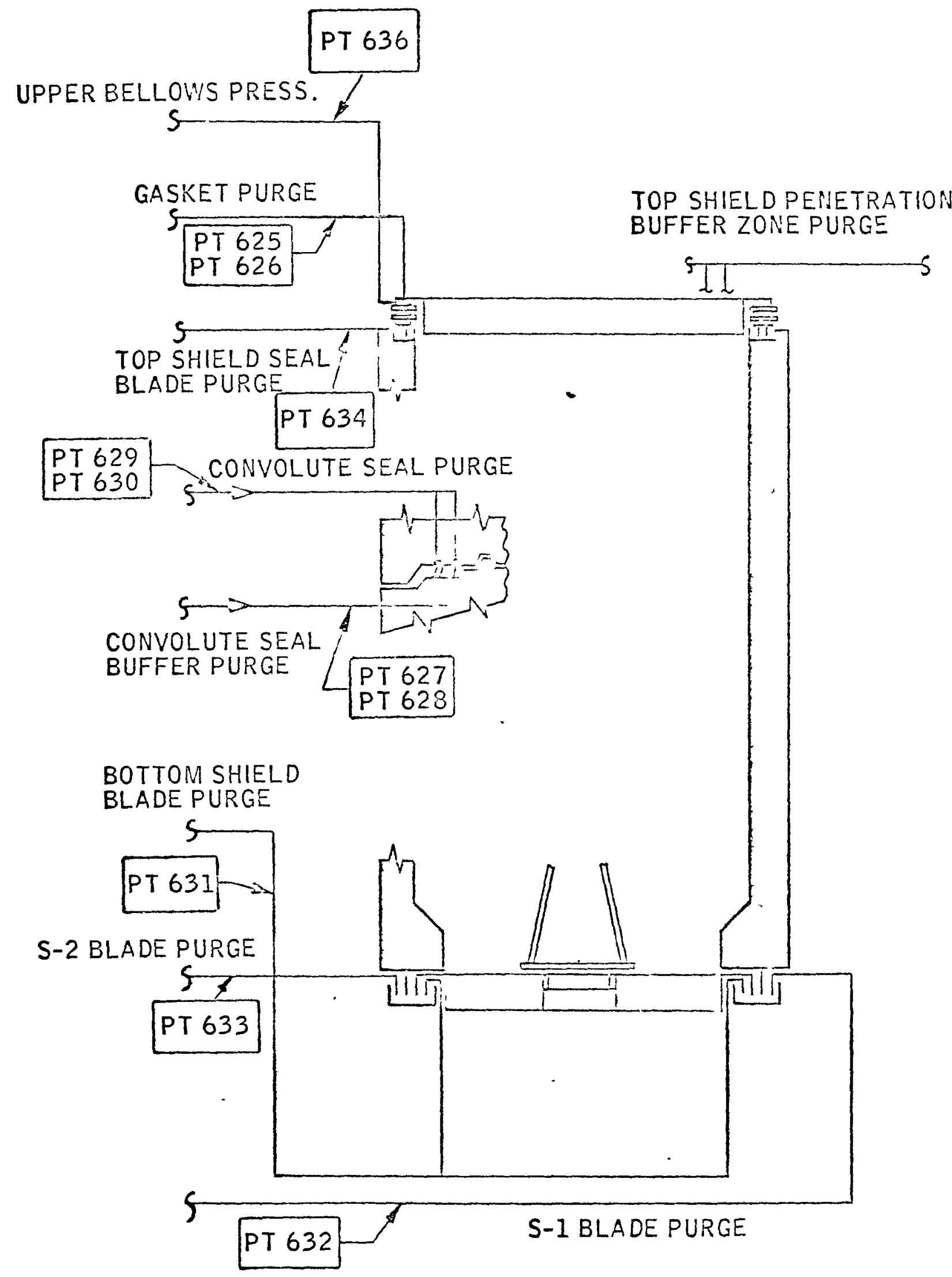

FIGURE I

ETS-1 ENGINE TEST COMPARTMENT

$\mathrm{GN}_{2}$ BUFFER PURGE AND SEMLL SYSTEM 
Pre-test

Time to

Pressure Initial Pressure Decay to Zero

PT 625

PT 626

PT 627

PT 628

PT 629

PT 630

PT 631

PT 632

PT 633

PT 634

PT 636
$2.0 \mathrm{psig}$

2.0

2.0

2.2

3.8

6.0

2.0

2.0

2.0

3.2

15.9
$60 \mathrm{sec}$

$60 \mathrm{sec}$

$0 \mathrm{sec}$

$20 \mathrm{sec}$

$255 \mathrm{sec}$

$355 \mathrm{sec}$

$35 \mathrm{sec}$

0 sec

No Decay

$80 \mathrm{sec}$

No Decay
Post-test

Time to

Initial Pressure Decay to Zero

$1.5 \mathrm{psig}$

$82 \mathrm{sec}$

1.6

87

2

20

2.2

20

3.8

$360+$

4.0

$400+$

2.0

40

2.0

5

2.0

No Decay

1.4

$80 \mathrm{sec}$

15.9

No Decay 


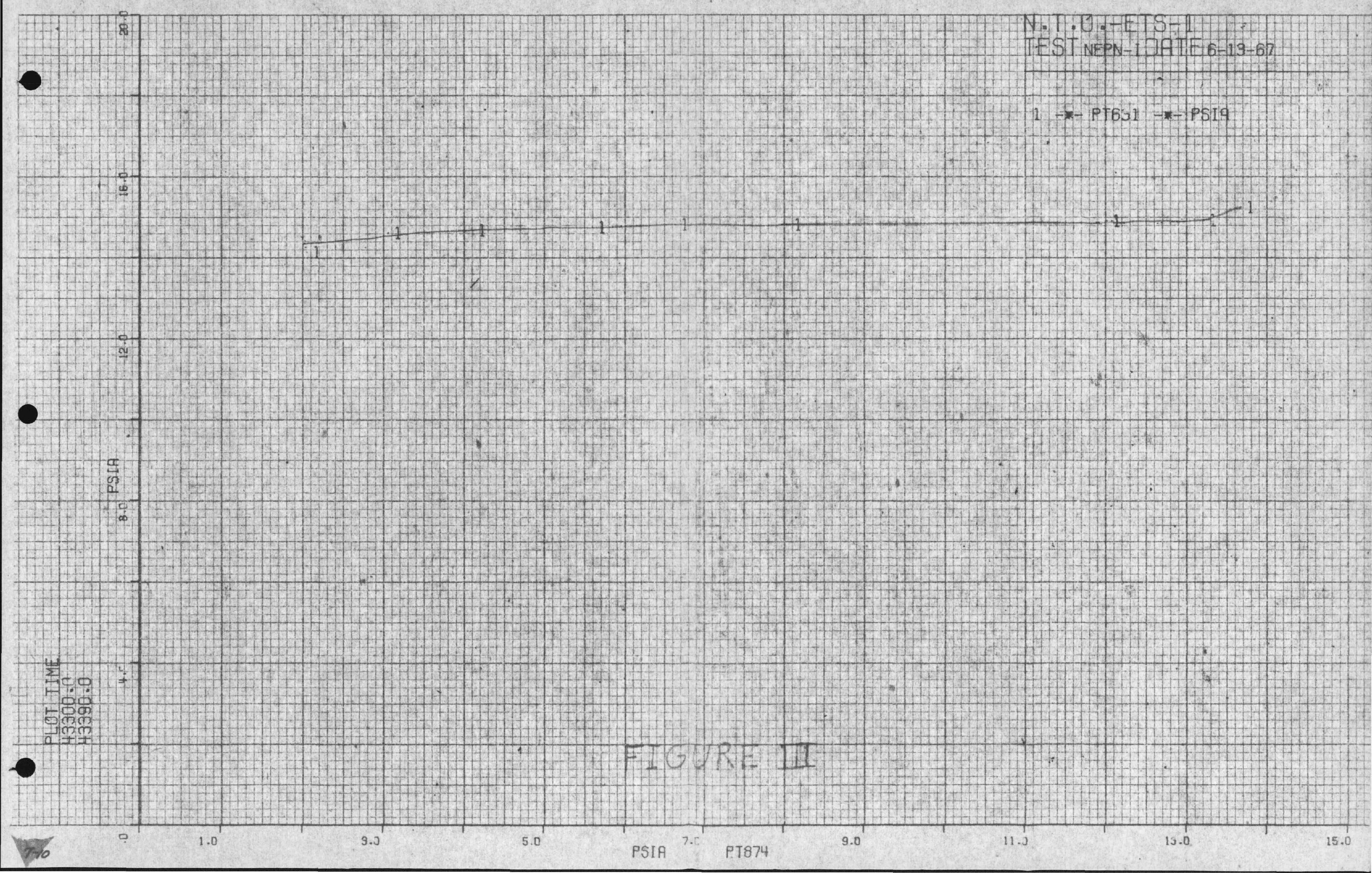




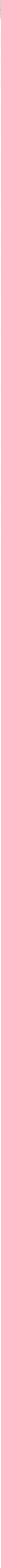


TO: J. H. Ramsthaler

FROM: $\quad$ J. K. Endo

SUBJECT: NEPN-I Test Results on Initial Inerting of ETC, Shield water Flow Rates, Structural Integrity of the ETC, and ETC Pressure Drop

Summary

Initial Inerting

The ETC was inerted from $16 \%$ to less than $3.5 \%$ with a $\mathrm{GN}_{2}$ purge of 15 $\mathrm{Ibs} / \mathrm{sec}$ for 52 seconds. The objective was to lower the ETC $\mathrm{O}_{2}$ concentration to $3.5 \%$ or less which was easily accomplished. The data from the $\mathrm{O}_{2}$ detectors were in general agreement with previous test data from CEP-I, and concluded to be satisfactory. It should be noted that the $\mathrm{GN}_{2}$ temperature (TE-826) entering the ETC dropped to $481^{\circ} \mathrm{R}$ during the $15 \mathrm{lb} /{ }^{2}$ sec purge.

\section{Shield Water Flow Rate}

No data was available from the test to determine the shield water flow rates except for $\mathrm{Pt}-168$ which was used to indirectly calculate average flow rates of $1285 \mathrm{gpm}$ and $635 \mathrm{gpm}$ to each side shield and bottom shield, respectively. $1745 \mathrm{gpm}$ is the current requirement for side shield f'.ow and NRO will have to determine if modifications are required or 1285 is satisfactory.

\section{Structural Integrity}

The ETC was overpressurized by 1.6 psig. However, visual inspection by Q.A. indicated that there was no visible damage to the exterior or interior of the ETC. The pretest and posttest loading on the 12 cables around the ETC was approximately 7,000 Ibs except for three cables that had a post test loading slightly less than 7,000 pounds. This was probably due to the cables stretching.

\section{ETC Pressure Drop}

The ETC experienced no pressure drop across the intermediate shield during the 5 tests as recorded by PT-874 and 875. The permanent pressure transducer Pt-290, 291, 292, 293, and Pt-800 were slow in response and gave readings that did not correspond with Pt-874 and 875. After the test, the tubing to the 5 pressure transducers were leak checked and several small leaks were discovered and repaired. The small leaks were probably the major cause of the slow responses and erroneous readings recorded by the transducers. 
$\underline{\text { Recommendations }}$

\section{Initial Inerting}

It is recommended that the permanent $\mathrm{O}_{2}$ detectors be left on one sensor during any test because of the 8 second response time required after switching and that $\mathrm{O}_{2}$ detectors be installed for each sensor. The problem of the slow response time should be looked into further by the Nucleonics and Safety Group and if possible, improved.

\section{Shield Water Flow Rates}

The data required to determine shield water flow rates have been requested for $N E P-V$ and $V I$.

\section{Structural Integrity}

The problem of the ETC being overpressurized is being analyzed by INRO and is beyond the scope of the Spear effort.

\section{Initial Inerting of ETC}

The objective of the initial inerting of the ETC was to lower the $\mathrm{O}_{2}$ concentration level to $3.5 \%$ or less to establish a non-combustible environment within the ETC. GN $\mathrm{GN}_{2}$ was introduced into the ETC through the top purge ring at approximately $15 \mathrm{lbs} / \mathrm{sec}$ for 52 seconds which includes the ramp up and down. Approximately 745 pounds of $\mathrm{GN}_{2}$ was used to inert the ETC.

Figure 1 and 2 illustrate the $\mathrm{GN}_{\bar{z}}$ flow rate (Ft. 426) and $\mathrm{O}_{2}$ concentrations versus range time. $\mathrm{O}_{2}$ concentrations within the ETC are indicated by KT-001A, 002C, 002D, KT-704, 705, 706 and KT-707. Figure 3 illustrates the locations of the $\mathrm{O}_{2}$ sensors within the ETC. At the time when the $\mathrm{GN}_{2}$ purge was shut down, $\mathrm{KT}-0 \mathrm{OD}$ indicated the highest $\mathrm{O}_{2}$ concentration of $2 \%$ which indicates the $\mathrm{GN}_{2}$ purge time and flow rate is adequate if the safe $\mathrm{O}_{2}$ concentration level is $3.5 \%$ or less. The $\mathrm{O}_{2}$ concentration continues down to less than $1 \%$.

KT-704 was $3 \%$ at the start of the test and decreased to $0 \%$. The initial low reading was the result of $\mathrm{GN}_{2}$ purge on the connectors in the top shield. KT-704 is located at the top of the ETC as shown in Figure 3.

KT-705 and KT-002C are located below the intermediate shield and initially indicated approximately $10 \% \mathrm{O}_{z}$ concentration. KT-002C was switched to sensor $\mathrm{KT}-002 \mathrm{D}$ and approximately 8 seconds were required for the $\mathrm{O}_{2}$ detector to respond to the new reading. KT-0O2D is located at the bottom of the ETC along with KT706 and $\mathrm{KT}-707$ which initially indicated 16\%. Approximately 40 seconds were required to lower the $\mathrm{O}_{2}$ concentration at the bottom of the ETC to $3.5 \%$ or less after the start of purge flow.

The scale on KT-002D in Figure 2 was switched from 0 to $25 \%$ to 0 to $5 \%$ at a range time of 41,110 secs. Therefore, the readings after this time must be divided by a factor of 5.0 . 

J. H. Ramsthaler
$-3-$
22 June 1967

KT-00IA is located in the simulated upper thrust structure and initially indicated 16.5\% and started to decrease 8 seconds after the start of $\mathrm{GN}_{2} \mathrm{purge}$ fllow.

The objective of the test was to lower the ETC $\mathrm{O}_{2}$ level to $3.5 \%$ or less and this was easily accomplished. The final $\mathrm{O}_{2}$ level decreased below $1 \%$ as indicated by KT-707 approximately 60 seconds after the start of purging.

At the present time the permanent detector (KT-001A/B and KT-002 C/D) have the capability to monitor two sensors by merely switching back and forth. However, due to the slow response time ( 8 seconds), it is recommended that the detectors be left on one sensor during any test. Or more $\mathrm{O}_{2}$ detectors be supplied for each $\mathrm{O}_{2}$ sensor.

The purge flow for the previous test was Iess than $13 \mathrm{Ibs} / \mathrm{sec} \mathrm{GN}_{2}$ and the initial $\mathrm{O}_{2}$ concentration was approximately $20 \%$ at $\mathrm{KT}-704$. Therefore, it is difficult to say exactly how the characteristics varied. Although, it appears as though the inerting characteristics are in general agreement.

\section{Shield Water Flow}

The objective of the shield water flow test was to verify that the required flow rates to the shields could be achieved. The required flow rate to each side shield (intermediate included) and bottom shield is $1474 \mathrm{gpm}$ and $604 \mathrm{gpm}$, respectively, as per NRO Memo No. 7860:0339M, dated 3/10/67. The only requirement on the top shield is that it be full of water.

Based on past test data, the flow rate to each shield was determined by temporary flow meters and correlated with the shut-off valve inlet pressures. However, the valve inlet pressures were not requested to be recorded. Therefore, no data is available from NEPN-I with respect to water flow through the shields except for PT-168. The required pressures have been requested to be recorded for $\mathrm{NEP}-\mathrm{V}$ and $\mathrm{NEP}-\mathrm{VI}$.

PT-168 is located upstream of the shield shut-off valves at the 42 " tee that divides water flow to the duct and steam generator. Assuming a flow rate of $3,550 \mathrm{gpm}$ (total required flow) to the shields, the theoretical pressure drop from PT-168 to the inlet of the shut-off valves is approximately 0.2 psi with an elevation head of 2 psi on the valve inlet pressure. PT-168 indicated 221 psig during the test, therefore, the theoretical valve inlet pressure should be approximately $222 \mathrm{psig}$ which corresponds to an average flow rate of approximately $1285 \mathrm{gpm}$ to each side shield and $635 \mathrm{gpm}$ to the bottom shield. The theoretical flow rate to the side shields is approximately $190 \mathrm{gpm}$ less than that required and the flow rate to the bottom shield is approximately $30 \mathrm{gpm}$ in excess of that required. This can be verified during NEPN-V and VI. 


\section{Structural Integrity}

Visual observation by $Q$. A. indicates that there is no visible external damage to the ETC. A check on the shield latches with feeler gauges indicated that there was no space between the latch hook and latching surface. No damage to any of the latching mechanisms was observed. All eutectic seals were intact and no anomalies were noticed.

Post test inspection of the 12 cables around the ETC indicated that 9 cables around the mid-section of the ETC still had a force of approximately 7000 1bs (pre test loading) and three cables around the ends of the ETC were slightly less than 7000 Ibs possibly due to the cable stretching. It should be noted that the tensiometer that was used to apply the pre-test load on the cables was slightly in error. Therefore, the pre-test loading on the cables can only be approximately at 7000 lbs.

The side shields were separated and the internal surface of the ETC was visually examined. No visible damage was noticed.

\section{ETC Pressure Drop}

Prior to the test temporary pressure transducers PT-874 and PT-875 were installed above and below the intermediate shield, respectively, to give fast response and accurate pres,sure readings across the intermediate shield. During the 5 tests, PT-874 never exceeded PT-875 by more than 0.10 psig which indicates the pressure drop across the intermediate shield is negligible.

Figure 4 and 5 are cal-comp plots of PT-874 and PT-875 respectively for Test No. 4. The two curves are identical except at the lowest pressure where PT-875 started to read low by 0.1 psig. PT-875 is reading 0.1 psig low since it did not return to the original atmospheric pressure by 0.1 psig after the test.

The pressures at the top and bottom of the ETC were monitored by permanent pressure transducers PT-290/291, and PT-292/293, respectively. However, due to the long length of tubing to the transducers (approximately $60 \mathrm{ft.}$ ), the pressure responses were damped for all four transducers and lagged PT-874 and PT-875.

PT-292 read low and responded, as though, it had a restriction in the tubing, therefore, PT-800 the differential pressure transducer that was installed between PT-290 and PT-292, gave erroneous readings.

It was recommended that the tubing be cleaned out by blowing $\mathrm{GN}_{z}$ through it and inspecting for any type of restriction in the tubing. PT-292 was blown out with $\mathrm{GN}_{2}$ and no restriction or foreign material was noticed. However, the tubing to the four permanent pressure transducers were leak checked and several small leaks were discovered and repaired. The leaks were probably a major cause of the slow response and erroneous readings recorded by PT-290/291 and PT-292/293. 


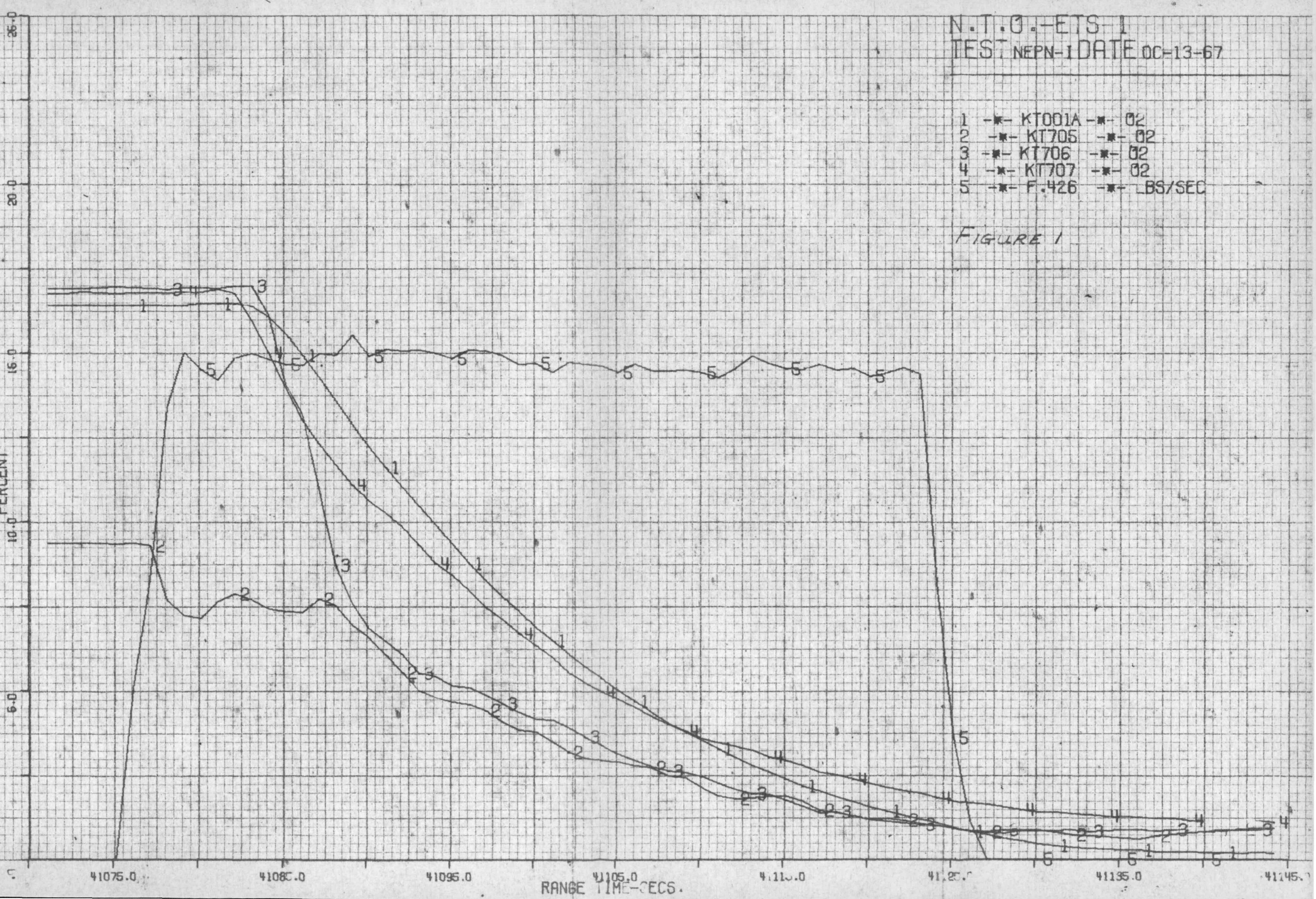




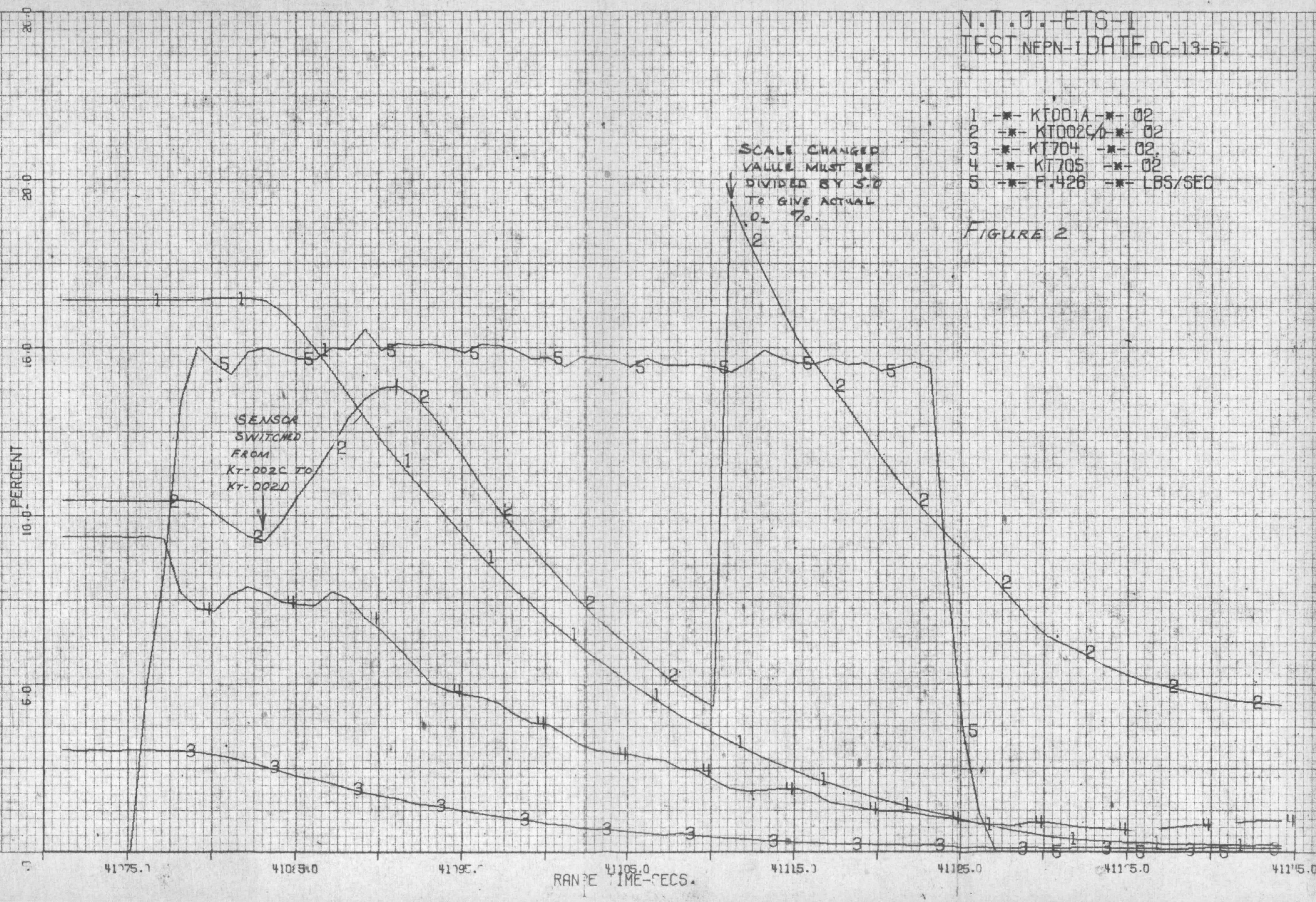




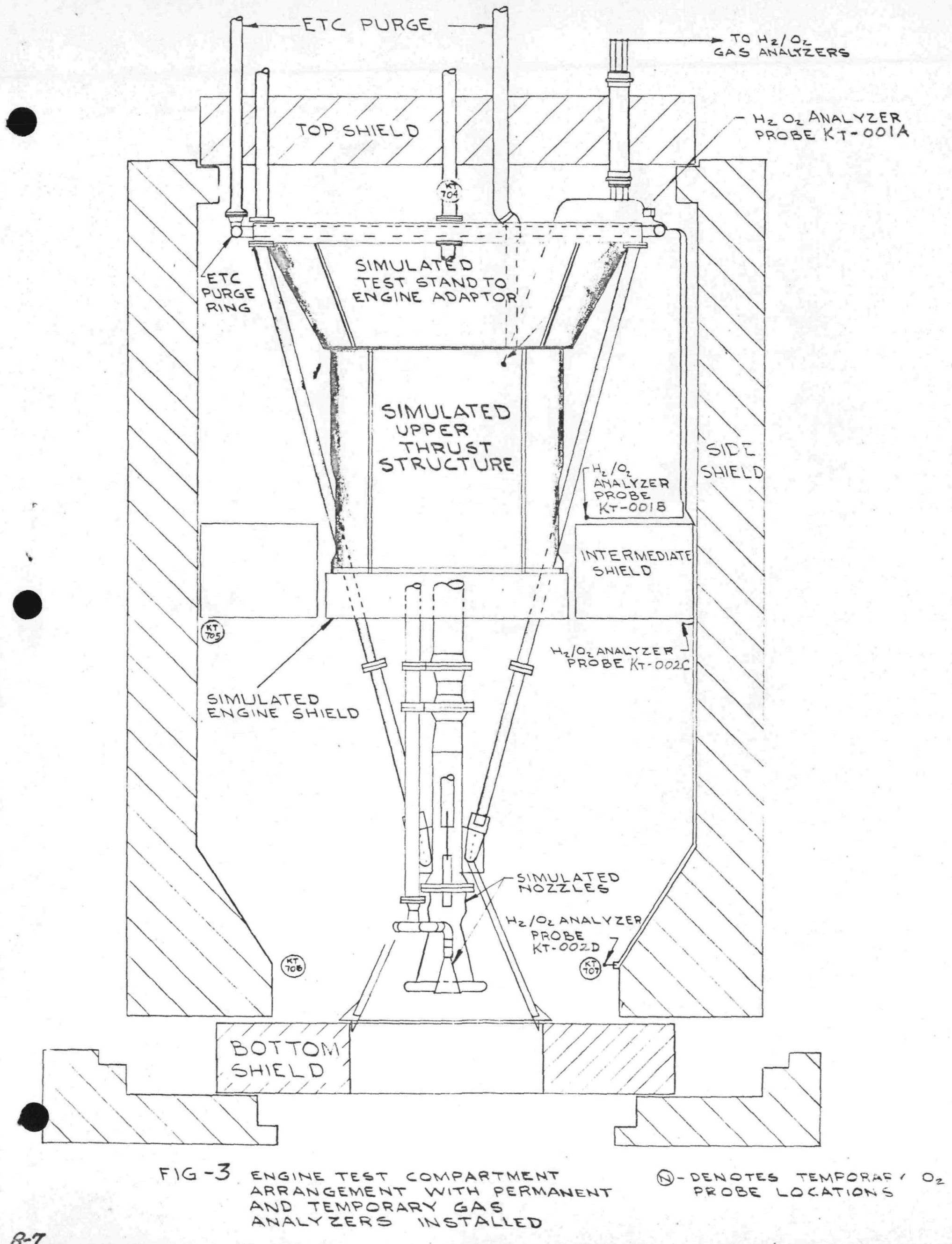




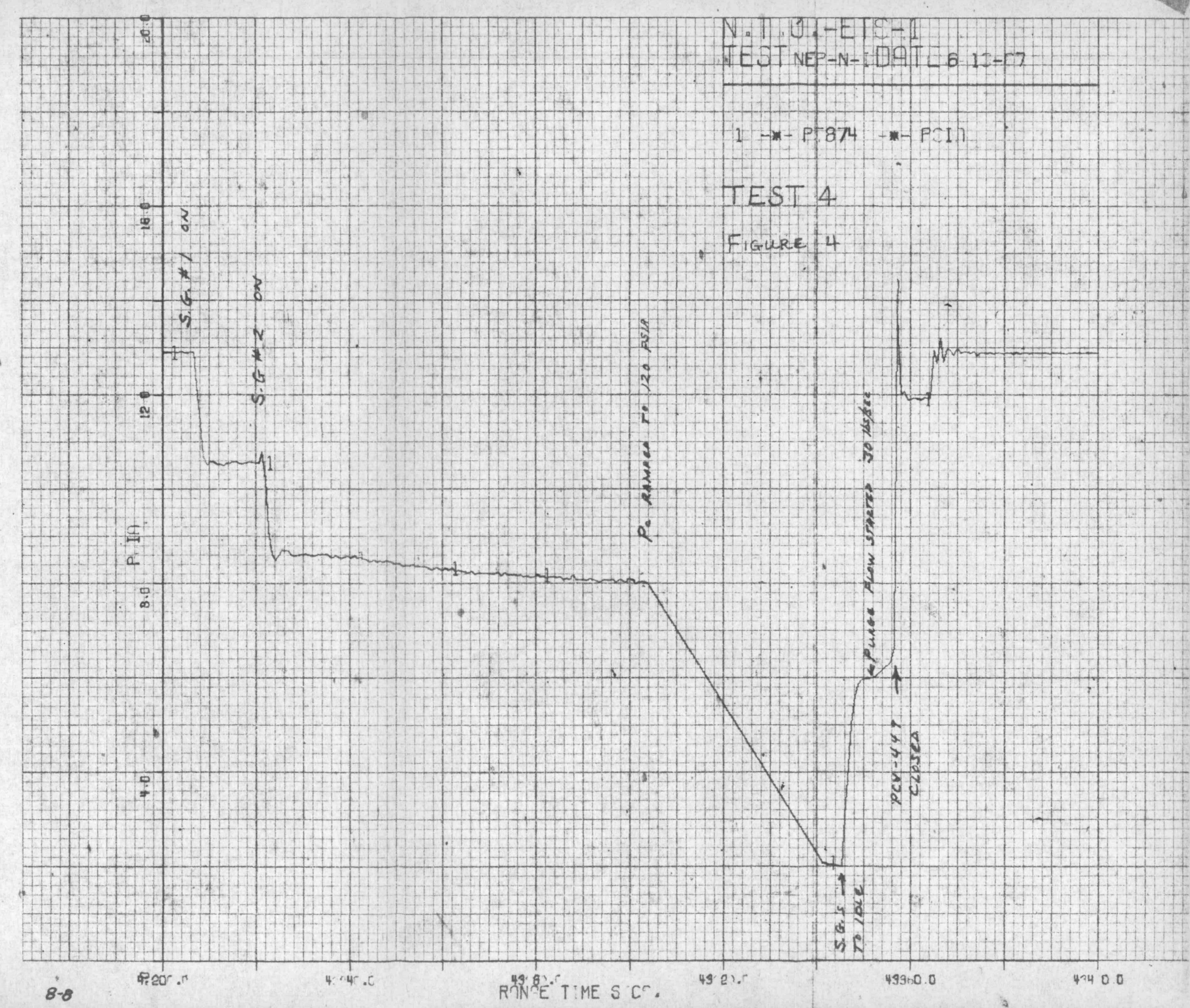




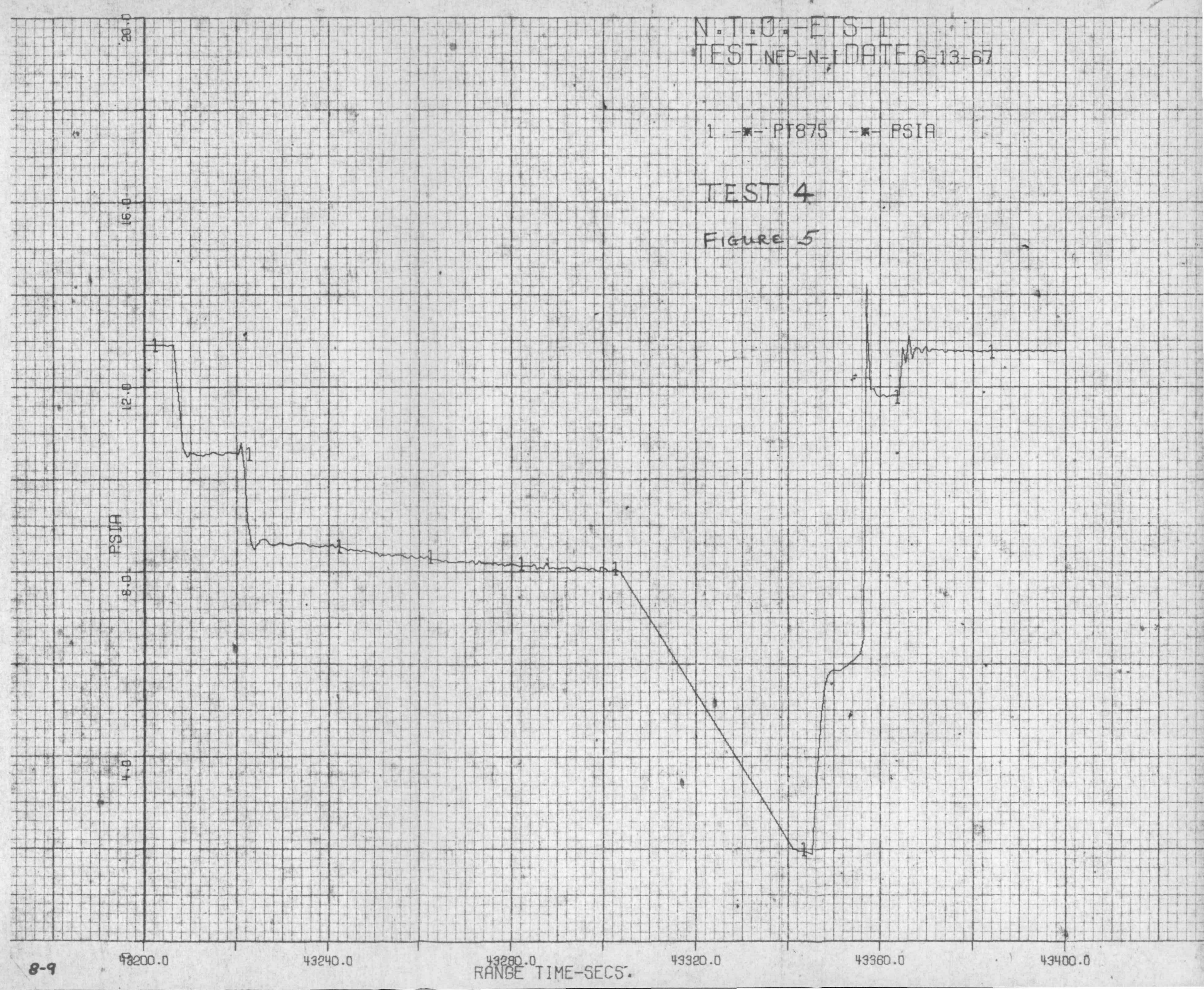


TO:

J. H. Ramsthaler

21 June 1967

FROM:

SUBJECT:

Enclosures:
R. J. Gulde

Evaluation of Primary Gas Blowback

(1) Figure 1, Test 4 Comparison of Blowback Temperatures to Primary Gas Flow and ETC Pressure

(2) Figure 2, Test 5 Comparison of Blowback Temperatures to Primary Gas Flow and ETC Pressure

(3) Figure 3, Test 2 Comparison of Blowback Temperatures to ETC Pressure

In an attempt to determine whether exhaust gas will blowback into the ETC during engine operation, the temperature outside of the exit cone was measured during primary flow operation. Six thermocouples (TE 810-815) were located between the primary and turbine exhaust nozzle exit cones, and one temperature probe (TE 903) was located in the primary flow line.

It was believed that if flowback of the primary gas would occur, the thermocouples could indicate a change in temperature. However, since the primary gas temperature was $500^{\circ} \mathrm{R}$ which is nearly the same as ETC temperature, it was not possible to determine whether or not blowback did occur.

As shown in Figures 1 and 2 which are a comparison of blowback temperatures to primary gas flow and ETC pressure, the temperatures do decrease when primary flow is introduced. This decrease in temperature, however, correlates with the ETC pressure. As also shown in Figure 3 when no primary flow was introduced, the temperatures drop as the ETC pressure is decreased, and the temperatures rise with an increase in ETC pressure.

Since the temperature of hydrogen also will not be appreciably different from the ETC temperature, it is recommended that the thermocouples be replaced with hydrogen sensors to evaluate blowback when hydrogen is used for primary flow.

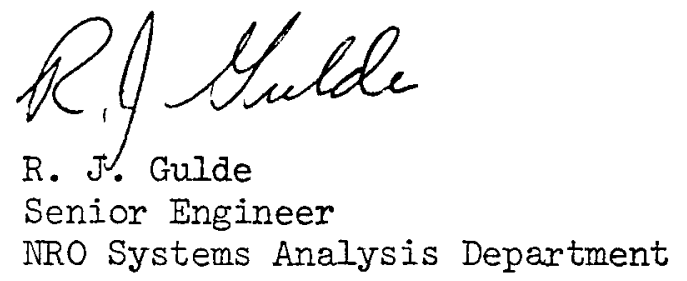




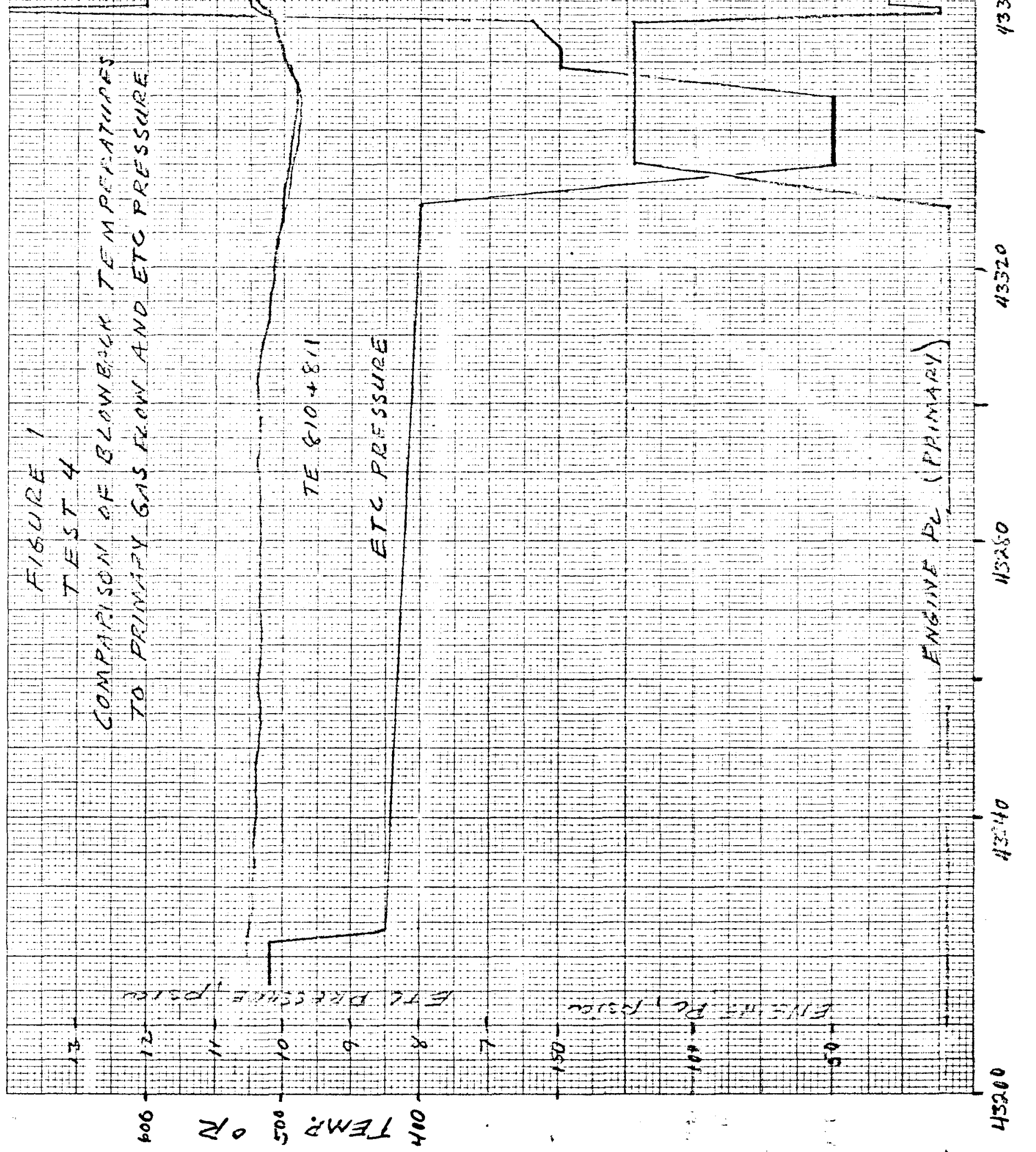




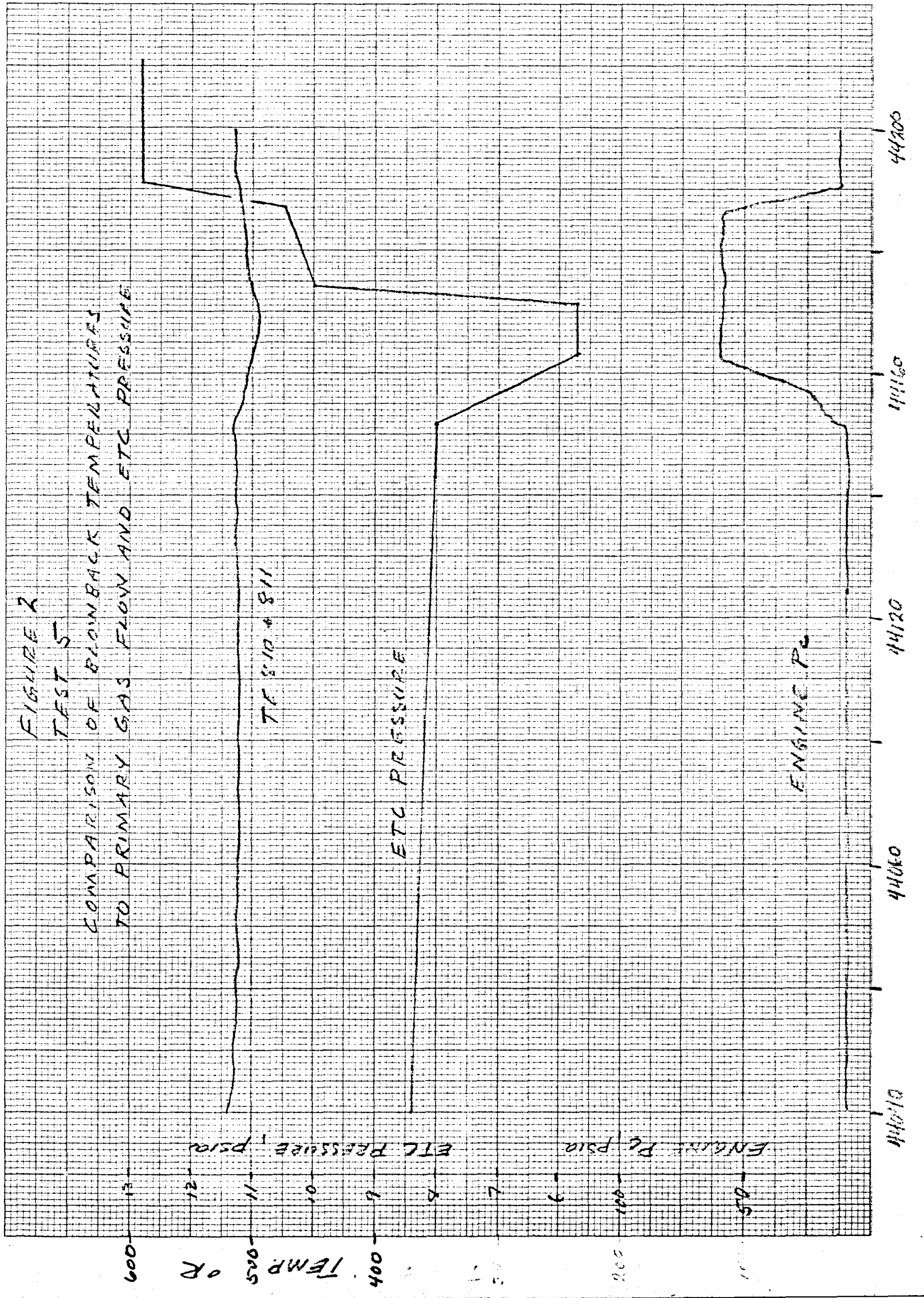




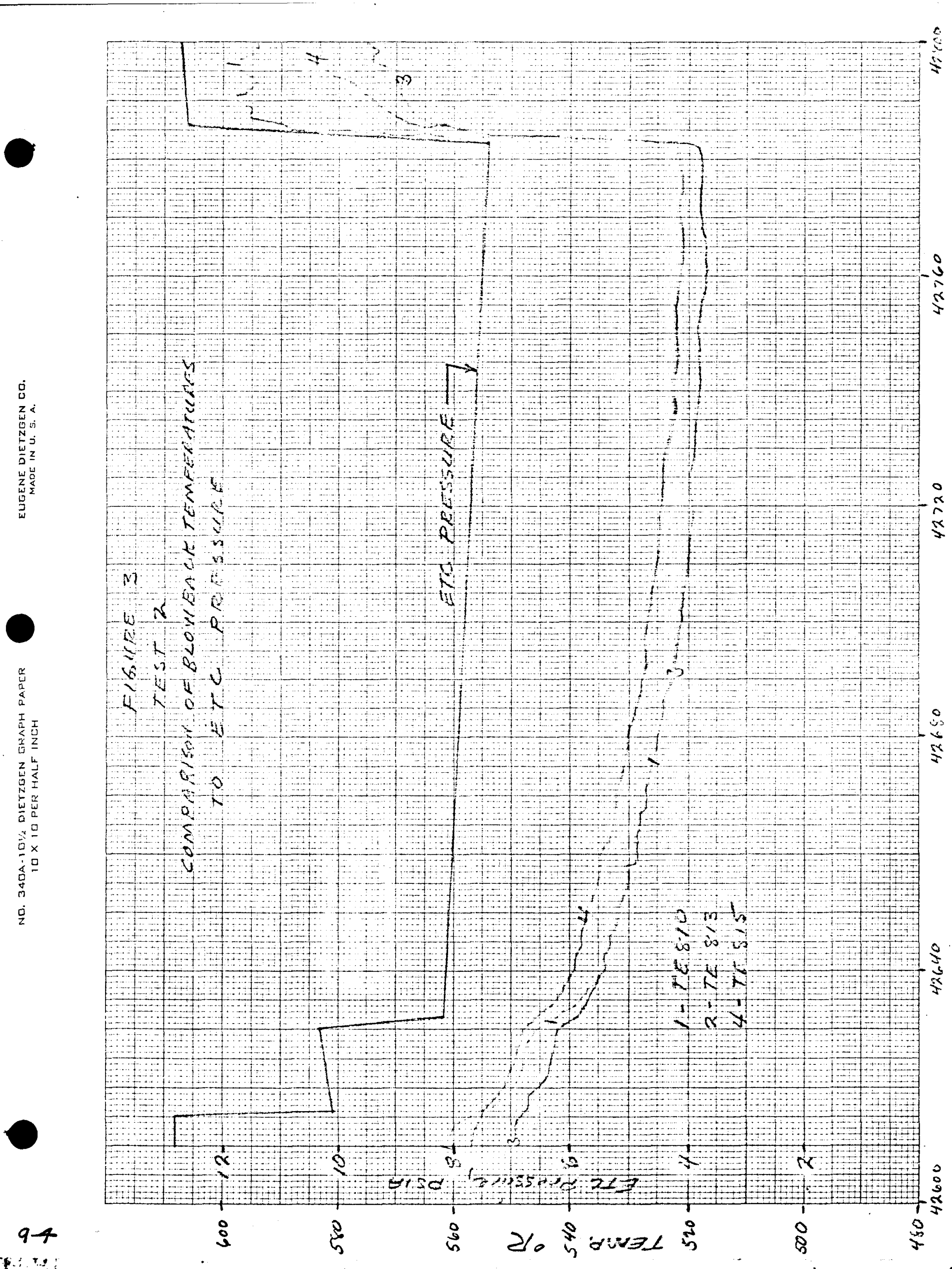


TO:

J. H. Ramsthaler

20 June 1967

FROM:

R. J. Gulde

SUBJECT:

Comparison of Permanent and Temporary Oxygen Analyzers

Reference: Memo, H. W. Brandt to B. S. Maxon, Subject: Results of CEP-I Data Evaluation Effort

Enclosures: (1) Figure 1, Test 1 Shutdown

(2) Figure 2, Test 2 Shutdown

A comparison of data obtained from the permanent and temporary type oxygen analyzers was made during DDT Phase II Tests 1-5. Two permanent and four temporary analyzers were located in the ETC. Of these, KTOO2 (permanent) and KT707 (temporary) were located in the same area with KTOO2 located approximately 24 inches above KT707.

Figures 1 and 2 show the results obtained from KTOO2 and KT707 during shutdown of Tests 1 and 2. As may be seen from these plots, KT707 responds immediately with KTOO2 responding about 3 seconds later. The slower response of KTOO2 is due to the length of line from the probe location to the analyzer. Figure 2 shows that the peak values are in the same range, particularly if a zero calibration adjustment is made.

The operation of the oxygen analyzer system was as expected based on CEP-I data (Reference 1). A more detailed analysis is required to determine whether the permanent type oxygen analyzer is satisfactory for use during a test run with hydrogen.

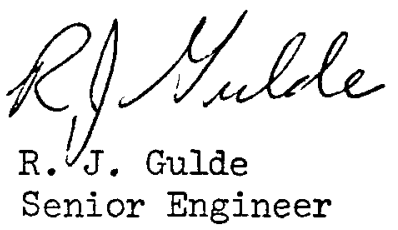

NRO Systems Analysis Department 


$$
\begin{aligned}
& E x \in E=
\end{aligned}
$$

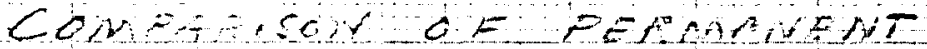

$$
\begin{aligned}
& \text { GHDTEN CARY OCZ ANALYZEES } \\
& \text { TEST L SHUTOHWA } \\
& +
\end{aligned}
$$

4.0

$3.0-\alpha^{2}$

KT:OOZ-PERMANET

$K T>0\rangle-T E N$ NOARAY

KTOOZ LOCATED RULWHES

 $A P O V E K T>07$

1.0

8

$$
\text { s. }
$$




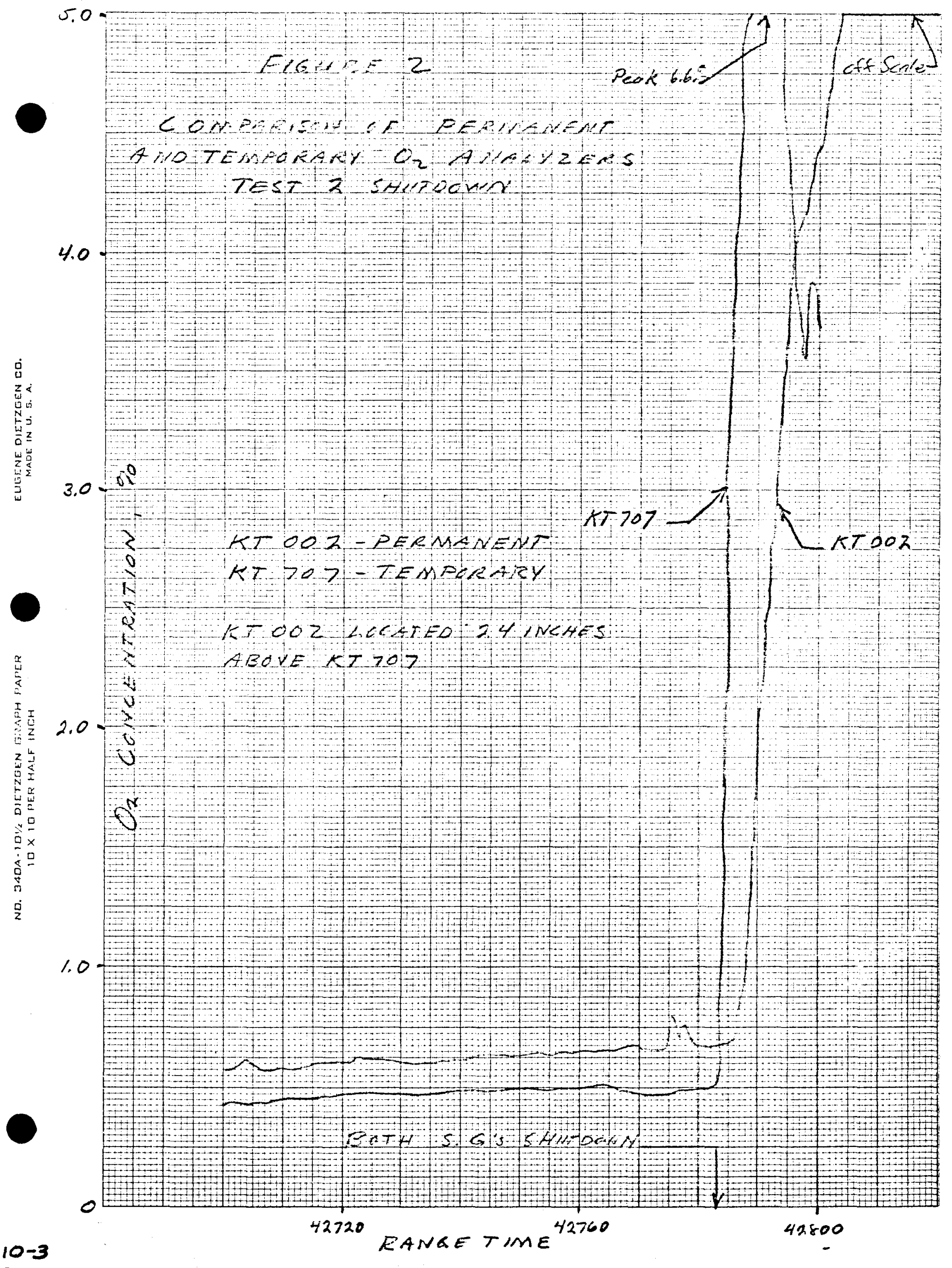


SPEAR MEMORAIDUH ITO. 11

TO: J. H. Ramsthaler

DATE: 22 June 1967

CWK:gg:rja

FROM: $\quad$ C. W. Kerisi

SUBJECT: Steam Generator System Operation - NEPN-I

\section{SURARY}

Operation of the SGS was normal during the NEPN-I test series. Reliable idle and full-steam performance was demonstrated from range time 42254 to 42209 , or a total of 1955 seconds.

Tables 1 through 5 indicate typical SGS parameter performance during the idle and full-steam modes. Transducers PT-416 and 417 (1st and 2 nd stage trausducers, respectively) indicate that the SGS performance with the continuous propellant bleed modifications is within the range predicted by Phase I tests.

Pressure buildup (SG-1 to full-steam) becomes asymptotic to a value of approximately 47 psig within 4.5 to 5 seconds in Tests 2, 3 and 4. In Test 5, the pressure increases to approximately 46 psig within 2 seconds.

Figure 1 illustrates SGS 1 ine decay during Tests 1 through 5. Steam line pressure decayed from approximately 100 psig to equivalent slope points near zero psig within 3 seconds in Tests 2, 3, 4 and 5 . In Test 1 , decay time was also approximately 3 seconds to the point where the slope is zero. Further examination of the curves reveals that the buildup and decay rates are similar and reasonably predictable. The "hump" in Test 1 during pressure decay and the negative pressure values (instead of zero) plus the 2-second pressure buildup in Test 5 are reconmended for further investigation.

A momentary "firebal1" was observed during the previev of the Phase 2 movie as the SGS was abnormally shutdown. This phenomenon has been deduced to be the normal action of the SGS purge system expelling residual propane through the INES. At the duct exit, the propane and GN mixture burns briefly as a "fireball" when ignited by the duct flare system, or is vented and dispersed in the atmosphere as a highly diluted, non-combustible propane gas.

Post-test inspection of the SGS revealed the normal injector/ combustion chamber fastener relaxation. Leak-checks of the system indicated normal "gas-tight" integrity after full-steam operation. 


\section{Steam Generator System Operation - Continued}

It can be stated that the SGS "bleed" product improvement objective has been achieved and the system can be pcepared for test NEP-V.

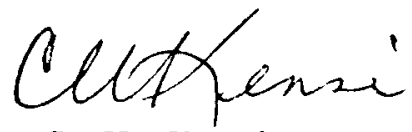

C. W. Kensi 


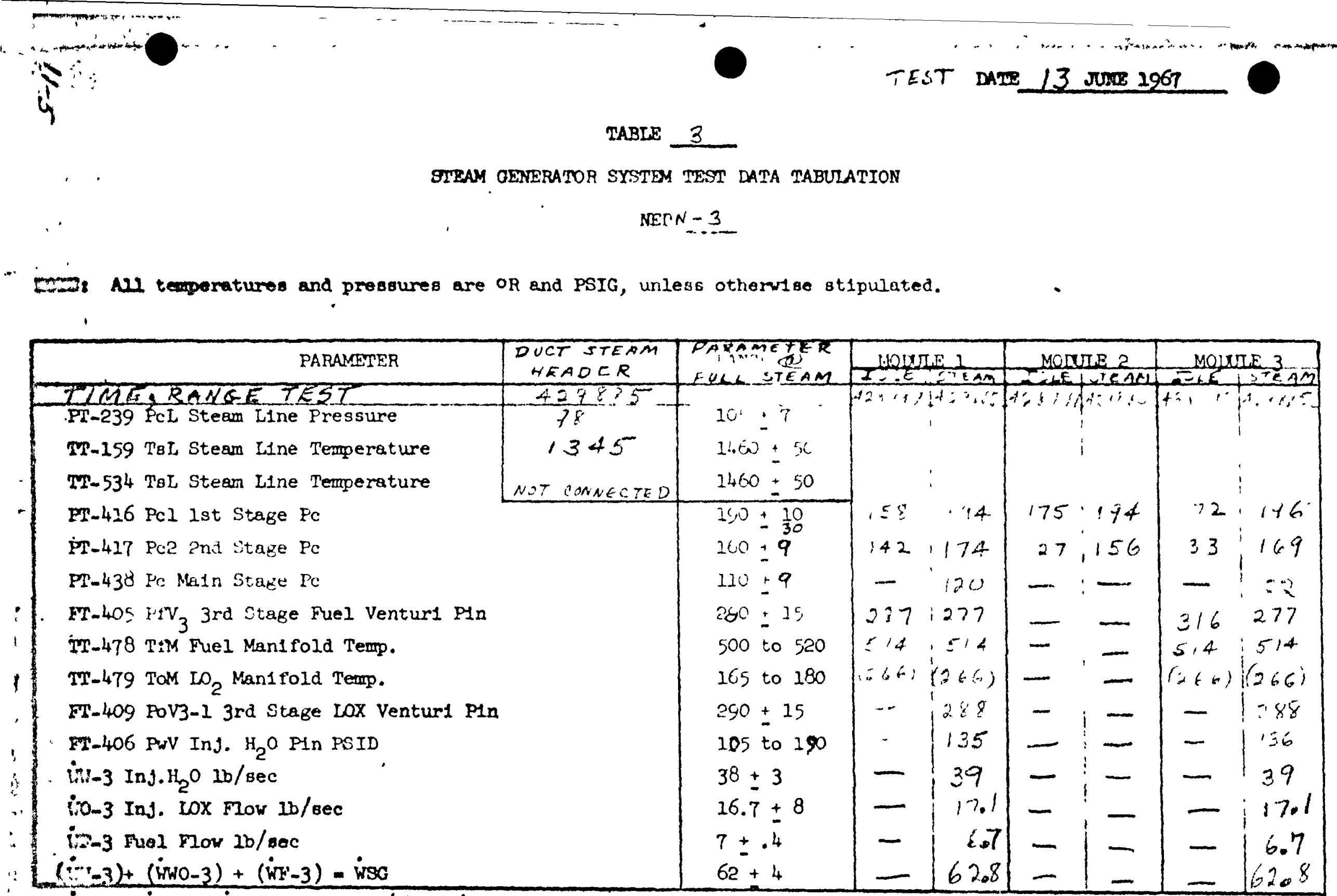

- WEaI + WSG2 $^{2}$ WSG3 $+15=141 \mathrm{Ibo} / \mathrm{sec}$ 


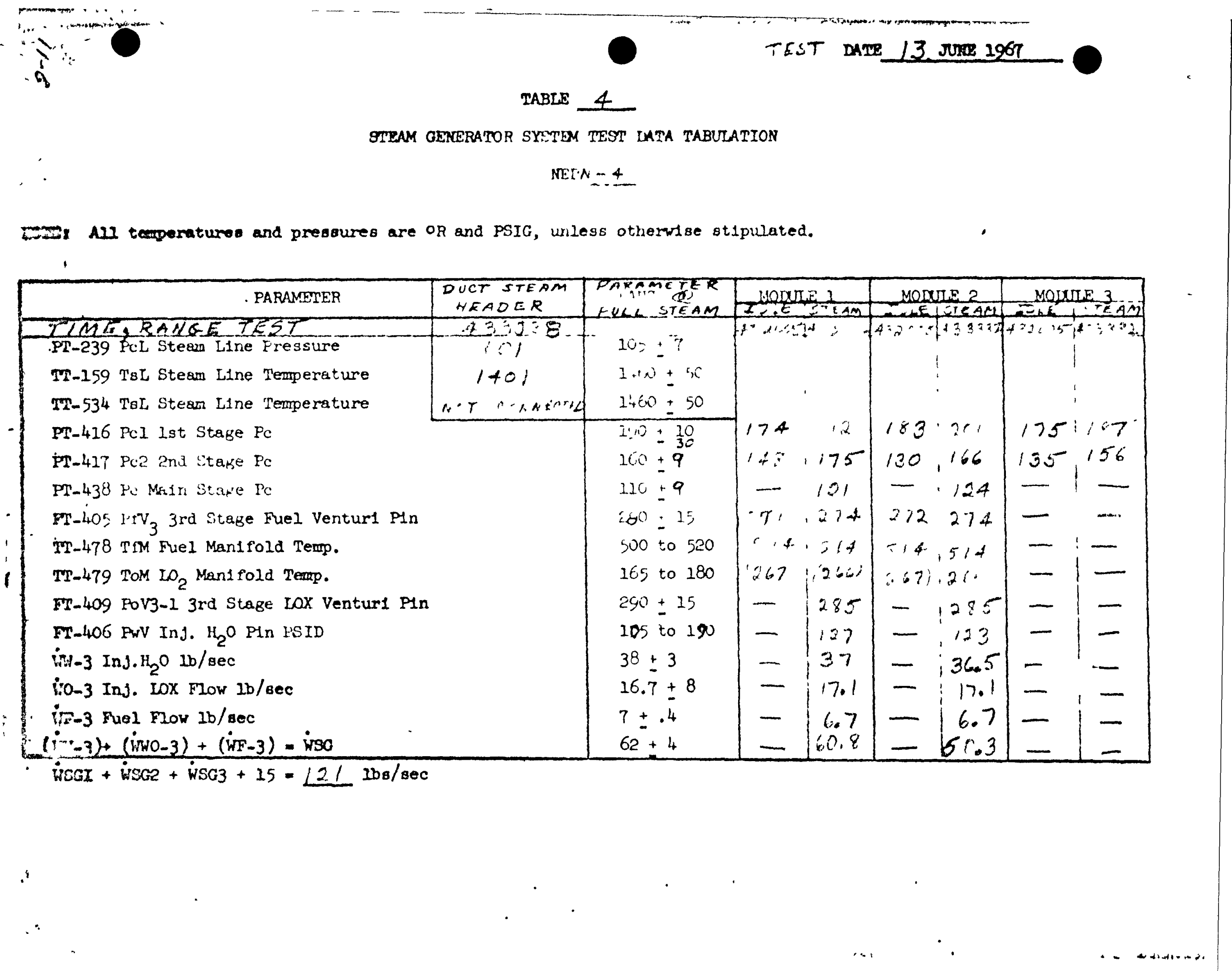




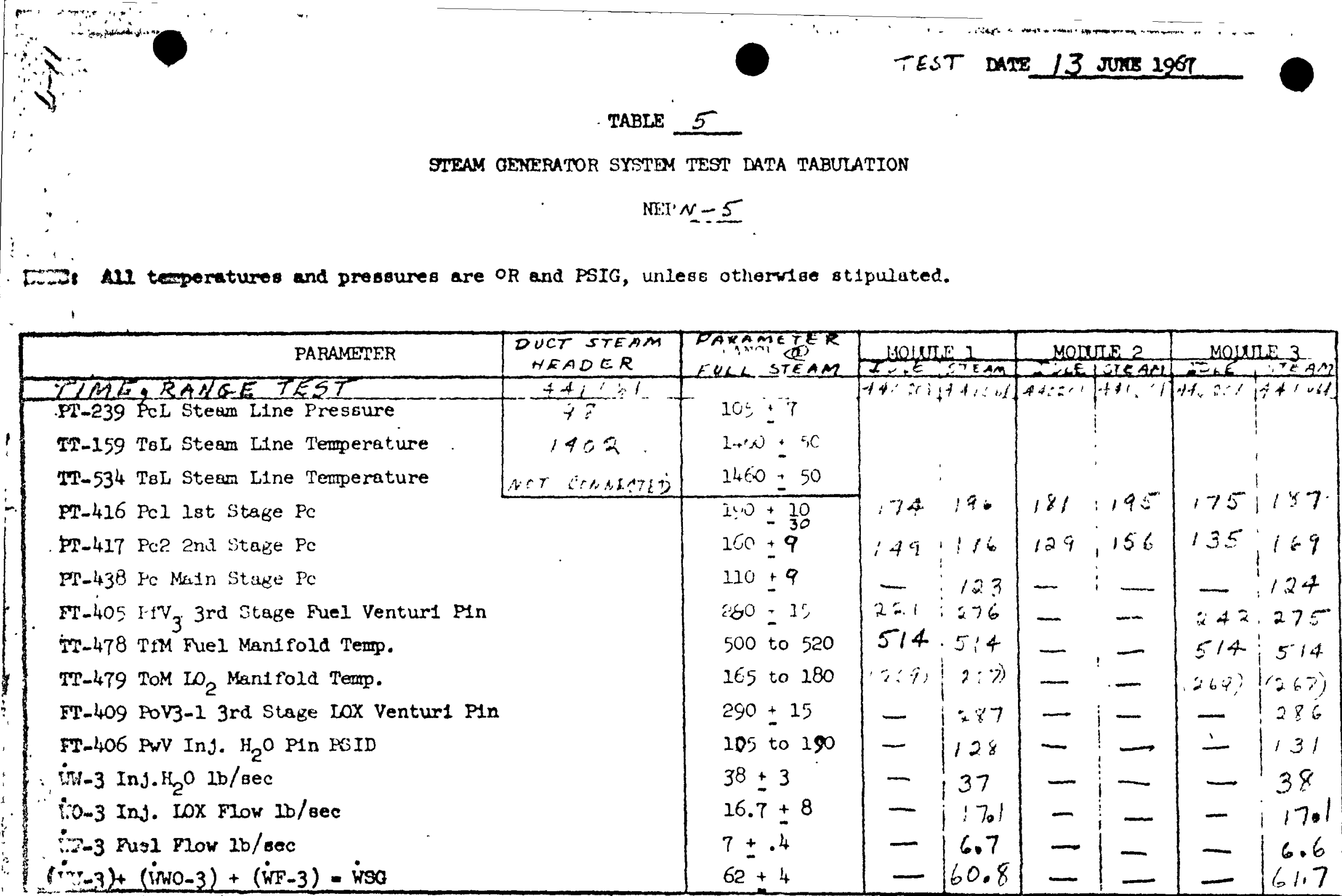

WoOI + $W_{S G 2}+\dot{W S G 3}+25=1232 \mathrm{bo} / \mathrm{sec}$ 


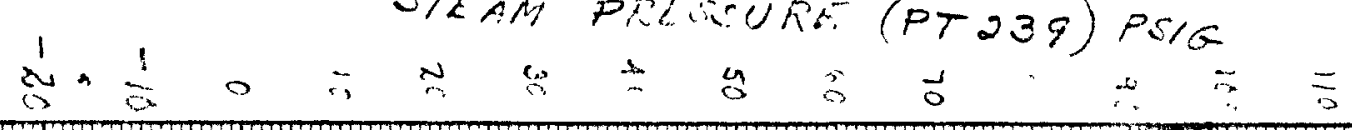

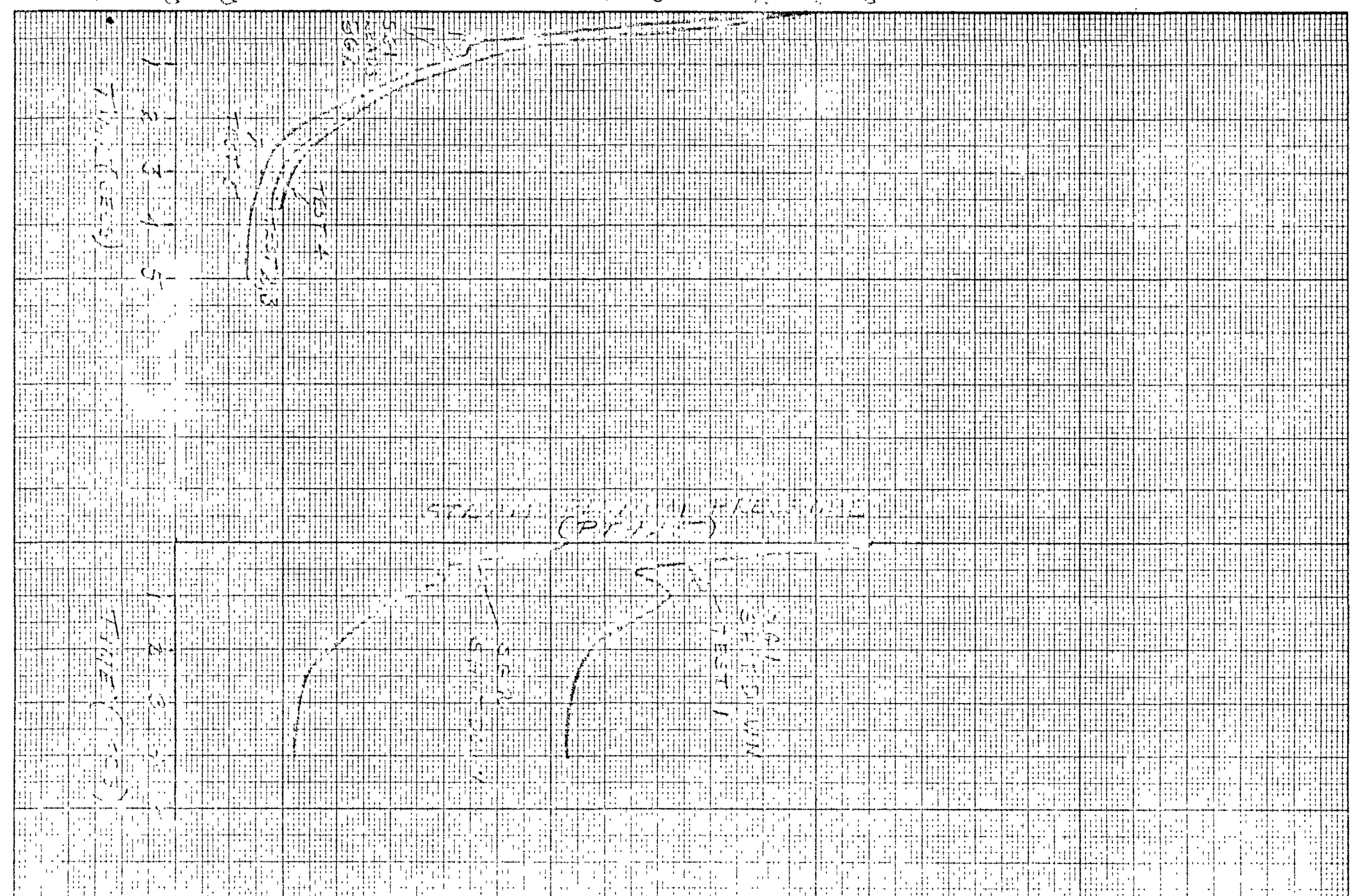




\section{SPEAR MEMORAINDUI: No. 12}

TO: J. H. Ramstialer

FROI: $\quad$ E. J. Fuller

SUBJECT: Analysis Stearn Iine Condition

Encl: (1) 20" Steam Iine Report ITo. 1 20" Steam Line Prior to and During REP III

(2) 20" Steam Iine Report Iro. 2 $20 "$ Steam Line During NEP IV

During the hydrostatic proof test of the steam line system, the gimbal rings and the hinge joint was stressed beyond yield which resulted in large distortion. They were re-designed and replaced in the system. The first steam test was conducted with the constant load hangers in their locked position. The hanger $\| 3$ (Fig. I) was damaged and replaced.

During the subsequent steam tests, the constant load hanger movement was erratic: particularly, the bottom elbow hanger travelled to the cold stop instead of to the hot position at high temperature. Excessive vibration of the line was also noted at the moment of start up of steam flow. After each test, the hanger position had to be re-adjusted.

It was found last August, that the hinge joint was pinned in the rrong direction. The top horizontal section and vertical section of the line were also noted boved. The hinge joint vas re-installed to allow movernent in the vertical direction.

After this modification, two steam tests, NDP-I and NEP-2, vere run. The hanger movements remained abnormal. The bend in the vertical line appeared more noticeable after the NEP-2 test. It was decided to lover the steam temperature for the NEP-3 and NEP-4 tests, and collect data to help analyze the proolem.

During INP-3 and INP-4, instrumentation was provided to measure the pipe temperature and gimbal movement. High speed camera was also used in NEP-4 test to film the motion of the top gimbal ring during start-up. These data rere used to support the analysis. The constant load hancers were reset before the MEP $-\overline{4}$ test by raising the bottom elbor hanger to $5500 \mathrm{lbs}$. and lowering the vault hanger to about $3500 \mathrm{Ibs}$. All the hanger movements were in the correct direction and approximately correct amount in this test for the first time during NEP-4.

II PREPARATION OF INEP N-I

Prior to NEP N-I two additional 20,000" hydraulic snubbers vere intalled at point $\mathrm{E}$, Fisure (1), a 20,C00, struct installed at point B to restrict any $\pm X$ movernent and a $6 "$ high dam installed at the sGS 18 " $x 20$ "Tee to prevent the flov of vater dorm the steam line during the idle operation. 
At point $C$ two more sinin thermal couples vere added to the existing four in an atternt to detemine the Iines circumferential vall temperature gradient. At point two $\pm 20 \mathrm{~g}$ accelerometers vere installed to measure the $\pm X$ and $\pm \bar{Y}$ acceleration. All previous instmimentation was sustained excert for the vertical line vall temperature and TV coverage of han oer $t / 3$.

\section{TEST RESULTS}

1. 200 frame/second cameras. The start up of the first module from idle of full steam for run 1 , the start up of the 2nd module from idle to full stean for run 1, and a SGS fast shut down was recorded.

The first module start up from idle to full steam caused some jolting. of the line. The upper elbow had a slight lst motion of about 1 or 2 cycles followed by a heavy jolt of about $+1 / 2$ " in the $X$ direction and a slight movement in the $Y$ direction. This movement is superimposed on the IIEP IV movement for the same SGS operation, Figure 2.

2. Sxin Temperature. The steam line skin temperaturs for runs 1 and 2 are plotted on Figure 3 and 4 respectively. In run 1 a block of data was lost betreen ranze time 42512 and 42550 , horrever at 42550 the top wall to bottom wall delta $T=420^{\circ}$ and during the run 2 shut down a delta $T$ of $520^{\circ}$ was obtained.

3. Steam Line Pressure Transient. Steam line inlet and exit pressure as depicted in Figure 5 and 6 for muns 2 and 3 respectively, the $X$ axis acceleration is superimposed on run 3 .

4. Accelerometer. The accelerometer data for the Ist module to full steam transient is plotted from the beginning of the steam line pressure rain to the steaciy-state accelerometer trace for runs 2 and 3 on Figures 7 and 8 respectively. The 2 nd module to full stean would cause a slight disturbance of 1 or 2 g's of .1 to .2 second in some runsaid no disturbance on other runs. The shut dorn rould cause a slight disturionce of 1 to 2 cycles. The runs 3 and 4 shut dom caused a half cycle -15 and $-20 \approx Y$ axis disturbance respectively. During the steady-state full flor the $X$ axis acceleroneter recoried a $40 \mathrm{G}$ 's pea: to pea' 9 about $2000 \mathrm{cus}$ and the $\mathrm{Y}$ axis $20 \mathrm{~g}^{\prime} \mathrm{s}$ peals to peal $a$ aiout 2000 cps.

\section{COIJCLUSIOIS}

At the present the hangers \#2 is 75\% towaras itsfull up or hot position and hanger "t:2 is hard against its cold stops. This condition indicates that the vertical section. has been borted or its vertical dimension shortened. Present support Contractor scheduling has not permitted the construction of the scafiolding required to ascertain measurement which can be compared to the pre-IFP II-I measurements. Therefore the magnitude of the ncw deformation, if any, cannot be determined until these measurements have been taken.

The $X$ axis acceleration vas superimposed on the run 3 pressure transient curve, Figure 6 , because it has the most severe pressure transient but the least severe acceleration transient. Fresently it appears as if the pressure might cause the first disturbances with a water hamer 
causing the severe shocls. In past tests the vater plus products of combustion temperature caused the lag in the saturated steam pressure for a number of seconds as the steam line pressurs increased; horever, this occurred only durins run $7^{\prime} I$ and then only for about 1.5 seconds. These facts, plus the visiole vater dischargino from the duct exit with the first burst of 1 module steam and the line skin delta $T$ indicates that there is still consicerabie water carried over the $18^{\prime \prime} \times 20^{\prime \prime}$ Tee dam.

With the exception of the run 3 start wo the accelerometer data folloved the same trend and about the same magnitudes. Although the acceleration calculated from Figure 2 for IJP IV vere in the order of $200 \mathrm{~g}$ 's it was expected that the modification would reduce this to less than $20 \mathrm{~g}$ 's, and it was felt that the available $20 \mathrm{~g}$ accelerometers would be adequate. The $Y$ axis which vas controled by the snubbers did not exceed a recorded $27 \mathrm{~g}$ 's which was demped in $1-1 / 2$ cycles while the $X$ which was restrained with a rigid strut overranged values over 20 to $30 \mathrm{~g}$ 's, the accelerometer for 1.5 to 2.5 second in the Figure $1(-)$ direction.

Extrapolation of $X$ axis data during the first severe shock indicates values of about $100 \mathrm{~g}$ 's for all test except run 3 which indicates about $60 \mathrm{~g}^{\prime} \mathrm{s}$, and requires about 3 cycles for darpening.

The steam line slin delta $T$ exceed terperatures of about $200^{\circ}$ recorded in the past. During the post investigation it vas felt that a delta $T$ of $500^{\circ}$ would produce a stress freater than the yield stress of $347 \mathrm{ss}$. Data from runs $I$ and 2 indicate delta $T$ of 420 to $520^{\circ}$ resoectives indicating possible yicld of the horizontal scction duc to thermal stress.

IV RECOIITIDATIOIS

1. Steam line measurements be taken as soon as possible.

2. Investicate need for water after SGS has been shut dom or make it mancatory to cool down steam as in IIEP $V$ and IV before shut dorm to prevent the large shut dow Iine vall delta.

3. Attempt to ma'se a computor dynamic analysis of the steam line with the accelerometer data from IISP IJ-1 to try to deterrine the line stress during start up transicnt.

It is recommended that these items must be completed before the steam line is returned to service.

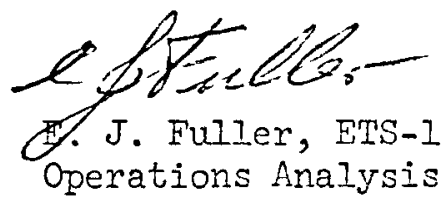


$\grave{n}$

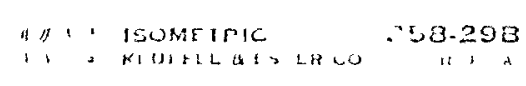

20" STEAM LINE SCHEMATIC
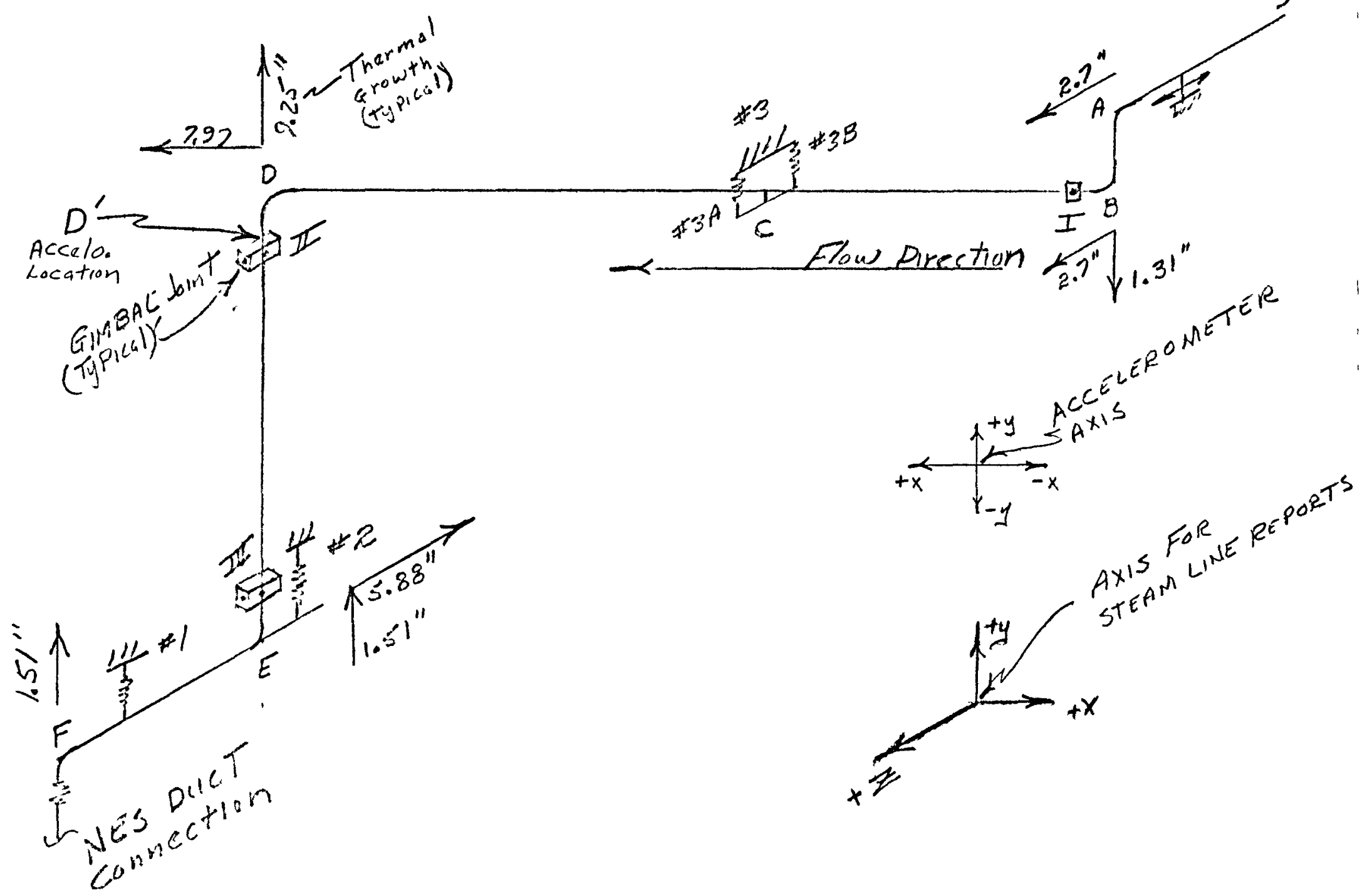

figure 1

$g(t) 2 / 2 / 6\rangle$ 


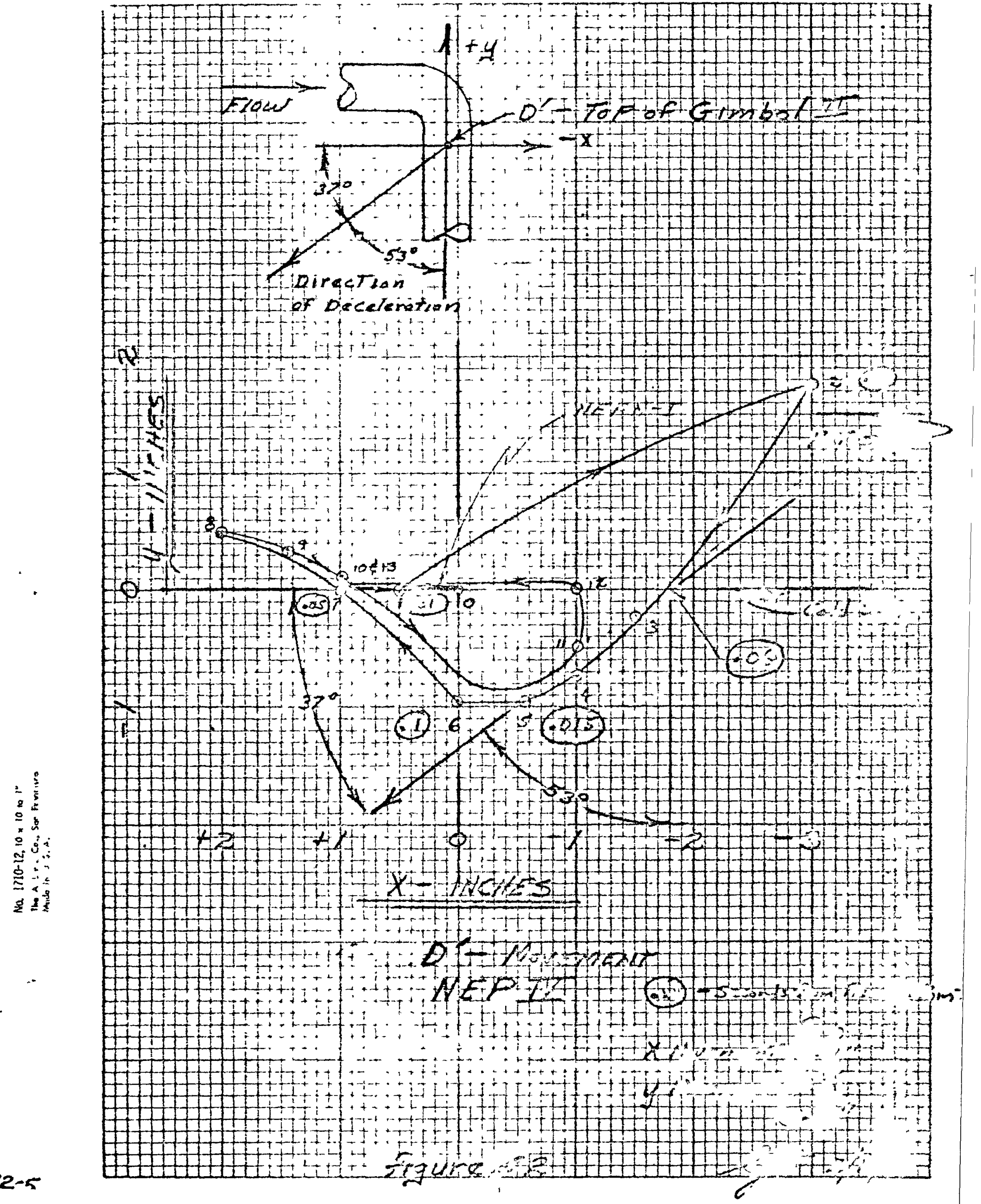


... 1400 \%

1300

1200

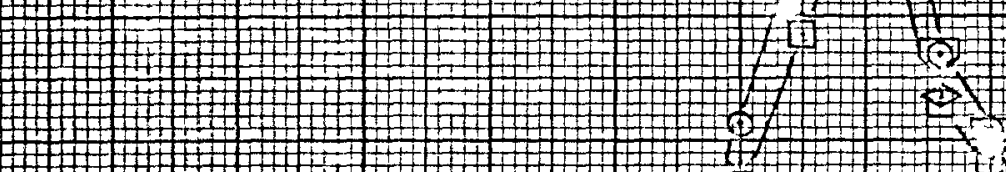

1100

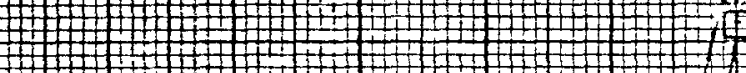

$+1$

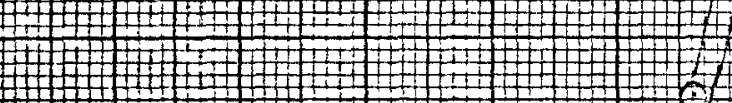

$\mathbb{1}_{0}$

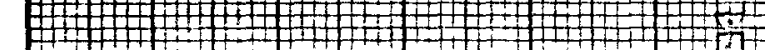

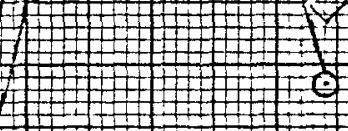

W1000

1 - 11 1

$+$

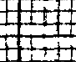

\section{7}

$+5$

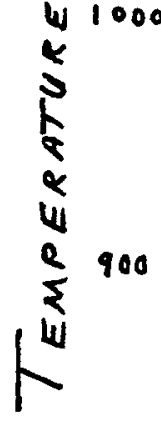

800

(1)

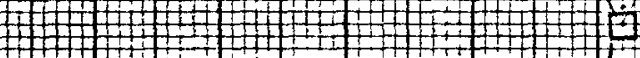

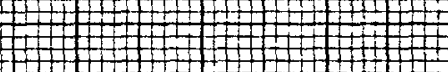

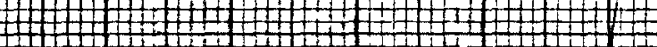

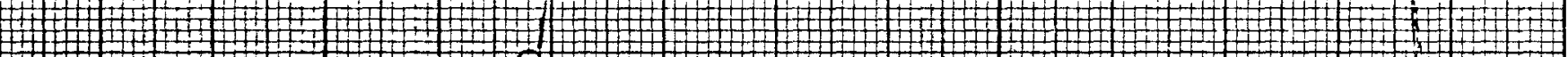

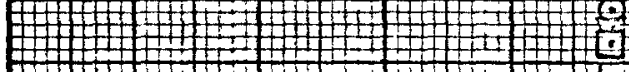

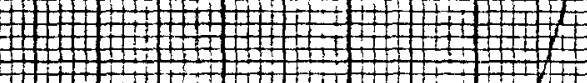
$+1$

$+1+2$

$+1+$

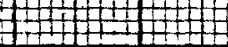

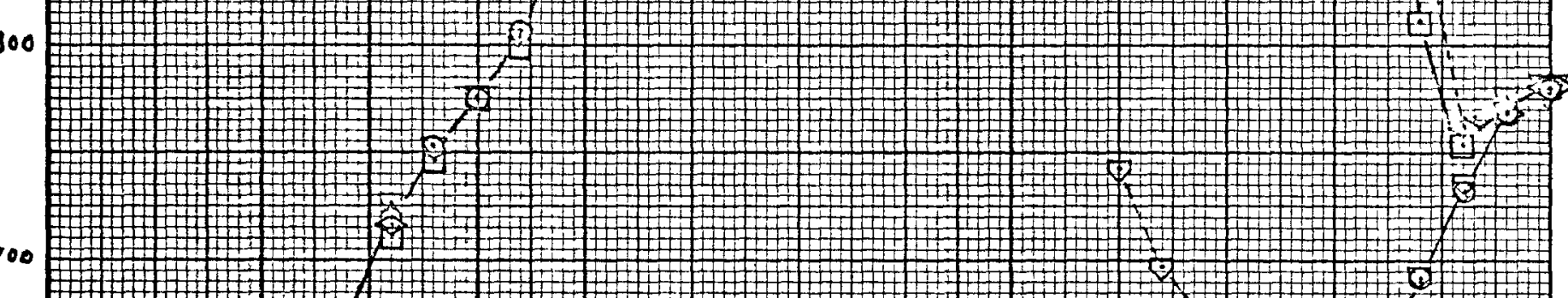

+ \#+

700

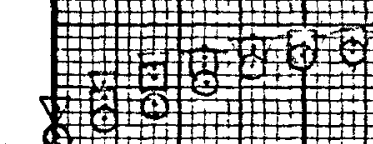

600

500

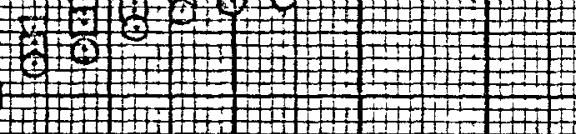

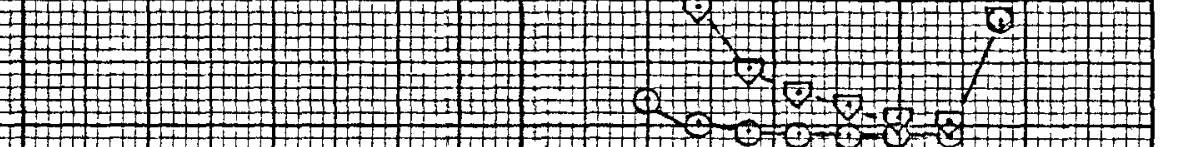
$1+$ 
1400

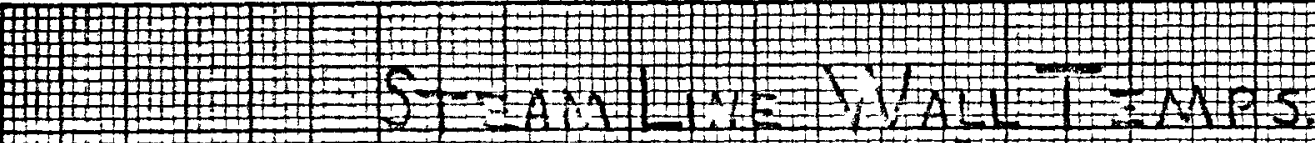

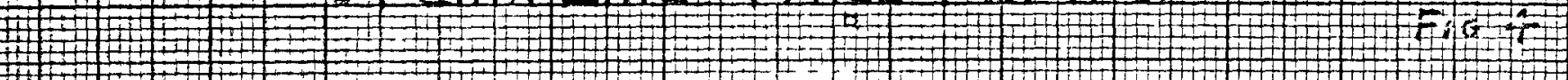

$+1$

1300

1200

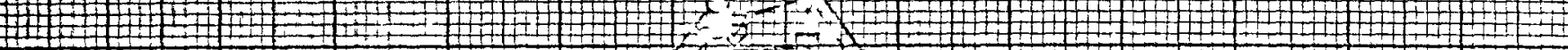

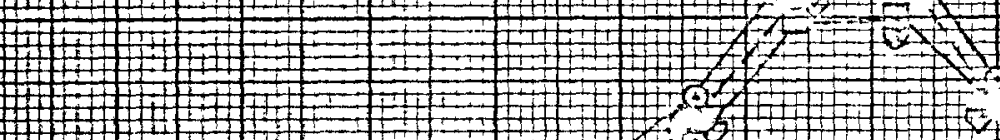

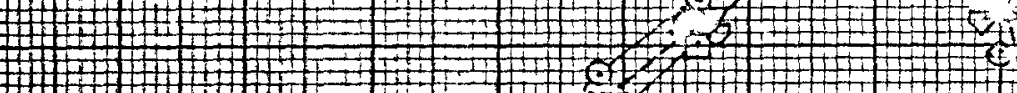

W

+217\%

$1+27$

W

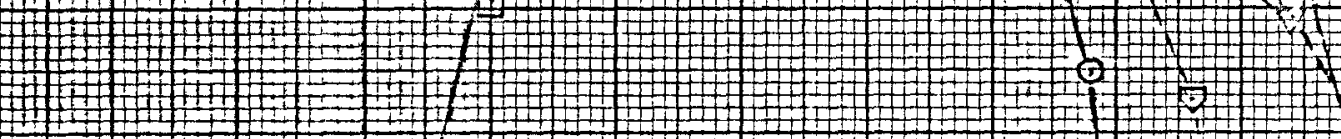

1100

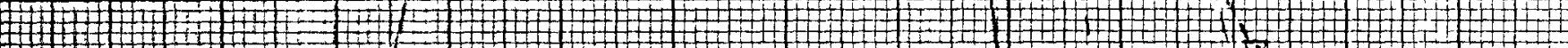

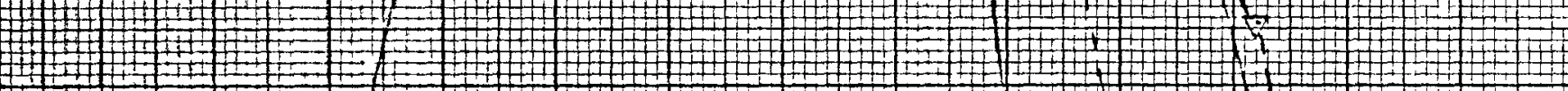

$\frac{w}{2} 1000$

+17
+17

0

W

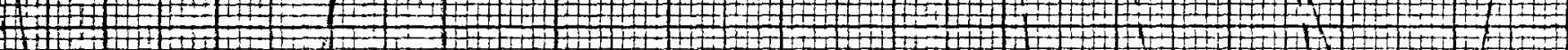

$\begin{array}{r}+11 \\ +11 \\ \hline+11\end{array}$

a. 900

$+1+1+1$

$+1$

$+1+1$

$+ \pm$

$\sum^{w}$

800

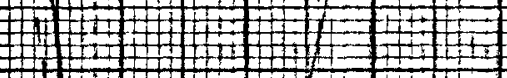

-127

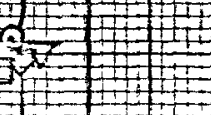

700

$+1$

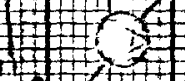

1111

\%

(1)
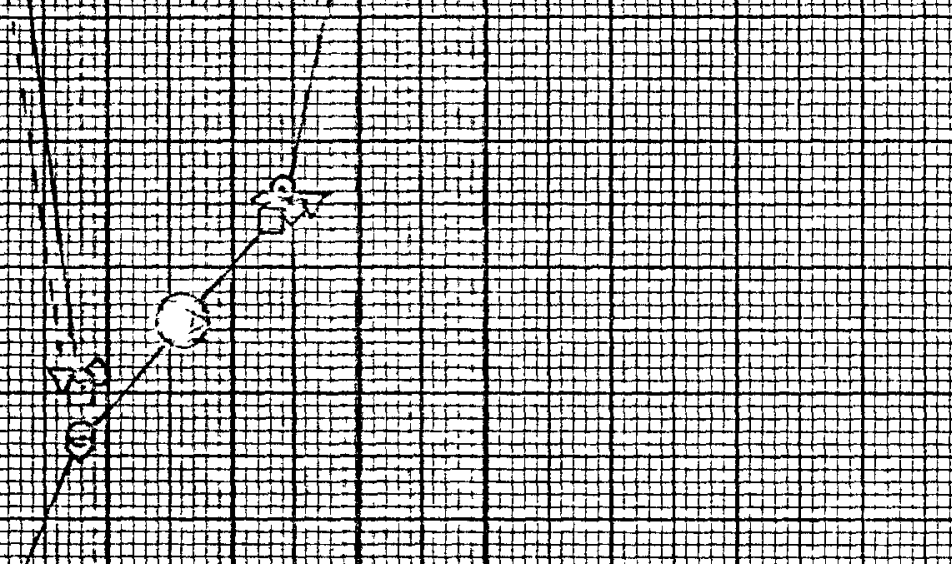

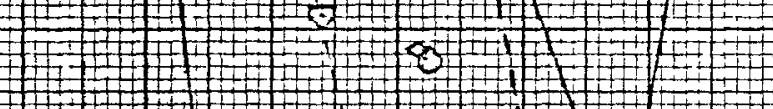
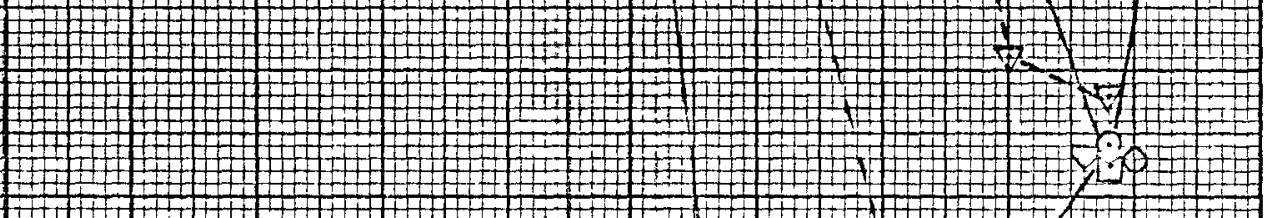

( (I) \#) ( $+$

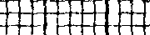
Rawer Time 42620.9 


\section{Accelerometers at Point $D^{\prime}$}

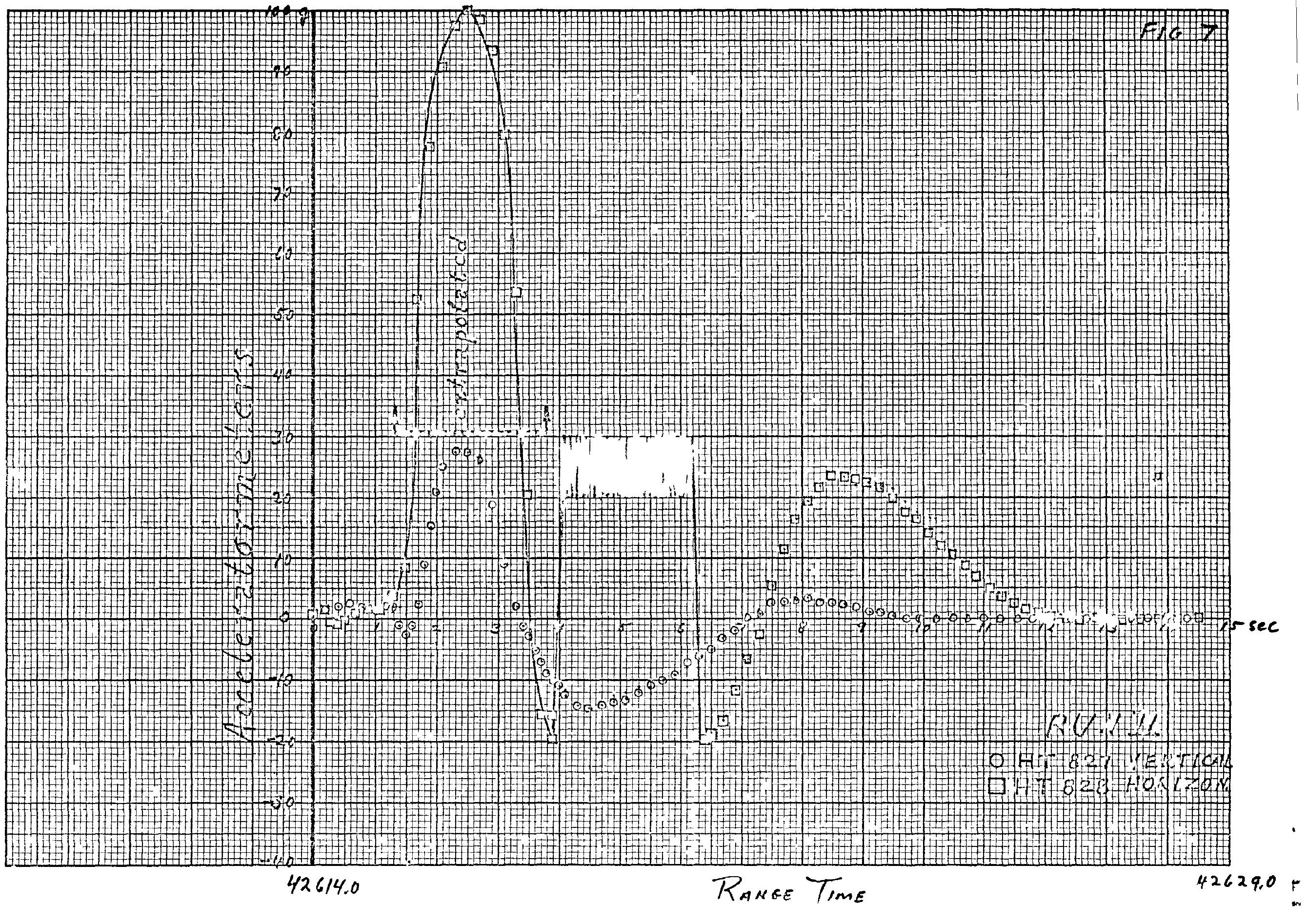




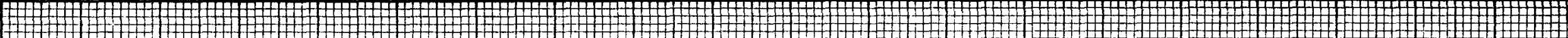

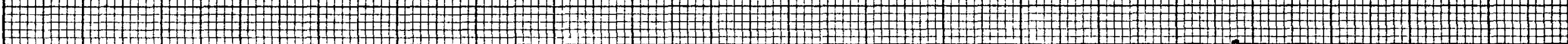

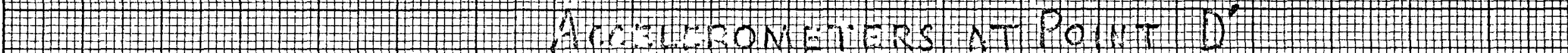

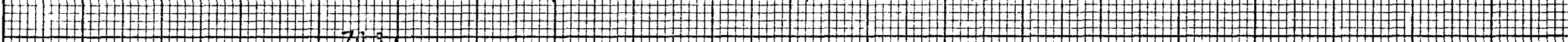

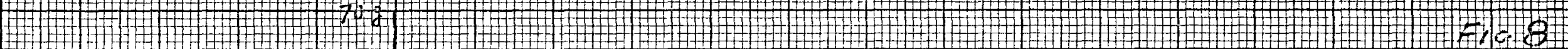

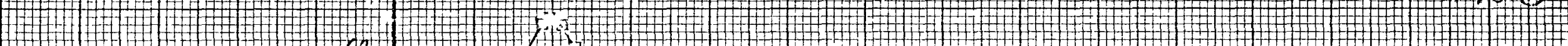

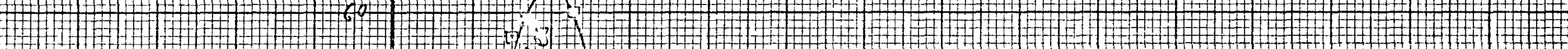

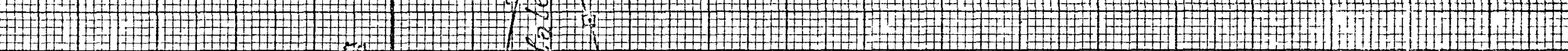

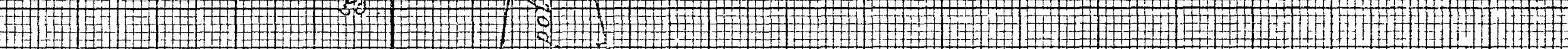

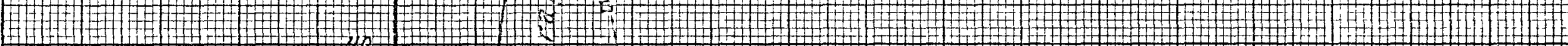

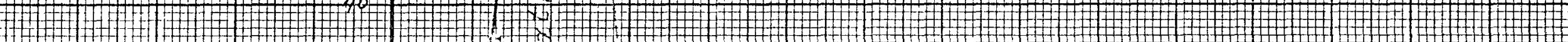

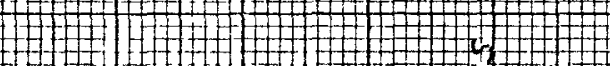

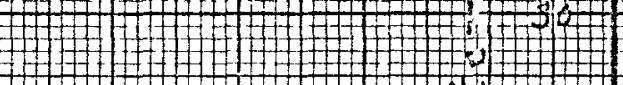

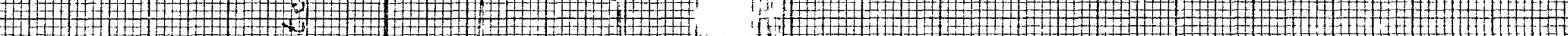

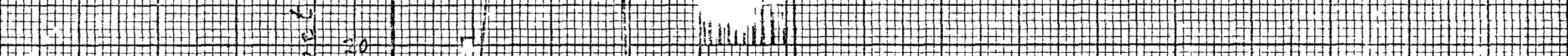

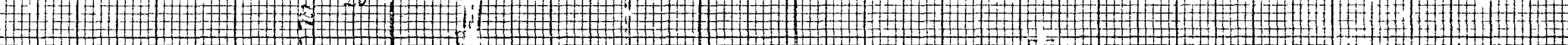

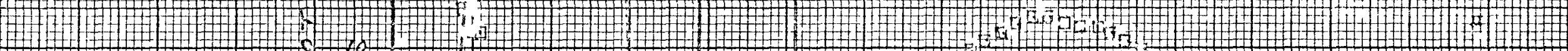

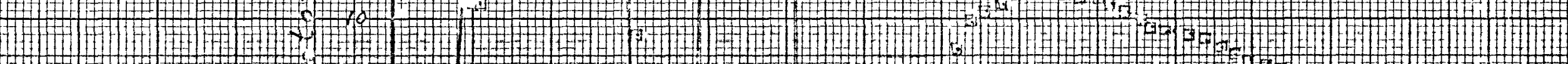

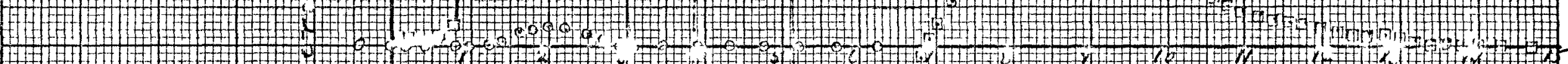

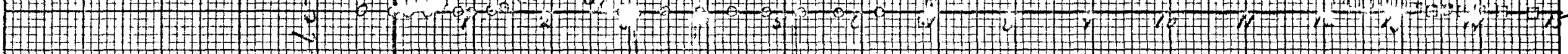

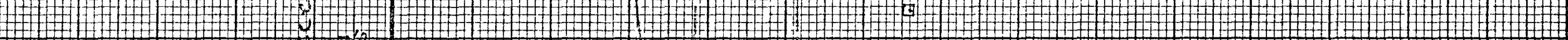

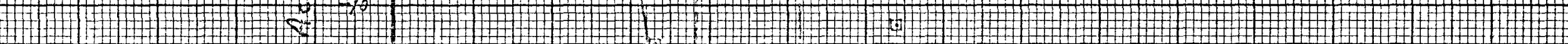

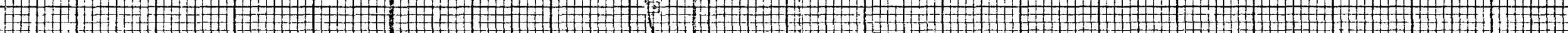

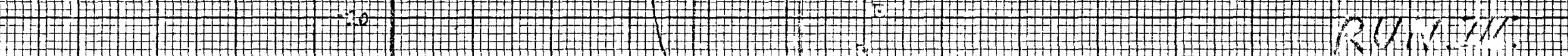

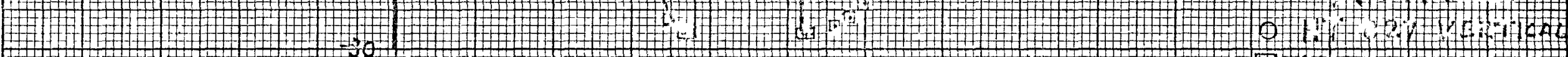

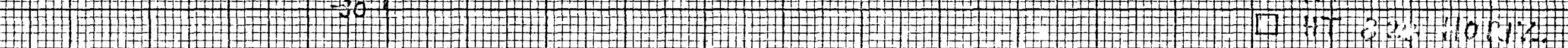

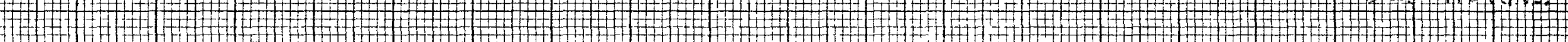

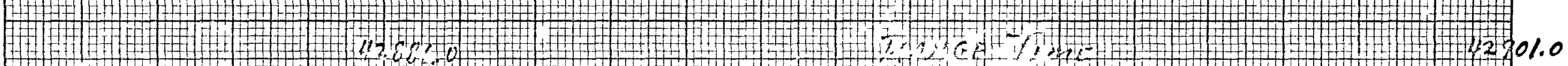

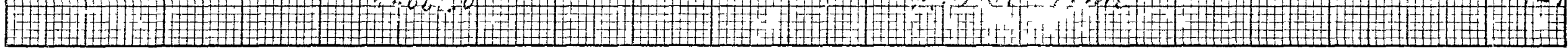




\section{$20^{n}$ ETE: IITE}

REPONT MO. 1

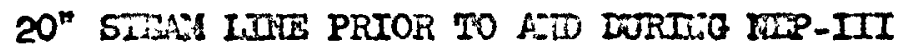

Co 27 Jesuary 1557 en investigation was started to detoraine the cause of the present deforiation and what corrective action was needed to prevant furtber deforistica of the 20 " etcas line between the Stear cmerstor Systea (EGS) and the res onct.

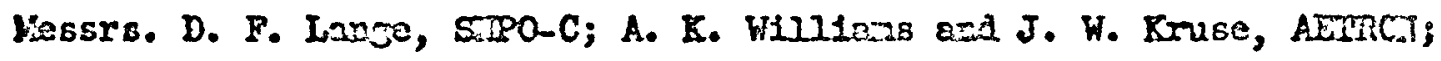

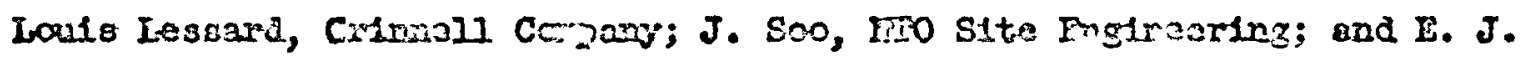
Faller, EIS-1 Test Operaticus were orgealzed by W. D. Hevae, ErS-1 and H. C. Hilstoed, Ema-c to pursue a solutiom.

This Eica lina, Fioure (1), las been nesd epproxinstely elfit (8) timss prior to lop-III and has alkays tad percasent defortation in the vortical

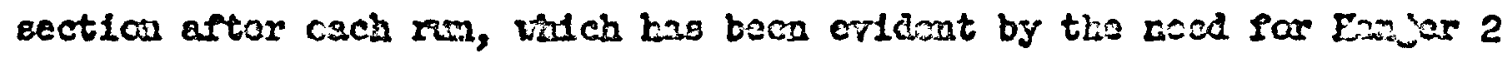

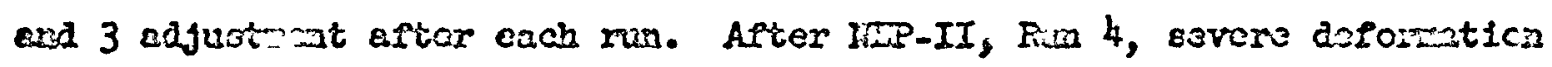
of the vertical section kas perceptible by observatica.

\section{PAST EISTIORX}

Prior to ILP-III, no objective dats hed been gethered, but interviews with the porscinel involved in the operation of this systen, hessrs. J. Christenson and V. Hill, has staplled history of the character1otics of Eanjar 2. During ell the runs in which this hanjer has been menttored on $T$, the low elbow bogins to ralso during the Sas idle cycle and whas the sas is put on tis full ateca operation, tha lower

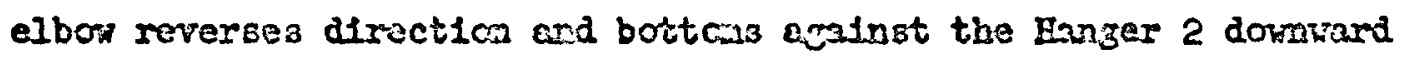
tratrel stc2. 
After HFP-III and the line had cooled, Hanger 2 vas a fraction of an inch of 1to unpar travel limit and Hanger 3 was hard against its lower stops. When the Hanger 3 arms were lengthened about $3 / 4 "$, the line was agaln flosting on 1 ts hangers and all the hangers were in their norwal positions.

II. RECO2ETDATIOI FOR PRECAUTIOTSS FOR TEP-III

Much thought was given to "why" this deforastion should occur whth alnost as many theories as investigations. However, three (3) agreaable conclusions were arawn:

1. Henger 3 would reach 1ts upper limit prematurely placing an excossive laed on point $D$, Flgure (1).

2. IIIe bowing due to a high $\Delta I$ between the bottom and top of the line was a probable cause of Item 1 .

3. Find conditions of the upper horizontal run B, C, D could allow convexed bowing and the concaved deformation in the upper korizontel mun, $\mathrm{CD}$.

In concurrence with the prelininary theoretical investigation, instruintation was installed to gather data to bulld a foundation of objective facts and consisted of:

1. Line skin temperatures at point $C$ and the mid point of D, E.

2. APlxing scribes to gimbal jolnts II and III to detcruine maximum trevel.

3. Scribes on Hangers 2, $3 A$ and $3 B$ to deteruine maxirum travel.

4. Scribe to deterilino relative movenent between Hanger 3 cradle and Iine.

5. Video tepe of TV montors on Hangars 2 and 3.

Based on the conclusion of the prelininary investigation, the followIng precautionary caasures were taken:

1. Liafted the SCS stean temperature to $1000^{\circ} \mathrm{F}$. Th1s will reduce thermal growth about $40 \%$ and doubles the naximim possible netal temperature strosith. 
2. Loosen tha " " bolts on Harjer 3 to pernt unrestreined upvard Growth at point $C$.

3. Installed cable restraints at polat $C$ and $D$ in the event the line did fall.

4. Obtalned good neesurenents of the vertical line deforistion in three (3) plones, Figure (2) and assessed these values to deteraine the safety of an addition run or runs.

III. DAWA OBTAIIED DURIIIG HEP-III

The Hanger 2 and 3 chronology is given in Table $I$ and was deternined by eany repleys of the video tepe. In sumary, three (3) seconds arter the SES was pat on full stean the hangers recelved a severe jolt, $3 A$ ccpleted three (3) cycles to one-half its full upward travel and 33 corpleted three (3) cycles to one-fourth fuld unward travel. At the sario tire, Eanger 2 slessed agalnst its full up travel stop in cne-half second and then slawsed egainst its full down travol stop and reasined there the resainder of the test and thereafter. The first motion of Hanger 3 after the initial jolt occurred 52 seconds after sas full stean though the rum Eanger $3 B$ always lazged Hanger $3 A$ travel by cons-half the $3 \mathrm{~A}$ travel. About a melnute after SCS shutdoin, Eenger $3 \mathrm{~A}$ bezen to raise at a steady rate to about $75 \%$ of this travel and $3 B$ to about $40 \%$. TV monitoring was discontinued at this time.

Ins skin teperatures are l1sted in Table II and depicted for point C in Fleare (3). In Flgure (3) it is illastrated that the terperature on the top of the line alightly lags the botton during the cooldown until the SGS 18 shut off. After shut off, $15 \mathrm{Ibs} / \mathrm{sec}$ of vater contimues to llow through the SaS and stean line which caused a peak top to botton line texperature difference of $200^{\circ} \mathrm{F}$.

The scribe traces $w 11$ be placed in a 20 " steam ine Data File and in sumsary are waxinam gimbal jolnts II and III novezent $1.4^{\circ}$, full travel on Hangers 2 and $3 \mathrm{~A}$, and $7 / 10$ travel on Hanger $3 B$, relative between 1 ine and Hanger 3 credle was epprortuntely $1 / 4^{\prime \prime}$ up and $1 / 4^{\prime \prime}$ in the cpposite 
diraction of expected thermal gronth. Additional data that will be placed on flie are high speed film of line E, F during IFP-II, Funs 3 and 4 and FID-III; Film of point B during Fro-II, Runs 3 and 4 and IIIn of video tepe of Hangers 2 and 3 durlag IEs-III.

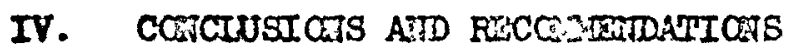

These conclusions and recconendaticns are those of the wrter's and might not egree with those of the other Imvestigators.

1. Polnt D, whan the SGS is placed at full stean, is accelerated unward putting $\mathrm{DE}$ in tension when $\mathrm{E}$ hits its upper travel stop. Polnt $E$ is than accelersted doward and instantly decelerated when it hits its donnward travel stop. The only way point D and $C D$ can be deceleratod is to put to in corpression. The ragnitude and direction of this deceleration force could concelvably be in the order required to deforn this section of line, since its direction is not paraliel to $D E$ or $C D$ and could also produce the concaved deforntion in CD.

2. The cause of this brosering is the coedensing of the residue SGS 1dle steas in the line when tive pressure ratses for 13 psia lde pressure to 58 pala 1 codule full stean operation. At lale the pressure 1a $13 \mathrm{psla}$ at $209^{\circ} \mathrm{F}$ while the saturation teiperature 1s $207 \mathrm{~F}$; in 1.7 seconds the presoure 18 incressed to $58 \mathrm{psia}$ at $225^{\circ} \mathrm{F}$ whlle the saturation teperature $18292^{\circ} \mathrm{F}$, Figure (4B). In eddition to the condensing of the residue idle stem, there is the free water depicted in Figure (4A). This phoncsenon is caused becence we do not have pure steen but a niximre of IOX, Propane and water. The hot LOx, Propene mixtare can hold only 60 wach water just as a mixture of alr and water; this exount 18 that weight of water that causes a $100 \%$ relative mwidity on the mixture. This supercooled steas (hot water) is then swept doun the Ilne causing a severe water herser as it hits each elbow.

The writer reccheads that hydraulic snubbers that linit tho velocity in cae or both directicas be instalied, two (2) at point $B$ wth the 
relocity lintt in 1) $-X$ and 2) ty direction, Flgure (5), cae or two at point $D$ with the velocity indt in $-y$ directicn, two at polnt $B$ with the velocity 11 alt 1 ) $+y$ ard 2$)+z$ directi on. This sycted would permit norcal thercal browth but woild force all the witer hamer energy to be absorbed in line tension strain and the valocity limiters.

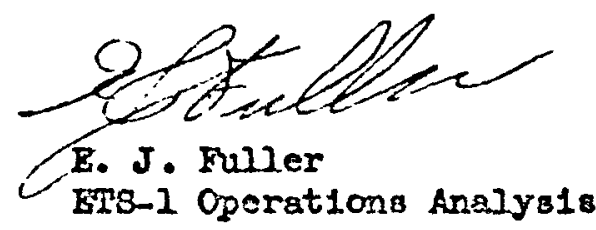

ESF: $\mathrm{J} \mathrm{sb}$ 
- icksicis

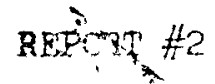 \\ $20^{\circ}$ Steam Lirs ing IEP-IV
}

February 17, 1967

I. SUMAARY

Prior to NEP-IV, the loadine on hanger $f 2$ was increased from 5000 Ibs to 5500 Ibs, and hanger \#1 decreased from 3900 lbs to about 3600 Ibs. Also a grid work was affixed to the top of gimbal II with its movement to be recorded by a 200 frame per second camera. With the exception of proper hanger movement, Table I, all operation and line characteristics were, within limits, the same as in NEP-III. The one module to full steam pressure transient was from 13 to 68.5 psia in 1.9 seconds, with the mixture temperature transient about $40^{\circ}$ below the NEP-III values, compared to a pressure transient of 13 to 68 psia in 2.1 seconis in NEP-III. The first line jolt appeared I second after one module went to full steam compared to 3 seconds ruring NEP-III, this 2 second decrease in response time could be attributed to the .2 shorter pressure ramp and considerably more free water. The line skin temperatures obtain the same maximum values with the same top-to-bottom delta-T after SGS "stop" as in NEP-III.

The general motion of the top of gimbal II is lepicted in Figure 5. With a frame-by-frame examination of the gimbal II gria ilim, an averace " $y$ " direction deceleration at point $D^{\prime}$ of about 10 gs was determined. Inis average " $\mathrm{y}$ " deceleration corresponds to an average $F y$ of $40,0001 \mathrm{~b}$. The resultant deceleration at Doint $D^{\prime}$ is about $37^{\circ}$ from $C D$ to $D E$ with a force of about 50,000 Ibs. It is conceivable then that the instantaneous deceleration resultant force could be in the order of 100,000 Los. which is the order and direction of the force required to yield the line DE at elevated temperature as were the conditions during the NEP-II, Run 4 SGS startup when the large DE deformation occurred.

II. Data Obteinsi puring MPIV

The hanger 2 ani 3 chronology is given in Table I. In summary, one (1) second aiter the SGS was put on full steam, the hangers received a severe jolt that moved hangers $3 A$ and $3 B$ through three ( 3 ) cycles with a maximum travel of $80 \%$, while hanger 2 completed a full travel cycle. During this run, the hangers, for the first time, were observed to function as designed. Hanger 2 reached a maximum travel of $60_{0}^{\circ}$, \#3A $40_{\%}^{\circ}$, and $\$ 3 B$ 30\% during the 2 module full steam portion of the run. Two hundred seconds after SGS "shut off", hanger $\# 3 A$ and $\# 3 B$ obtained a maximum travel of $55 \%$. The general motion of the gimbal II grid is described in Figure 5. 
This motion was latermined by a frame-by-frame examination of the 200-frame per second film of point $D^{\prime}$. By a frame count from point-to-point, a relative time of about $\pm \frac{2}{200}$ second can be determined and is encircled adjacent to the point number. No significant change in the DE deformation can be detected, Figure 2. Skin temperatuee, free water, and mixture temperature and pressure have been superimposed on Report I, Figure 3, 4A and 4B, respectively.

III. Conclusions and Recommendations

As in Report $I$, these conclusions and recomendations are those of the writer and not necessarily those of the other investigators. During NEP-III, the pressure ramp from idle to one (I) module full steam was the same magnitude but .2 seconds faster, the free water $40 \%$ greater, and the first jolt occurred 2 seconds sooner. These facts, plus the fact that heaver hanger \#2 loading resulted in improged hanger performance, point to the conclusions made in Report $I$. Since the pressure ramp was more severe and there was a greater amount of free water, it could be expected that the line folt w uld occur sooner. A quick dynamic analysis of point $D^{\prime}$ esteblished an average " $y$ " deceleration of about 10 gs which represents about a 40,000 Ib average " $y$ " force. The $37^{\circ}$ resultant force is then about 50,000 1bs. It is very possible then to have an instantaneous resultant force in the order of $100,000 \mathrm{Ib}$. If the IIne would have been at an elevated temperature as in start transient of NEP-II, Run 4, a force of this meanitude and direction could cause larger deflections and the observed daformation. A detail dynamic analysis of this problem is complex and sinee the deceleration $\mathrm{g}$ distribution, Figure 6 , is unknown, the construction of an analog dymamic analysis model would have to be based on many assumptions.

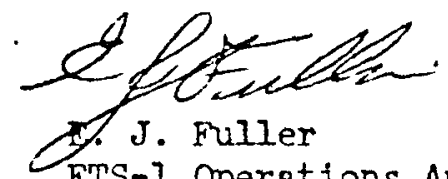

ETS-I Operations Analysis 
TO:

J. H. Ramsthaler

FROM:

J. W. Holaday

SUBJECT: NEPN-1 Duct Coolant water Flow Report

Summary

The duct coolant water was limited to partial flow during the NEPN-I test series. FCV-03I was set at 40\% open and 5860 GPM of flow were obtained compared to a mininum requirement of 4300 GPM for steam generator operation. Water temperature rises of $10-20^{\circ}$ were attained which appeared reasonable.

The modification to increase flow to the bottom 8 tubes of section 3 was successful and $1120 \mathrm{GPM}$ were obtained compared to a minimum requirement of 810 GPM.

As a final check on the Coolant flow system it is recommended the duct be operated at full coolant flow during NEP-5.

\section{Discussion}

I. NES Duct Water Coolant Checkout

A. The object of this part of NEPN-I was to determine if the modification to the water return line of section 3-B (bottom eight tubes of section three) would produce the required coolant water flow rate of $810 \mathrm{GPM}$.

B. The following is a brief history of the checkout of the NES Duct Coolant System:

1. DEP-I-1, the first orifice sizing test conducted on 16 November 1966, was run at full flow with all three flow control valves 100\% open. Flow rates through Sections one and Three were lower than required and the flow rate through section Two was higher than required. Severe vibrations were visually observed and were attributed to cavitation induced by the reduced back-pressure conditions. Analysis showed that with a backpressure of approximately $60 \mathrm{psi}$ on the duct and with flow control orifices removed from sections one and Three, the flow rate in each section would be at or near the design requirements. This increase in backpressure would have the additional advantage of suppressing cavitation resulting in a smoother operation. DEP-I-2, conducted on 7 December 1966, used FCV-32 to establish the required flow of approximately 5576 GPM at FE-56 and FE-57, the flow elements for section Two. Measured flows in Sections one and Three were approximately 6850 and $7700 \mathrm{GPM}$, respectively, as compared to the specified 5878 and 
7563 GPM minimum. Observed duct vibration was significantly less than in the previous test.

2. Prior to DDT Phase I, a Potter Flow Meter was installed in the 3 " water return line of Section Three for accurate measurement of the coolant flow through the bottom eight tubes of Section Three.

3. The Phase I Tests were conducted during the period of 19 January through 7 February 1967. It was determined during these tests that the flow through Section three duct exit eight tube cooling system was inadequate with flow rates of approximately 650 GPM being recorded and a minimum of $810 \mathrm{GPM}$ required. Larger orifice plates were reinstalled in section One bringing the flow rate to 6,200 GPM (required $5878 \mathrm{~min}$ ).

4. Prior to Phase II test, the 3 " water return line of Section 3-B was removed from the main water return line. A separate 4 " line was installed that discharged the water to atmosphere through two parallel 4" valves (RSV-858 and PSV-859). A 4" potter flow meter was installed upstream of the discharge valves for accurate measurement of the flow.

\section{NEPN-I - 13 June 1967}

1. The coolant water flow rate throuth the NES duct was established by opening the number two water inlet valve RSV-297 full open and by opening the number two water return line valve FCV-031 to a $40 \%$ open position.

The min. required flow rate for SGS operation is 4300 GPM. The flow rate, as measured at flow tube FT-031, was 5560 GPM. The flow rates through each section of the duct were as follows:

$\begin{array}{ll}\text { Section One } & 1970 \mathrm{GPM} \\ \text { Section Two } & 1540 \mathrm{GPM} \\ \text { Section Three } & 2350 \mathrm{GPM} \\ \text { Total } & 5860 \mathrm{GPM}\end{array}$

This total does not agree with the total through FT-03I possibly because FT-054 through FT-059 are operating well below their design conditions and FT-03I was operating well within its design condition.

2. Prior to bringing the SGS to full steam, the discharge valves (RSV858 and RSV-859) for section 3-B were temporarily opened and a flow rate of approximately $1120 \mathrm{GPM}$ (810 GPM min. required) was obtained through potter flow meter FTO 87. The valves were then closed. Although the duct was not at full flow conditions and the head pressure was maximum, a calculation of the KW factor for the 4 " system (Enclosure 1) indicates that it will be possible to obtain greater than required flow when the duct is at full flow conditions and the head pressure is at a minimum. 
During SGS operation the increase in coolant water temperature during the low flow conditions previously mentioned, was between $10^{\circ} \mathrm{R}$ and $20^{\circ} \mathrm{K}$. The increase in coolant water temperature in Section $3-B$, with no coolant water flow, was less than $10^{\circ} \mathrm{R}$. The total coolant water flow rate was less than $1 / 6$ of normal and the temperature was approximately $1 / 5$ of normal.

D. The following test is recommended for $N E P-V$ to determine if there is possibly a vibration problem in Section 3-B discharge line and to verify the water coolant flow through section 3-B when the duct is at full flow conditions:

1. Establish full flow condition through Section 3-B and observe the 4" discharge line for vibrations.

2. Close one of the 4" discharge valves in Section 3-B, observe 4" line for vibrations, and record steady-state data.

3. Establish full flow conditions through the duct as well as Section 3-B and record steady-state data.

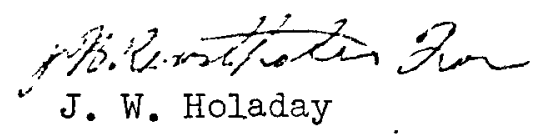

$J W H: c j b$ 


\begin{tabular}{lllll} 
& Section 3-B $\Delta \mathrm{P}$ & $\Delta \mathrm{P}$ & $\mathrm{WH}_{2} \mathrm{O}$ & $\mathrm{K}_{\mathrm{W}}(\mathrm{GPM})$ \\
\hline 1. & $231.8 \mathrm{psid}$ & 15.25 & $1155 \mathrm{GPM}$ & 75.8 \\
2. & $226.8 \mathrm{psid}$ & 15.10 & $1145 \mathrm{GPM}$ & 75.8 \\
3. & $220.2 \mathrm{psid}$ & 14.85 & $1120 \mathrm{GPM}$ & 75.3 \\
4. $219.3 \mathrm{psid}$ & 14.80 & $1110 \mathrm{GPM}$ & 75.1 \\
5. $221.8 \mathrm{psid}$ & 14.91 & $1125 \mathrm{GPM}$ & 75.4
\end{tabular}

The only variable effecting the flow through section 3-B is the inlet manifold pressure in Section 3. The normal operating inlet pressure is 190 psig. Due to section 3-B discharging into the atmosphere, the $\Delta \mathrm{P}$ will be $190 \mathrm{psid}$.

$$
\begin{aligned}
& \Delta \mathrm{P}=13.80 \\
& \mathrm{~K}_{\mathrm{W}}=75.5 \\
& \mathrm{WH}_{2} \mathrm{O}=1040 \mathrm{GPM} \quad \text { Minimum requirement } 810 \mathrm{GPM}
\end{aligned}
$$



TO:
J. Ramsthaler, Chaiman, Spear Tuan
DATE: 21 June 1967
FROM:
H. W. Brandt
SUBJECT:
$\mathrm{GN}_{2}$ Supply System Steady-State Performance Characteristics

DISTRIBUTION:

An evaluation of the NEPN-1 data related to the primary GN ${ }_{2}$ NES Supply System has been made and the results are presented herein.

The significant findings related to this evaluation ar:l the line resistance between the three GiJ storage Vessels dischar ce lines and PCV449 inlet were higher then the theoretical predicted values and 2) the PCV-449 flow coefficientrave position relationship more nearly approaches the characteristics for a valve with flow under the plus; however, it appears that flow is over the plug.

Tables 1 and 2 list the pertinent NES Supply System data related to Test Nos. 4 and 5, respectively. It should be noted that at "no flow" conditions the GN, header pressure transducer indicates 13 psig higher than the average $V-3201,02$ and 03 discharge line pressures prior to Test 4 and 18 psig after the test. Also a 17 psi difierence was noted prior to and after Test No. 5.

Figure $I$ is a plot of PC/FV versus PCV-449 position. The curve is based on both IEP-1II-I and NEP-i-I data as noted on the graph. The data from both tests appears reasonably consistent. Pc is the chamber pressure PT-905 or PT-906 and PV is the PCV-44.9 inlet pressure PT-904.

For sonic flow at the valve and a constant inlet gas temperature, the relationship $:=\mathrm{K}_{I} \mathrm{C}_{V} \mathrm{PV}_{\mathrm{V}}$ is applicable. Since flow through the simulated primary nozzle is proportional to the chamber pressure at constant tenperature, the equation $\mathrm{Pc} / \mathrm{Pv}=\mathrm{K}_{2} \mathrm{CV}_{\mathrm{V}}$. The general shape of the curve reflects the percentage characteristics of the valve trim. For sonic ilow at the valve; ie, $\mathrm{Pc} / \mathrm{Pv} \cong 0.5$, and a reference valve inlet gas temperature of $5000 \mathrm{R}$, the equation $\mathrm{CV}=2410 \mathrm{Pc} / \mathrm{Pv}$ can be used to calculate $\mathrm{Cv}$. The equation for subsonic flow is $\mathrm{CV}=1210$ (Pv-PC). It should be noted that the calculated $\mathrm{CV}$ will include line losses between the valve and the upstrean and domstream pressure taps.

Figures 2 and 3 are vendor suoplied curves reflecting CV versus PCV- 449 position characteristics for flow over and under the plug, respectively. Also plotted on the curves are the $\mathrm{CV}$ data based on Figure 1 and the aforenentioned sonic and subsoi.ic relationships. It should be noted that the data arrees more closely with the "flow under plug" curve, however 
inspection of the vaive installation and corralatim with vendor valve drawings evidences that $.10 \mathrm{~W}$ is over the plug. Future evaluntion of the valve characteristic data is recormended to accurately define the $\mathrm{CV}$ versus valve position relationship and determine the cause of disacreement, if any, betwesn the vendor curves and test data.

Figure 4 is a plot of the $\sqrt{P^{7}-P_{r}^{2}}$ versus $P c$ where $I b$ is the average $\mathrm{GN}_{2}$ vessel discharge line pressure, $\mathrm{P}$ is the $\mathrm{PCV}-449$ inlet pressure and $\mathrm{Pc}$ is the charber pressure. It should be noted that the bank pressure was corrected for the previous"y discussed "no-flon" differences. The significance of the curve is trat the slope of the "best fit" line is proportional to $\sqrt{K T} / A$ where $K$ is the total system resistance coefficient between the various Discharge lines and PCV-449 inlet. $T_{1}$ is the average ups-ream gas temperature, and $A$ is the equivalent pipe area in FT. The clcse grouping of data points at a chamber pressure of 124 psia feflect reasonably consistent steady-state data.

Omitting the tem $2 \log _{\mathrm{p}} \mathrm{PD} / \mathrm{Pv}$, which is negijgible, from the isothermal equation (1) reduces the equation to $W=c_{1} V V_{b}^{2}-P_{V}^{2}$ for a particular oipe diameter and gas temperature. Since $W=1.53 \mathrm{PC}$ at $5000 \mathrm{R}$, then $\left(\mathrm{Pb} 2-\mathrm{Pl}_{\mathrm{l}}\right)^{\frac{1}{2}} / \mathrm{PC}=$ $1.53 / C_{1}=$ slope of best fit line or $C_{1}=0.255$. Solving the modified isothermal equation for the impedance coefficient, $K$, yields $K=22.1$ based on $a$ 6.813 inch diameter pipe and $\mathrm{T}=500^{\circ} \mathrm{R}$. It should be noted that this valv? is lower than the comparable $\mathrm{K}$ valve of 28 used for pre-test predictions. This difference ray be attributed to the conservative $I / D$ valves $I$ isted in the reference (1).

Figure $E$ is a plot of the PCV-449 inlet pressure versus chamber pressure for rniols $\mathrm{GN}_{2}$ bank pressures. The valve inlet pressure $\mathrm{Pv}$ was plotted as a function of chamber pressure Pc for various valve positions based on the Figure I curve.

The equation $\mathrm{Pv}=\sqrt{\mathrm{P}^{2}}-\left(\frac{\mathrm{P}^{\prime}}{\mathrm{j}}\right)$, tas solved for bank pressures of 2500 , 2250, $2000,1750,1500$ and $1250^{\circ} \mathrm{osig}$ and the results are olotted in figure 5 . It whould be noted that the maximum attainable chamber pressure with a. bank pressure of 2500 psig and PCV-449 full open is 410 psia, whici is hicher than pre-test preaicted valves.

Figure $\sigma$ is a plot of the minimum required GN 2 Bank Pressure versus chamber pressure based on data presented in Figure 5. It is to be noted that a minimum $\mathrm{CN}_{2}$ three vessel bank pressure of $1260 / \mathrm{psig}$ is required for a charaber pressure of 210 psia.

To surmarize, it appears that the NEPN-I and NEP-111-1 GN 2 Supply System steady-state data are consistent and yield useful data related to the $\mathrm{GN}_{2}$ Supply System performance characteristics.

Future analysis related to the $\mathrm{CV}$ versus PCV-449 valve position characteristics is recommended. No serious anomolies related to steady-state system operation were evidenced.

(1) reference: Crane Technical paper No. 410 for definition of terms and assumptions related to the equations.

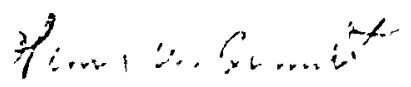




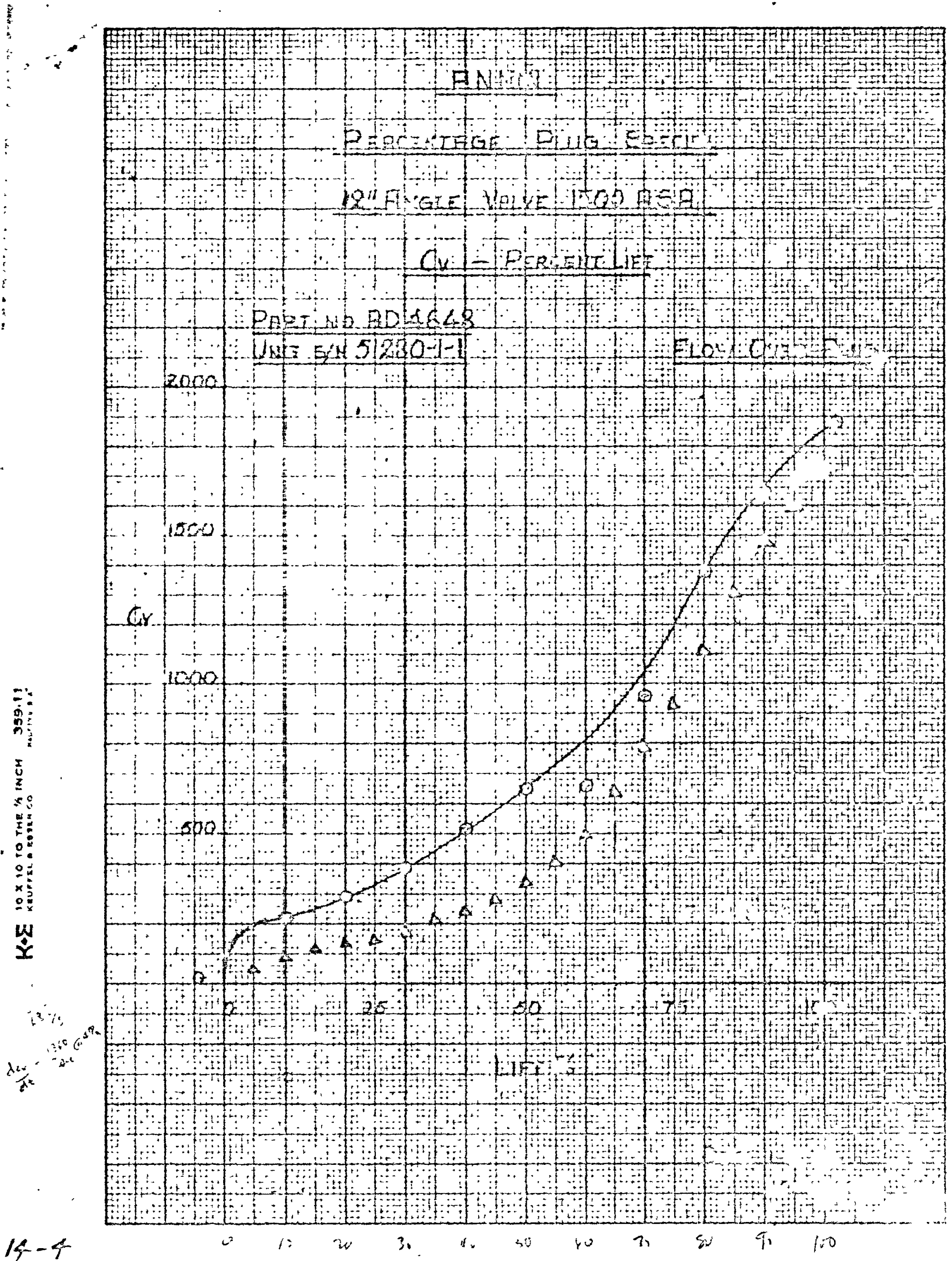




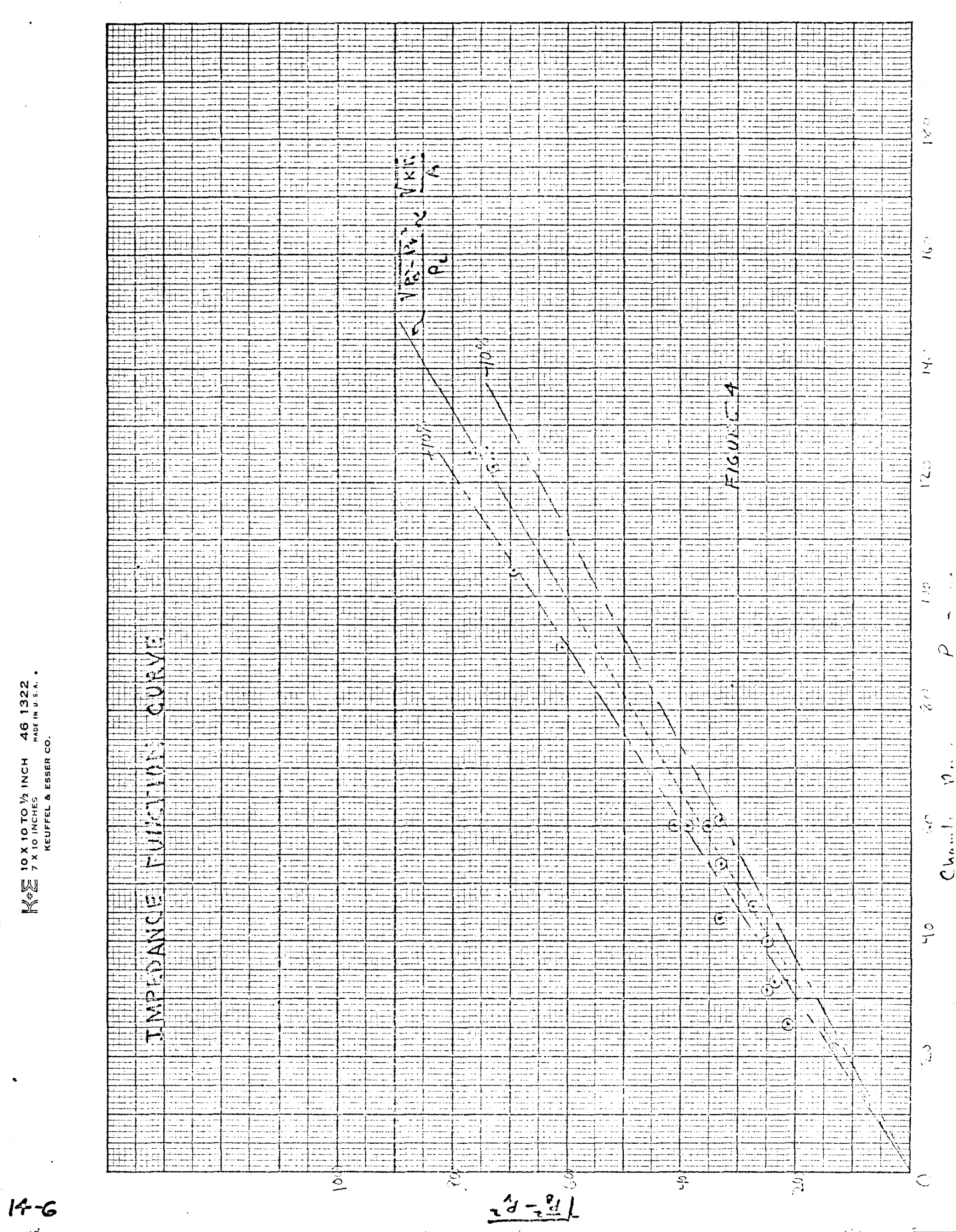




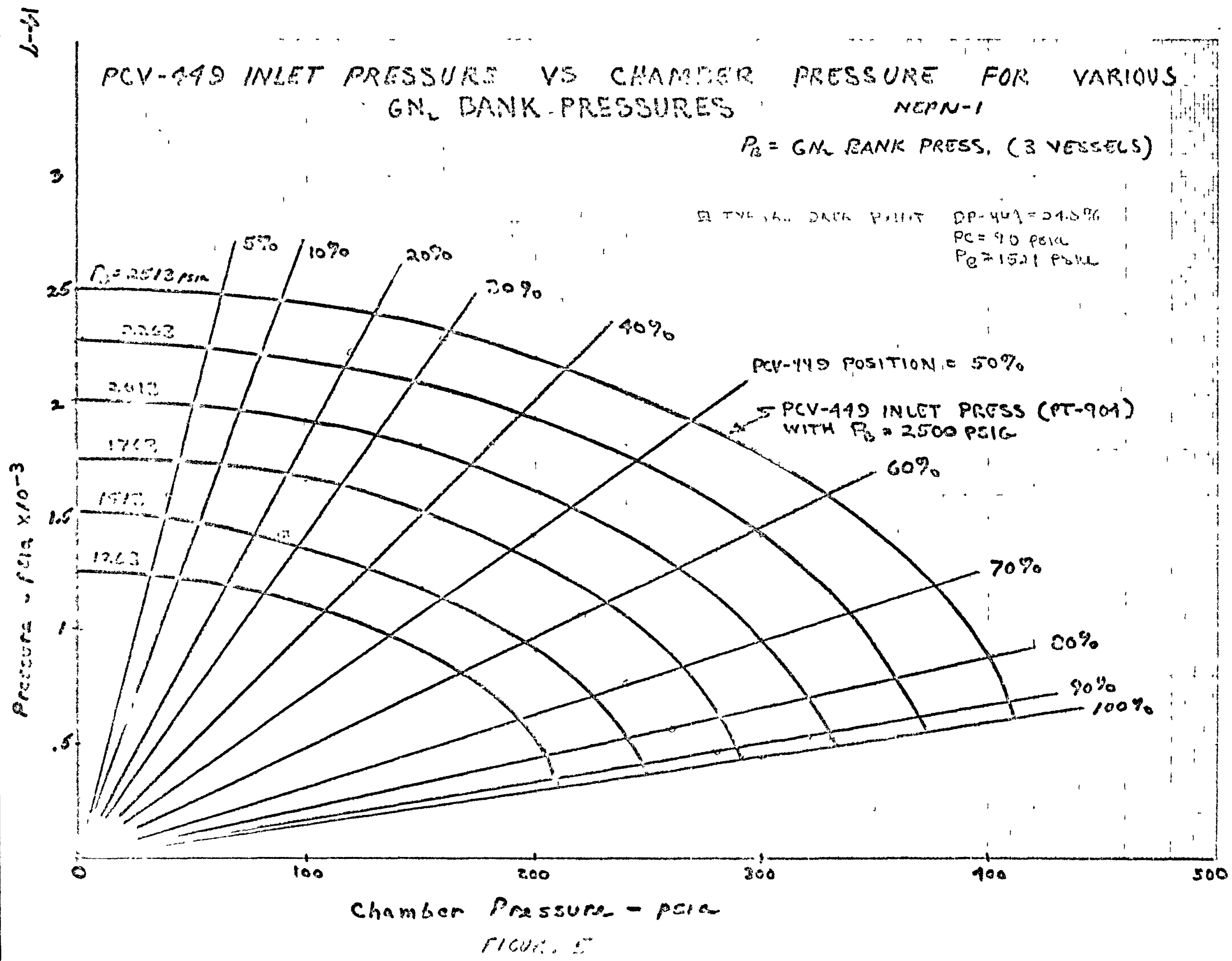




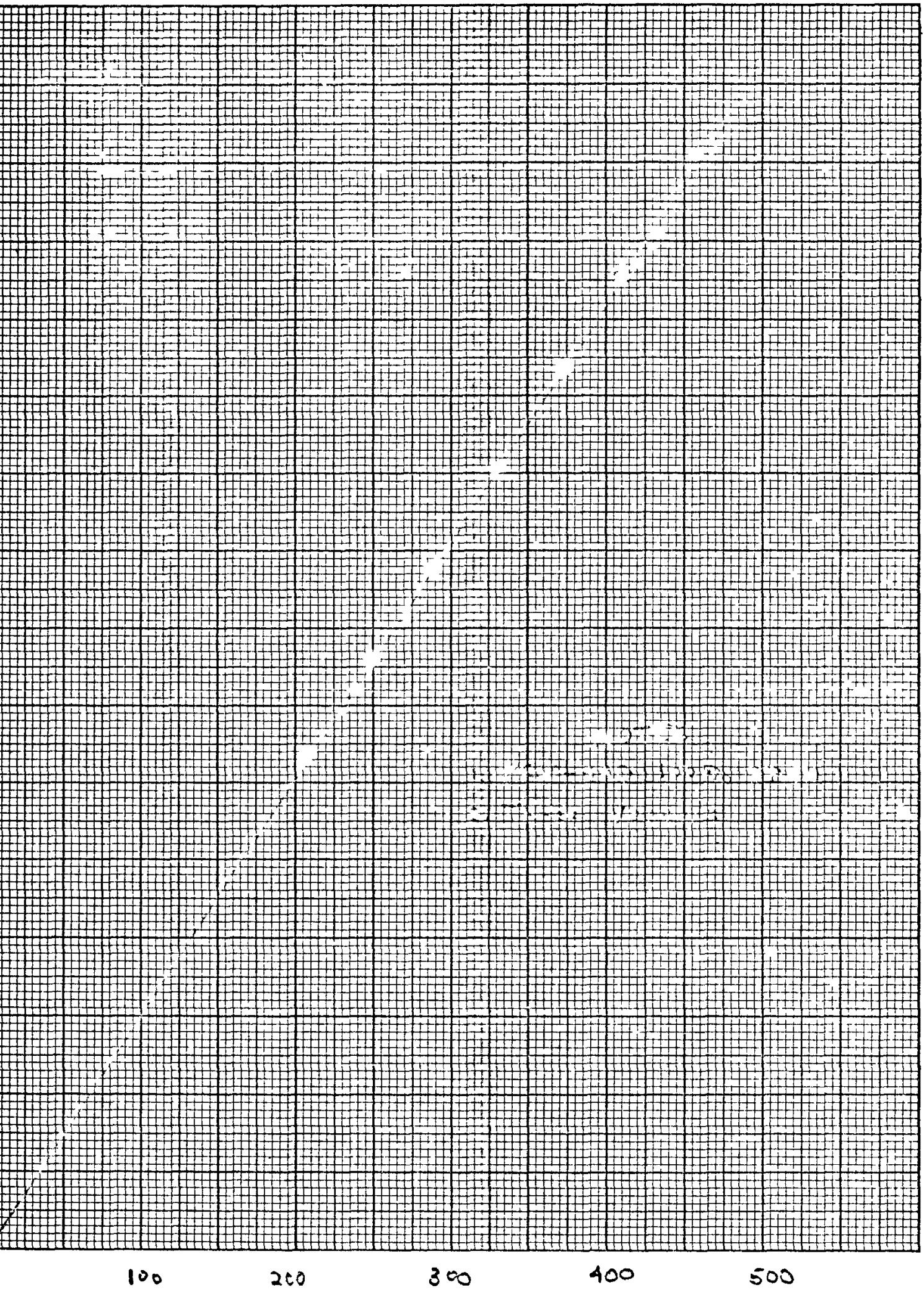

Chamber Pressure - psia

MINIMUM GN BRMK PRESBYGE US CHAMBEP PRESS $N E P B-1$ 


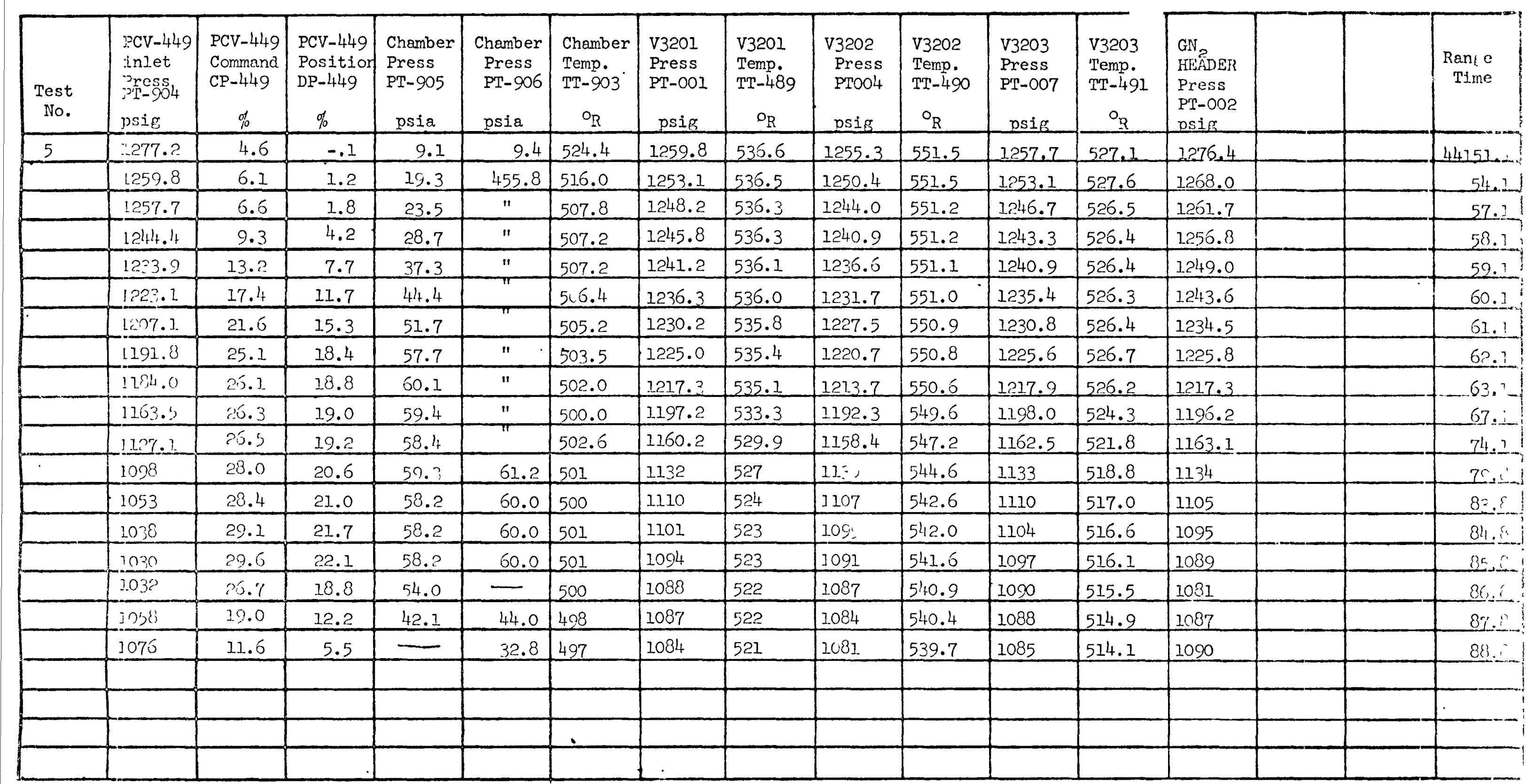




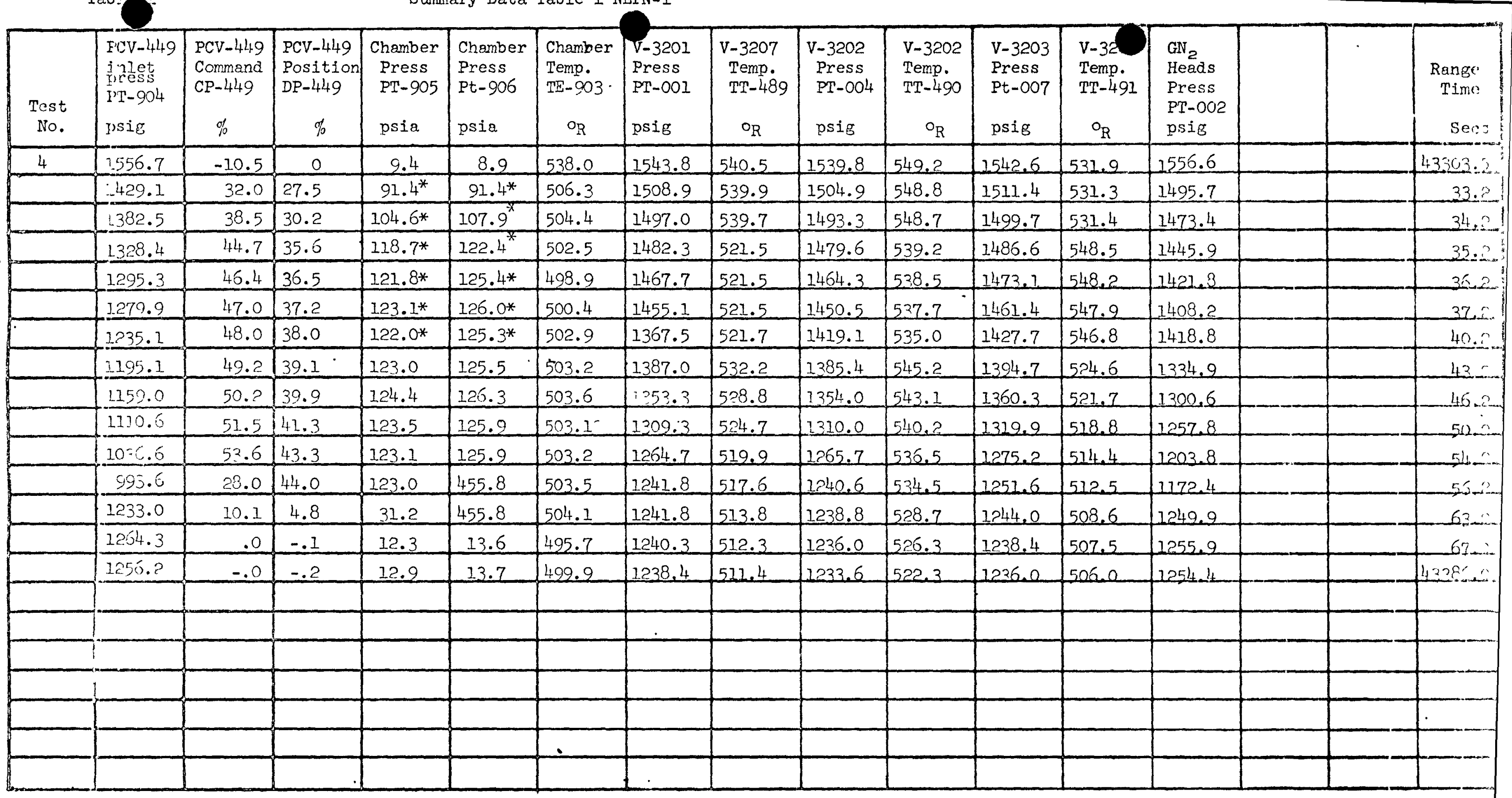




\author{
SPEAR MEMOTA:DUM No. 15
}

$\begin{array}{lll}\text { ro: } & \text { J. H. Raristhaier } & \text { DATE: June 22, 1067 } \\ \text { From: } & \text { D. J. NeCros'ey } & \text { DJI/JL/bso }\end{array}$

SUbJECT: Results of E.T.C. Post Fire Inspection of IVP IT-I

DISTRIBUTION:

Attachrent No. 1

Inspection of the Test Stand before and after INP $N-I$ ras accomplished jointly by Facilities Operation and Product Assurance parsonnel. The results are as follors:

1. A visual inspetion of the E.T.C. exterior vas performed by both ETS-1 Facilities Opcrations and ETS-l Product Assurance. Inspection was made on all attached harärare, latches, and pluring. ITo apparent damage vas noted to the exterior of the s.I.C. and attached hardrare.

2. O.D. measurements of the E.T.C. vere felt to be impractical by EIS-I Facilities Opcrations and Froduct Assurance. To measurements had been taren prior to IISP NII, so ve had nothing to base our measurements on. The outer diameter had been inspected thorouchly and no apparent bulging or damase vas noted.

3. Cable tension measurements vere taken with a tensiometer before and - atter ITP II-1. During the latter part of the process of applying the tension to the belly bands the tensiometer vas thou cht to have been possibly out of calibration. Investigation revealed one of the tension indicator "pus'l slide bolts" was bont slightly and was accounting for an apparent crroneous reading. A new "push slide bolt" was fabricated ani installed in the tension indicator and the tension operations completed. The pre-run and post-run tension data is indicated on Attachment No. 1 . To verify that tre tension indicator is vithin calibration the item is being returned to the manufacturer for repair and re-calibration, with a request for data points.

4. An inspection of the eutectic seal areas were made prior to openins the side shields. The seal biades depth on both the top and bottor seal had not changed. Then the side shields were opened the copper convolute seal ras inspccted for darase by ETS-I Eacility Operations and Product Assurance. The convolute seal showed no signs of bulging, varping or bent out of their no:mal position. 
J. H. Ramsthaler - $2-\quad$ NTO-M-13973

5. The inside of the E.T.C. Vas inspectec for loose and/or damaged hararare. The coly thing noted ra: some small pieces of slag laying on top of the botton shield. These pieces of slas ( 4 pieces) had apparently vibrated loose from the welacd areas on the ITS test device and fell on the top of the bottom shield. Iro apparert darnage had been caused by the falling slas.

6. The aligrlent of the tro side suields vas checked before the removal of the cables and after cable removal. Ho chance ras noted uncer either condition.

7. Visual inspection of the stean generator, stean line, and exhaust duct revealed the following:

a. The stear fenerator and steam generator erclosure ras thoroughly inspected by Facilities Operations and Product Assurance vith no apparent damage noted.

b. The stear line ras inspected starting at the baci: of the steam generator enclosure, runing throuch the pipe chase and encing at the exhaust dict. Fhe stean Iine 'onac'tet that is boltec' to the stean fenerator anclosure rall tas found to have a crached weld were the brachet reics to the steam lire. Gusset reicis betreen the stean sencrator exit rall plate and the P. Irst free in the stecu lins crackeu, provayjy due to trerial strass.

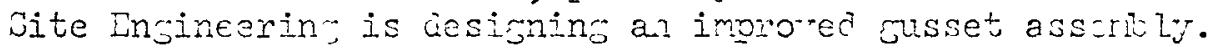
The steam line itself dia not rcturn to its pre-run position. Indications are thai the pipe chase elbow mored ubout I inch and out towari the d:-c'? about $1 / 2$ inch. ITO Jite Engineering is analyzine teroerature, accoleareter anu rution piciure

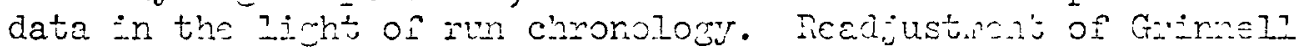
spring hangers rill be held off until sidc Inginsering has completed analysis of late and recomended proper positions.

c. The cxidust cuct ras inspected bor both Facilities orerations and Proinct Ascurance. Checired ruts, bolis, safotir ririns, and for carazed or loosa harivare. Intry vas also mece into the exhaust duct by both organizations, inspecting for any sigrs of forei-g obiects pass ing throurh the cuct as rell as loo'ing for additional dinced arsas and cracica relds.

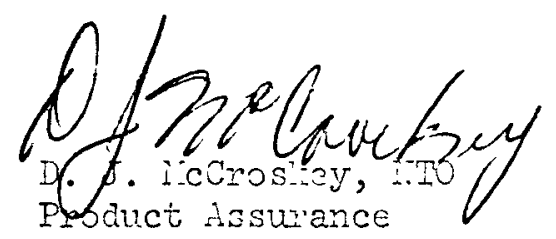

$15-2$ 


\begin{tabular}{|c|c|c|c|}
\hline \multirow[t]{2}{*}{ CABts \# } & \multicolumn{3}{|c|}{$\begin{array}{l}\text { PRE-PUIX } \\
6-9 / 10-67\end{array}$} \\
\hline & TERBSION & $\begin{array}{l}\text { IMBOARD } \\
\text { GAP }\end{array}$ & $\begin{array}{l}\text { OUTBOARI } \\
\text { GAP }\end{array}$ \\
\hline 敞 & 6800 & 0 & 0 \\
\hline 2 & 6800 & 0 & 0 \\
\hline 3 & 7000 & 0 & 0 \\
\hline 4 & $\begin{array}{l}7300 \\
(6175)\end{array}$ & 0 & 0 \\
\hline 5 & 7300 & 0 & 0 \\
\hline 6 & 7300 & 0 & 0 \\
\hline 7 & 7300 & 0 & 0 \\
\hline 8 & 7300 & 0 & 0 \\
\hline 9 & 7300 & .002 & 0 \\
\hline 10 & 7300 & .010 & 0 \\
\hline 11 & 7000 & 0 & .024 \\
\hline 12 & 6450 & 0 & .023 \\
\hline
\end{tabular}

\begin{tabular}{|c|c|c|}
\hline \multicolumn{3}{|c|}{$\begin{array}{r}\text { POET-RUN } \\
6-14-67\end{array}$} \\
\hline THASION & $\begin{array}{l}\text { INBOARD } \\
\text { GAP }\end{array}$ & $\begin{array}{c}\text { OUTBOARD } \\
\text { GAP }\end{array}$ \\
\hline 6200 & 0 & 0 \\
\hline 7050 & 0 & 0 \\
\hline 7500 & 0 & 0 \\
\hline 7400 & .002 & 0 \\
\hline 7200 & 0 & 0 \\
\hline 7500 & 0 & 0 \\
\hline 7400 & 0 & 0 \\
\hline 7300 & 0 & .005 \\
\hline 7300 & 0 & .012 \\
\hline 7200 & 0 & .005 \\
\hline 6200 & 0 & .002 \\
\hline 6200 & 0 & .002 \\
\hline
\end{tabular}

* Botton Cable 
TO: J. H. Ramsthaler

FROM: $\quad$ H. W. Brandt

SUBJECT: $\quad$ Summary Test Description and Chronology of NEPN-1

REFERENCES: (1) NTO-0223, Revision A, Support Operational Requirements Document for NES Design Demonstration Test, Phase II

NEPN-I was successfully conducted on 13 June 1967 and the test objectives as outlined in Reference ( 1 ) were satisfactorily met. The data has been evaluated and significant findings and conclusions, which are discussed in detail in other sections of this report, have been made.

The initial test operations were essentially started at 1000 hours and completed at 1300 hours. The test operations went very smoothly as a result of the highly efficient operations personnel performance and the high state of total system readiness.

A detailed chronology, which lists the approximate occurance times, is included as an attachment to this memo. The significant operations related to each test phase are briefly discussed below; however, a more detailed understanding will be attained by referral to the detailed memos related to specific evaluation efforts.

\section{Pre-Test Functions}

Certain test operations were performed to assure system readiness. These operations were: 1 ) the various seal blade purges were initiated and completed; 2) the LOX and Propane tanks were pressurized to 310 and 290 psig, respectively; 3) the ETC was inerted to $3.5 \%$ using a nominal purge flow of 15 pps; 4) PCV-449 operational status was verified; 5) the cooling water systems were activated; 6) the three steam generator modules $\mathrm{SG}-1, \mathrm{SG}-2$ and $\mathrm{SG}-3$ were brought to idle steam conditions and finally 7) the ETC purge flow rate was reduced to 1.5 pps.

Test No. 1

The primary purpose of this test was to determine the ETC repressurization rate when the Steam Generators were shut down individually with no primary nozzle flow. Using a standard start-up procedure SG-I achieved full steam conditions followed by SG-2. After steady-state operating conditions were achieved, $S G-1$ was returned to idle steam and $1 I$ seconds later $S G-2$ was returned to idle steam. A nominal 1.5 pps purge was maintained during the test. No significant anomalies were evidenced from the test plan. 
Test No. 2

The primary purposes of this test were to: determine the effects on ETC repressurization when two steam generators were shut off simultaneously and to evaluate ETC seal leakage under two module operation. SG-2 was brought up to full steam status approximately 16 seconds after $S G-1$ had achieved full steam conditions. The seal blade purges were turned off for approximately 2 minutes and then turned on. Subsequently both SG-1 and SG-2 were simultaneously shut down to idle. A 1.5 pps purge was maintained during this test. No significant anomalies were noted relative to the test plan.

Test No. 3

This test was performed to determine the effects on ETC repressurizations when two steam generators are shut down simultaneously with a 30 pps purge flow being maintained. The test was performed as described in Test No. 2 except the seal blade purges were not turned off and the purge flow was 30 pps.

Test No. 4

The primary objective of this test was to determine the effect of terminating primary flow, after the steam generators have been brought to idle, on the ETC repressurization characteristics. $S G-1$ and $S G-2$ were brought to full steam conditions. The top and bottom seal purges were turned off and PCV-449 was ranged up in the Auto Control mode to $125 \mathrm{psia}$. The top and bottom seal blade purges were subsequently turned on and $S G-1$ and $S G-2$ were simultaneously shut down. The ETC purge was being increased to $30 \mathrm{pps}$, when PT-906A (which was one of the PCV-449 control loop pressure transducers) failed and PCV-449 was commanded closed. The valve achieved a maximum slew rate of $-150 \% / \mathrm{sec}$ and the $\mathrm{P}_{c}$ decay rate during valve closure was $-252 \mathrm{psi} / \mathrm{s} \in \mathrm{cmax}$.PCV-449 subsequently opened briefly as a result of PT-905 feedback control; however, PCV-449 was switched to the manual control mode and assumed the pre-planned 5\% open position. PCV-449 was closed manually and the ETC purge flow was terminated. The basic test objectives were met despite the malfunction of PCV-449.

Test No. 5

The primary objectives of this test were to evaluate the ETC repressurization rate after a termination of primary flow from a chamber pressure of 50 psia with a 30 pps purge flow being maintained. Steam generators $S G-I$ and $S G-3$ were brought to full steam conditions and an ETC purge flow of 1.5 pps was established. Smoke pots were utilized to determine wind effects. The primary chamber pressure was manually ramped up to $50 \mathrm{psig}$ and $\mathrm{SG}-1$ and $\mathrm{SG}-3$ were returned to idle steam conditions after a steady-state primary $\mathrm{GN}_{2}$ flow was achieved. The ETC inerting flow was increased to 30 pps and PCV-449 was manually ramped closed. The inerting flows were terminated, the three steam generators were stopped and the facility was secured. The test objectives were successfully accomplished.

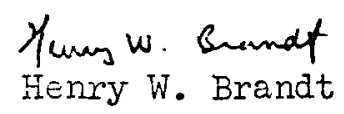

$H W B: c j b$ 
NEPN-I CHROLYLOGY

Start pressurizing $\mathrm{GN}_{2}$ supply line by opening RSV-273.

$\mathrm{GN}_{2}$ supply line pressurization complete.

start to pressurize ETC convolute seal.

Convolute seal pressurization complete.

Start to pressurize $\mathrm{IO}_{2}$ tank to 80 psig

$\mathrm{LO}_{2}$ tank pressurized to 69 psig

Vent propane tank by opening RSV-331.

Close RSV-331.

S-2 seal blade purge initiated.

Bottom seal blade purge initiated.

Top seal blade purge initiated.

S-2 seal blade purge complete.

Bottom seal blade purge complete.

Top seal blade purge complete.

Start to increase $\mathrm{IO}_{2}$ pressure to $320 \mathrm{psig}$.

Start to increase propane tank pressure to 295 psig.

$\mathrm{LO}_{2}$ tank pressure of $310 \mathrm{psig}$ achieved.

Propane tank pressure of 290 psig achieved.

Start to open PCV-621 to achieve $15 \mathrm{lb} / \mathrm{sec}$.

Achieved $151 \mathrm{~b} / \mathrm{sec}$.

Switch K-002 from sample tuoe C to sample tube $D$.
36995

37587

37628

37779

38141.0

38474

38515

39337

39344

39350

39350

39357

39351

40660.2

40976.2

41824.2

41986.2

41076

41079

41093 
NEPN-1 CHRONOLOGY (Cont'd)

RANGE TIME

$\mathrm{KT}-705$ reached $3 \frac{1}{2} \%$.

Switch KT-002 from $25 \%$ to $5 \%$ full scale.

KT-707 reached $3 \frac{1}{2} \%$.

41101

41710

41111

start to close PCV-621.

41123

PCV-621 closed.

41127

Start to open PCV-449 to achieve 25 psia.

41207

Achieved 25 psia.

41208

start to close PCV-449.

41222

PCV-449 closed.

41223

Open RSV-297.

41579

Open PSV-434.

41627.2

Open RSV-433.

41649

Open RSV-738 and RSV-739.

41684

Open FCV-30.

42008

start to open FCV-3I to achieve 4 psid on F-3I.

42019

Achieved 4 psid on F-3I.

42024

Open RSV-858.

42048

Open RSV-859.

42052

RSV-303, RSV-304, RSV-305, RSV-306 opened.

42085

Close RSV-858.

42098

Close RSV-859

42102.

Turn on SGS purge.

42232.6

s. 
NEPN-I CHRONOLOGY (Cont'd)

Start camera group A.

SG-l to idle.

SG-2 to idle.

SG-3 to idle.

Open RSV-853.

Close RSV-222.

Close RSV-727.

Stert to open PCV-447 to achieve $1.5 \mathrm{lb} / \mathrm{sec}$.

Achieved $1.51 \mathrm{~b} / \mathrm{sec}$.

TEST NO. I

Turn on camera group B for 5 seconds.

Start SG-I to full steam.

Turn on camera group B for 5 seconds.

start SG-3 to full steam.

Start to adjust until T-159 indicates 1460

$\pm 50 \mathrm{R}$.

Achieved $1360^{\circ} \mathrm{R}$.

Shutdown to idle $S G-1$.

Shutdown to idle SG-3.

Position FCV-423- 1 \& 3 pots to 10. TEST NO. 2

Start SG-1 to full steam.

Start SG-2 to full stecm.
42247

42251.6

42258.6

42262.6

42275

42281

42293

42310

42319

42361

42361.1

42383

42383.2

42396.0

42447.6

42476.0

42487.4

42495

42612.7

42628.5 
NEPNT-1 CHRONOLCGY (Cont'd)

EVENT

RANGE TIME

Turn off bottom seal blade purge.

42643.7

Turn top seal control switch to off.

42646.6

Start to adjust until $\mathrm{T}-159$ indicates 1460 $\pm 50^{\circ} \mathrm{R}$

42654.0

Achieved $1460 \pm 50^{\circ} \mathrm{R}$

42708.8

Turn on bottorn seal blade purge.

42766.8

Turn top seal control switch to purge.

42770.1

Shutdorn $t$, idle SG-1.

42782.0

Shutdorn to idle SG-2.

42782.1

Position FCV-423- 1 \& 2 pots to 10.

42799

TEST NO. 3

Open RSV-222.

Close RSV-853.

Open RSV-727.

42864.9

Start SG-1 to full steam

42884.2

Start SG-3 to full steam

42899.8

Start to adjust until $T-159$ indicates 1460 \pm 50 .

42911.6

Achieved $1460 \pm 50^{\circ} \mathrm{R}$

42966.6

St=rt to open PCV-6əl to achieve $30 \mathrm{lb} / \mathrm{sec}$.

42982.5

$\therefore$ chis:rea $3010 / \mathrm{sec}$.

42987.7

s. 
NEPNT-1 CHROIOLOGY (Cont'd)

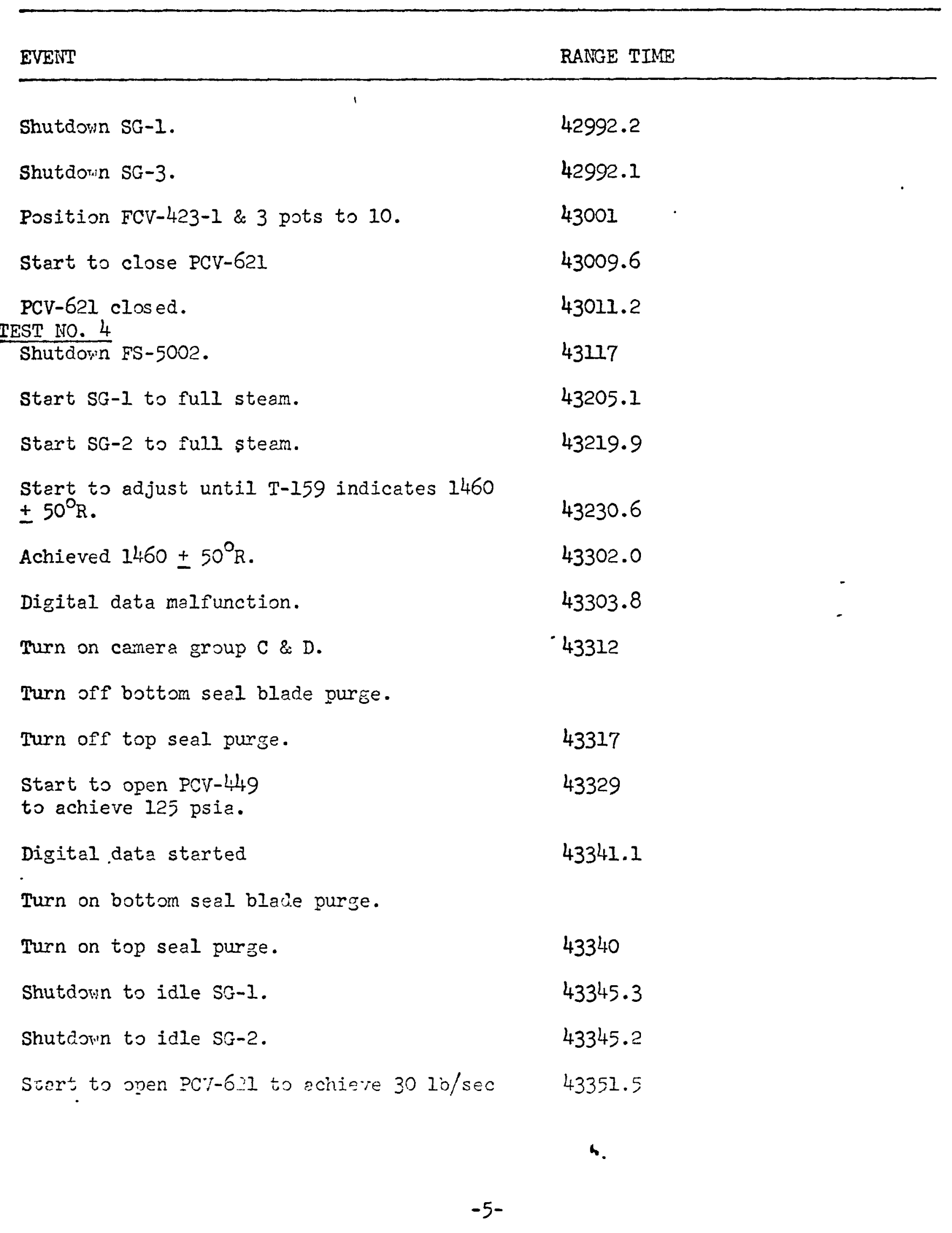


NEPIT-I CHRONOLOGY (Cont'd)

Malfunction of P-906 and PCV-449 starts to close.

43356.2

PCV-449 closed.

43356.6

PCV-449 opens.

43357.3

PCV-449 starts to close.

43357.4

PCV-449 closed.

43357.6

PCr-449 switched to manual.

43357.9

PCV-449 5\% open.

43558.0

Start to close PCV-449 in manual.

43364.2

PCV-449 closed.

43364.6

start to close PCV-621.

43371.8

PCV-621 closed.

43373.9

Start to close PCV-447.

43373.2

PCV- 447 closed.

43374.7

Turn off carera group D.

43380

Position FCV-423-1 and -2 pots to 10 .

43390

BRIEF DATA HOLD

43400

RSV-303, RSV-304, RSV-305, RSV-306 closed.

RSV-738 and RSV-729 closed.

start to close FCV-3I

43428.9

FCi -31 closed.

43445.8

Turn all cerer? ar ups oif. 
NEPN-I CHRONOLOGY (Cont'd)

INITIATION PHASE

43905

RSV-303, RSV-304, RSV-305, RSV-306 opened.

RSV-738 and RSV-739 opened.

Staried to open FCV-3I until F-31 equals 4 psid.

Turn on camera group A, C, D.

TEST NO. 5

Start $S G-1$ to full steam.

44021.2

Start $S G-3$ to fuIl steam.

44036.3

Start to adjust until $\mathrm{T}-159$ indicates

$1460 \pm 50^{\circ} \mathrm{R}$

44045.0

Achieved $1460 \pm 50^{\circ} \mathrm{R}$.

44098.9

Start to open PCV-447 to establish $1.5 \mathrm{lb} / \mathrm{sec} .44131 .1$

Achieved $1.5 \mathrm{lb} / \mathrm{sec}$.

44136.6

Turn on smoke pots.

Start to open PCV 449 to achieve 50 osia.

44151.5

Achieved 50 psia.

44161.0

Turn on camera group B.

44171

Shutdomn to idle SG-I.

44171.1

Shutdown to idle SG-3.

44171.2

Start to open PCV-621 to achieve $30 \mathrm{lb} / \mathrm{sec}$. $\quad 44180.2$

Achieved $30 \mathrm{Ib} / \mathrm{sec}$.

44185.6

Start to close PCV-\$49.

44186.4

4. 


\section{NEPN-1 CHRONOLOGY (Cont'd)}

PCV-449 closed.

start to close PCV-621.

start to close PCV-447.

PCV-621 closed.

PCV-447 clósed.

Stop SG-I.

Stop SG-2.

stop SG-3.

RSV-303, RSV-304, RSV-305 and RSV-306 closed.

Start to close FCV-3I.

FCV-3I closed.

Close FCV-30.

Turn off camera groups A, B and $C$. SHUTDOWN PHASE

Start to vent $\mathrm{LO}_{2}$ tank.

start to vent propane tank.

Close RSV-433 and RSV -434 .

Propane tank vent complete.

Turn off SGS purge.

start to open PCV-449 to vent header.

Close PCV-449.
44790.6

44795.5

44198.2

44196.9

44198.5

44203.5

44206.3

44208.4

44242.9

44266.3

$-44287$

44396

44431

44439

44590 .

44802

45710

45764

4. 
$\begin{array}{lll}\text { TO: } & \text { J. Ramsthaler } & \text { DATE: } 19 \text { June } 1967 \\ \text { FROM: } & \text { T. O'Callaghan } & \end{array}$

SUBJECT: EVALUATION OF STRAIN GAGE DATA ON NES DESIGN DEMONSTRATION TEST

\section{DISTRIBUTION:}

Ref. (a) Report No. RN-S-0211 to AEC-NASA Space Nuclear Propulsion Office. NES/ETS-1 Duct Structural Dynamies. August 1966

The attached Table shows the maximum strains measured during the subject tests. It is based on the digital data available at the site on the morning of June 14--a short listing. In preparing the table only 10 of the channels, thuse indicated on Table $I$, were scanned.

The maximum strain recorded on all five tests was 425 microinches per inch, corresponding to an ROM stress level of $12,750 \mathrm{psi}$. This was recorded during the second test on strain gage GG 017 located on top of the duct at Station 746 (after and near the entrance to the horizontal section) at time 427127. At this time two of the . steam generators were on, the nitrogen purge was at $1.81 \mathrm{~b} / \mathrm{sec}$ and the egine PC was zero psig.

With the engine running the calculated stress at a close location, Station 781.2 , is 11,917 psi static plus 572 psi dynamic $=12,489$ psi total normal stress; this level has a Margin of Safety of 0.20 based on an allowable stress level of 15,000 psi (Ref. 20 . In as much as the egine was not running during the test, the measured strain levels on this portion of the duct should be more closely examinea. A possible source of the large strain noted would be imperfect temperature compensation of the strain gauges; $i . e .$, the strain gauges may be partially reading the uniform stress-free expansion of the duct as strain. A temperature rise of $20^{\circ} \mathrm{F}$ in the duct would induce a maximum false strain of 200 micro inches per inch. This effect, if present, could reduce the meximum strain level noted form 425 to 225 micro inches per inch, corresponding to a maximum stress level in the duct of $6750 \mathrm{psi}$ induced by the test condition. The influence of chamber pressure on train levels will also be determined for selected locations. The frequency content of the wide band measured strains will also be examined.

Table I indicates for each of the three most critical strain gages, as determined from a visual scan of the digitized short list data, and for each test, the maximum strain levels recorded. The time is noted as Control Room Time and the nearest prior event is noted as well. 
The attached Fig. 28 and Table IX, taken from Ref. (a), indicate the potenially critical locations of the duct and, in script, the 10cations of the nearest strain gages and accelerometers; also indicated are the theoretically calculated margins of safety. The figure and table are based on the engine firing condition.

Reduction of Accelerometer Data has not yet been initiated.

A list of Recommendations is given in Table II. 
(Continuation of lemo No. 17)

\author{
TO: J. Ramsthaler \\ DATE: 19 June 1967 \\ FROM: T. O'Callaghan \\ SUBJECT: NES DESIGN DEMONSTRATION TEST, PHASEII; June 13, 1967
}

DISTRIBUTION:

TABLE II Recommendations

1. Instrument the Side Shields to determine their motion, if any, during overpressurization of the Egine Test Compartment.Range a. displacement transducer $-5 / 100$ to $+15 / 100$ of an inch (-denotes Shields moving together, + denotes Shields moving apart).

2. Instrument Top Shield to measure deflection in both upwards \& downwards directions, Range a displacement transducer $+\frac{1}{4} "$ to detect upward movement and - $-\frac{1}{4} "$ to detect downward movement.

3. a. Conduct Power Spectral Density Analyses of Wideband Accelerometer and Strain Gage data to determine presence and extent of excitation in the range of duct natural frequencies ( 31,39 , $43,46,53,63 \mathrm{cps})$ and in the range of Truss Frame natural frequencies $(7,9,15,17,23,29,31,44,50$, cps $)$.

b. Investigate Response of Accelerometers in the frequency ranges indicated. If poor develop means of obtaining true acceleration magnitudes or replace accelerometers by ones which will give true indications in the indicated ranges.

4. It is recommended pre-test stress predictions be made for NEPV to facilitate quicker analysis of strain gage data. 
TA BIE IX

VAXIPU: :CEUIL STRESS IN

Allowable :Hc nal Stress $=25,000$ psi

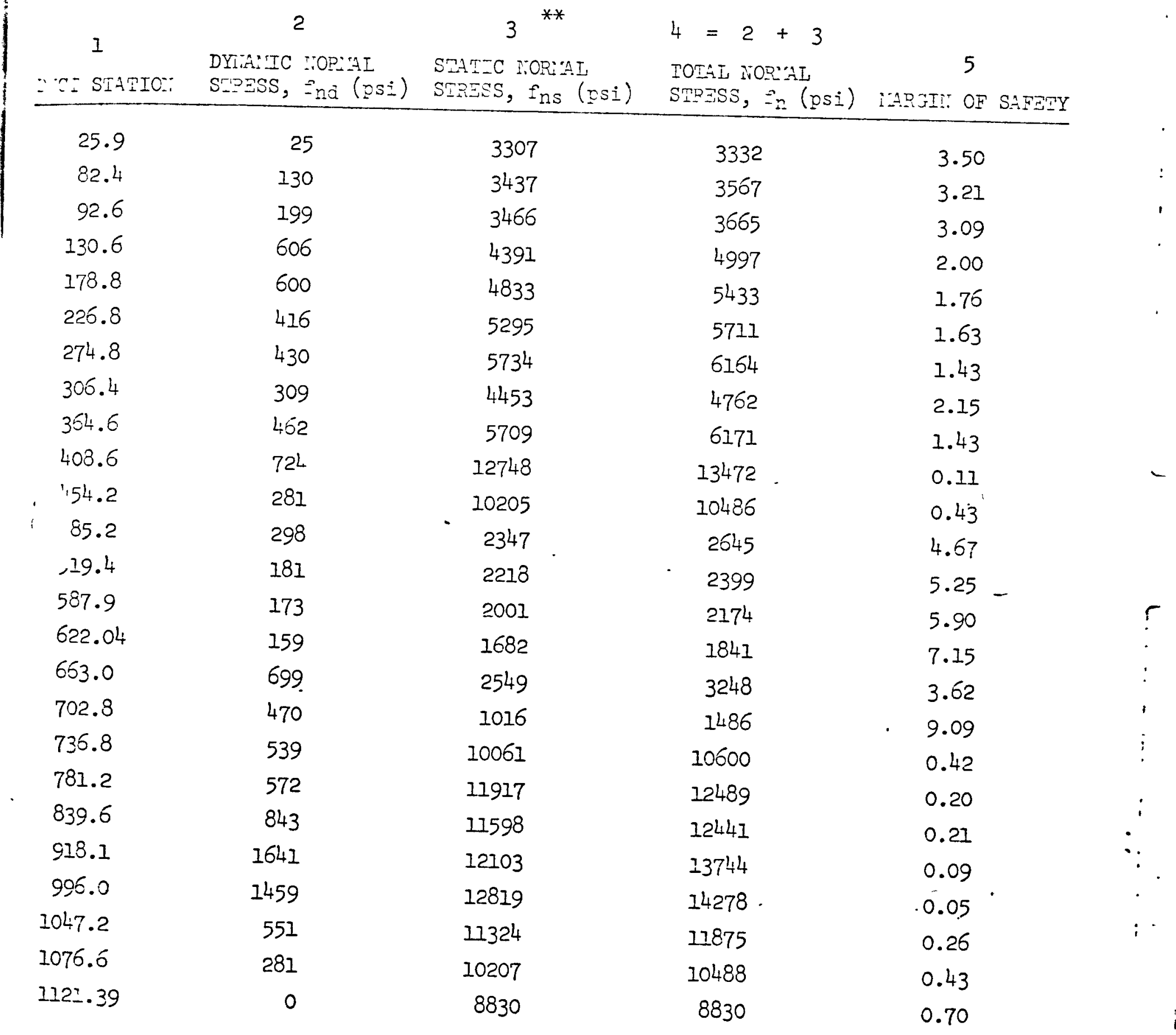

From ReZerence 2 


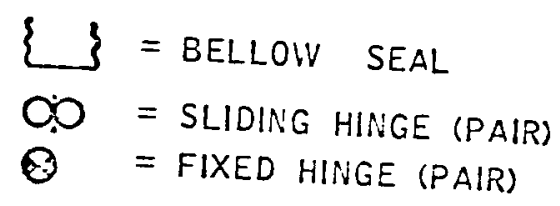

ALLOWABLE NORMAL STRESS = IE,000PSI

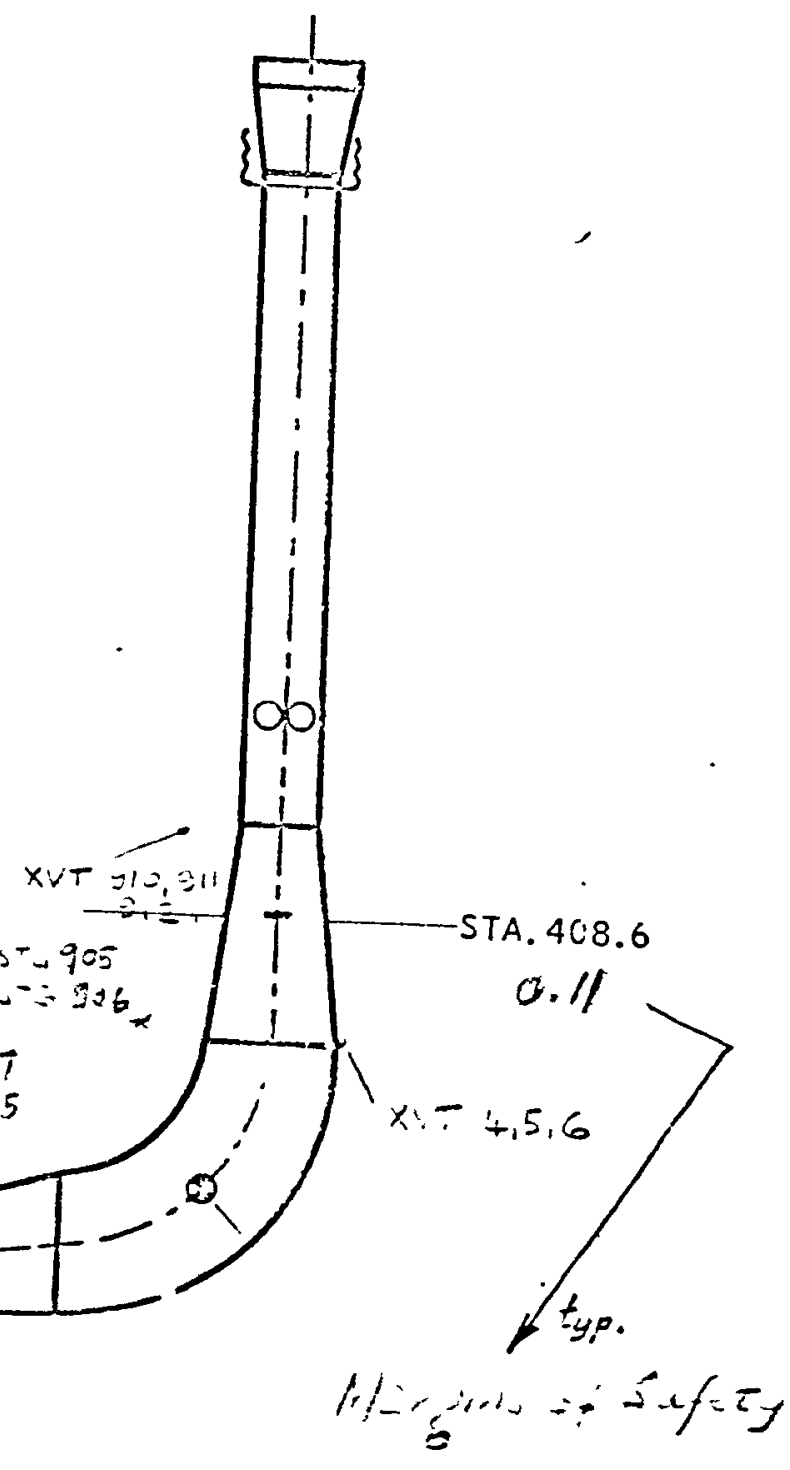

STA. $996.0 \quad 0.09$

$$
\begin{aligned}
& 0.05 \\
& \text { o. } 21 \\
& +
\end{aligned}
$$

Figure 18

$S T G=G G=$ Sirdin Gage XVT $=H T:$ Ascelerometer.

Locations of Critical Homal Stress in IIES Dhict

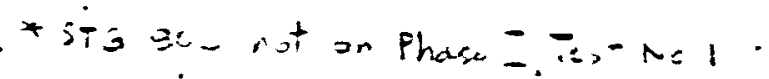




\section{TABLE I}

Maximum Digitized Stirains snmpled over $G G 006,007$, $011,012,013,015,016,017,018,019$.

\begin{tabular}{|c|c|c|c|c|c|}
\hline $\begin{array}{l}\text { STRAIN } \\
\text { GAGE NO }\end{array}$ & LOCATION. & $\begin{array}{c}T_{E} ; T \\
N_{0} .\end{array}$ & $\begin{array}{l}\text { M/AX, } \\
\text { STRAIN }\end{array}$ & TIME & Nearest Prior Event \\
\hline GGO OII & $\begin{array}{l}\text { On Stedm Line } \\
\text { before Bellows } \\
\text { near Ejector Nilld. }\end{array}$ & $\begin{array}{l}1 \\
2 \\
3 \\
4 \\
5\end{array}$ & $\begin{array}{l}288 \\
316 \\
363 \\
365 \\
353\end{array}$ & $\begin{array}{l}723789 \\
426297 \\
429937 \\
432215 \\
4+0341\end{array}$ & 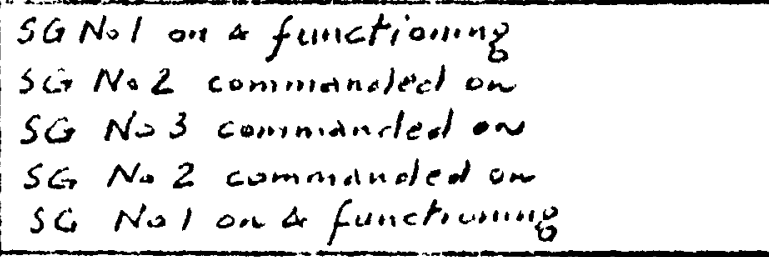 \\
\hline$G G 0 / 5$ & 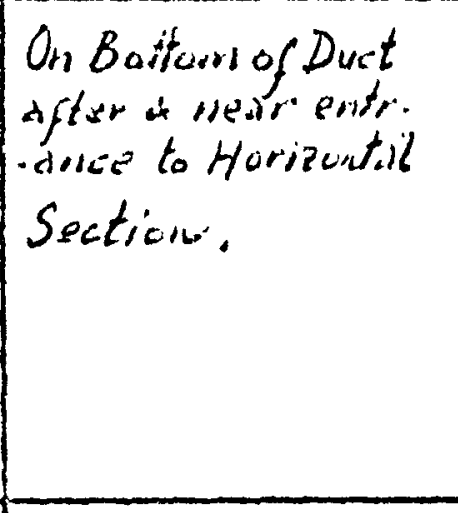 & $\begin{array}{l}2 \\
3 \\
4 \\
5\end{array}$ & $\begin{array}{l}299 \\
-172 \\
244 \\
-268 \\
160 \\
-366 \\
139 \\
-379 \\
64 \\
-342\end{array}$ & $\begin{array}{l}423790 \\
425099 \\
426297 \\
428067 \\
+29007 \\
430105 \\
432205 \\
433572 \\
4+0371 \\
4+1158\end{array}$ & 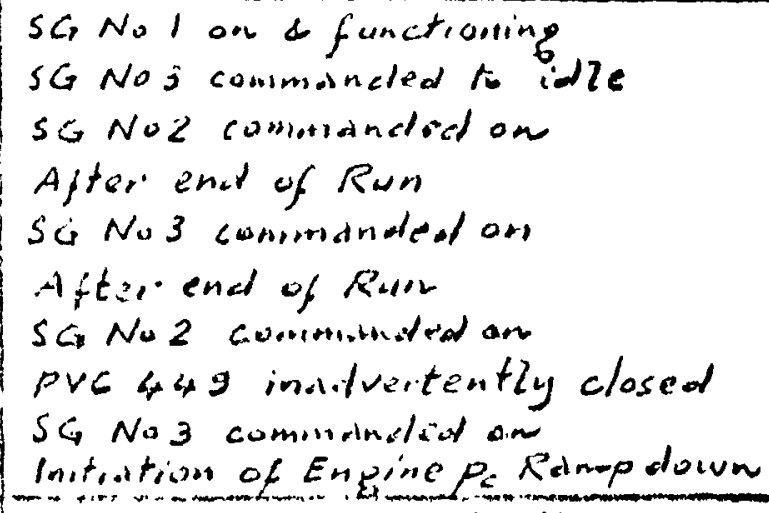 \\
\hline GGO1\% & 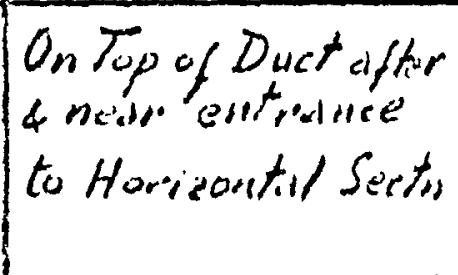 & $\begin{array}{l}1 \\
2 \\
3 \\
2 \\
5\end{array}$ & $\begin{array}{l}382 \\
425 \\
285 \\
370 \\
402\end{array}$ & $\begin{array}{l}42475 y \\
+127127 \\
428337 \\
+33452 \\
4+1321\end{array}$ & 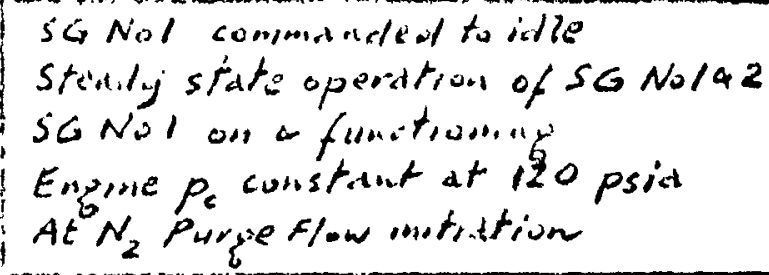 \\
\hline
\end{tabular}

Notes: Max Strains indicated are in Microinches per inch. ROM Stress Levels may be obtcined by nultiplying the numbers shown by 30 to get psi $S G$ : Stesm Gesserator. 
TO: J. H. Ramsthaler, Spcan Chairman

FROM: J. K. Endo, ' $r^{\prime}$ Exkis

SUBJECI: ilinimum Temperatire at $R$ Q'5 Cutiet

Temporamy tempratime indicator, In-325, was located at the outlet of $\mathrm{R} 045$ to determine what the Gira temperature entering the E.T.C. would be for various purge flow rates. The Gir enterino the I.T.C. is directed over certain pressure transducers located in the UTS that have a minimum operating temperature of $480^{\circ} \mathrm{R}$.

The folloring table shows that the temperature dropped belor $480^{\circ} \mathrm{R}$. after the 25 and $30 \mathrm{lbs} / \mathrm{sec}$. purge flow rates were shutcom with the E.T.C. at atmospheric pressure. Apparently the throttling effect across PCV-52I is causing the temperature to decrease by approzirately $20^{\circ} \mathrm{R}$. Iith PCV-62l closed, the temperature stayed belo-7 $480^{\circ} \mathrm{R}$ for approximately 17 , 18 , and 6 seconds for test nurbers 3,4 , and 5 , respectively, before warming

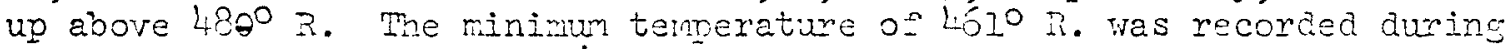
test INo. 3 after tie $30 \mathrm{lbs} / \mathrm{sec}$. purge flon was shutiorm.

It is recomended that $\mathrm{Imo}$ further eraluate the data and deternine if the time at rhich the tenoeraturea decreased belor $480^{\circ} \mathrm{R}$. rouli be detrimental to the instrumentation located at the purge exit.

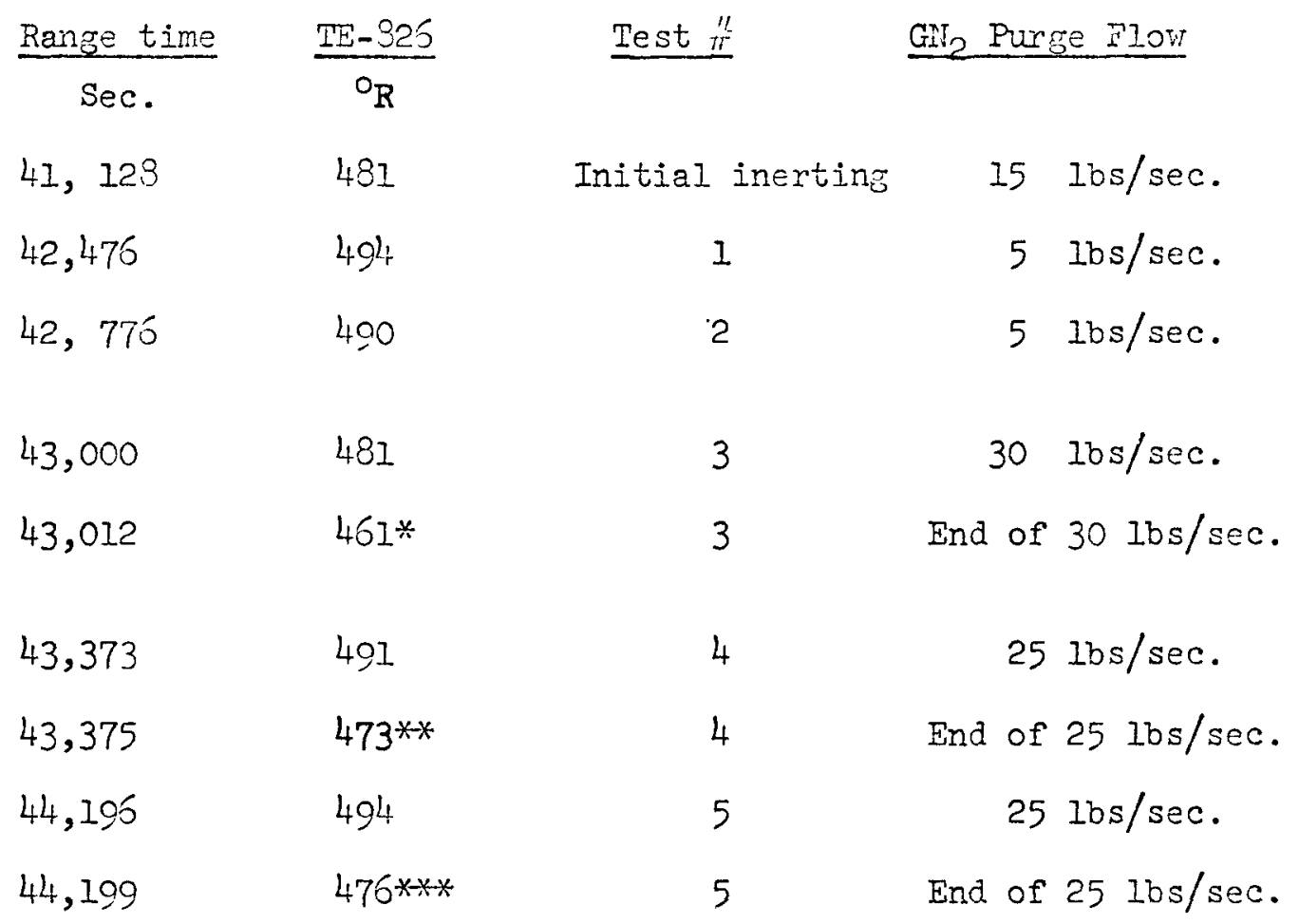

* Tr-826 stajca below $480^{\circ} \mathrm{R}$ for approximately 17 seconas.

* TE-826 stayed below $450^{\circ} \mathrm{R}$ for approyimately 18 seconds.

*** TE-826 stuyed below $480^{\circ} \mathrm{R}$ for approximately 6 seconas. 
TO: $\quad$ J. H. Ramsthaler, Spear Chairman

DATE: 23 June 1967

FROM: $\quad$ J. K. Endo

SUBJECT: Flare Operation

\section{SUMMARY:}

The flare operated for the entire test series without an unplanned flameout, indicating the modifications have successiully eliminated this problem. During Test Number 4, it was intentionally extinguished to determine if it could be reignited under flow conditions. A single attempt was made to reignite the flare which failed. However, past experience indicates that several attempts must be made to ignite a flare even under ideal conditions.

\section{RECOMENDATIOIIS:}

Since the flare remained ignited during rests $1,2,3$, and 5 , it has been recommended that a redundant system be installed to assure that the ilere once ignited, be continuously supplied with the proper amount of air and propane. Action on this item ras been initiated by ITTO.

\section{DISCUSSIOIT:}

FS-5002 was modified prior to the start of IIEP $\mathrm{N}-\mathrm{I}$. The various modifications appear to be adequate to keep the flare from flaming out during any particular test run. The flare remained ignited during test kuns Numbers 1, 2, 3, and 5. At the start of Test inumer 4, the flare was intentionally extinguished to determine if it could be reignited with two steam generetors on and a chamber pressure, Pc, of $120 \mathrm{psia}$ ( $180 \mathrm{Ibs} / \mathrm{sec}$ ) established. A single attempt was made to reignite the flare. This single attempt was unsuccessiul.

However, in view of past flare ignition experience, it cannot be concluded that the flare system will not ignite with primary flow established in the duct systern. Past experience has shown that several attempts are required to ignite a flare under ideal operating conditons.

It appears as though once the flare has been established the probability of it flaming out is small. Therefore, action has been initiated to install a back-up system across the critical components in the propane and air lines to assure that air and ruel be supplied to the flire at all times. The system consists of installing a redundant solenoid valve in parallel with SV- 118 and a redundant pressure reducing valve in parallel with PRV-73 in the propane line. In the air line SV-406 will be in parallel with a redundant solenoid valve. At the present time, the system is being further analyzed by INT to determine if the above modification will be adequate as a back-up system.

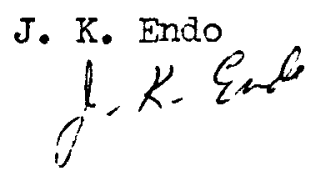


TO: J. H. Ramsthaler

23 June 1967

FROM: $\quad$ H. W. Brandt

SUBJECT: PT-906A Malfunction During NEPN-1, Test No. 4 (PCV-449 Closure)

$\underline{\text { Summary }}$

The rapid termination of primary nitrogen flow during Test No. 4 was caused by the malfunction of PT-906, a pressure transducer in the control circuit for the nitrogen flow. A third pressure transducer is being added to the control system and an average reject circuit being made which should eliminate a system malfunction if only one transducer fails.

Discussion

This memo presents the results of an evaluation of the NES GN 2 Supply System during the PT-906A malfunction.

The results of the evaluation revealed that the PCV -449 control system responded satisfactorily during the test; however, significant changes are being made to the feedback control circuit to eliminate inadvertant closure as a result of a transducer failure.

During Test Nos. 4 and 5, the primary nozzle chamber pressure was the controlling parameter. Primary flow was controlled by PCV-449 through a feedback 100p from PT-905 and PT-906A, auctioned to select the highest primary chamber pressure. A ramp generator was used for automatic startup during Test No. 4. Since PT-906A is located approximately 40 feet upstream of PT-905, PT-906A was the primary control transducer during NEPN-1.

Figure 1 is a plot of various NES GN Supply System parameters versus time. It can be noted that at 43356.15 seconds, PT-906A failed as indicated by the rapid change in the $\mathrm{PT}-906 \mathrm{~A}$ output from 125 psia to full scale value. Post-test checkout of the Taber transducer verified the ematic test behavior. Immediately after the transducer failed, PCV-449 went closed at a slew rate of $150 \% / \mathrm{sec}$. During the closure of the valve, the primary chamber pressure decayed (as indicated by PT-905) at a maximum rate of $-220 \mathrm{psi} / \mathrm{sec}$. The valve closed at approximately 43356.56 seconds at which time the chamber pressure decay rate increased to $-720 \mathrm{psi} / \mathrm{sec}$. A good average decay rate excluding the tail at both ends is $-250 \mathrm{psi} / \mathrm{sec}$. At 43356.61 seconds the PT-906A output went negative thus transferring the feedback control to PT-905 which was indicating 35 psia. 
The control valve did not open immediately in response to the PT-905 feedback due to the time response of the controller. The valve came open at 43357.2 seconds at which time PT-906A went to full scale resulting in closure of PCV-449.

It appears that the failure was intermittent possibly caused by induced vibrations transmitted from the main flow piping to the transducer, which was close-coupled to the primary NES pipe. Even after the failure, the transducer functioned properly from 43356.8 to 43357.2 seconds during zero flow conditions; however, PT-906 malfunctioned as soon as PCV-449 opened and flow was initiated.

Feedback control was again transferred to PT-905 when PT-906 went negative; however, PCV-449 was switched to the Manual control mode at approximately 43357.9 seconds. The valve opened to $5 \%$ since the control system was setup to provide a constant demand in Manual mode in order to eliminate a detrimental interaction between the plug and seat during a switch from Auto with the valve significantly open to Manual control with a zero Manual pot setting.

In order to reduce the probability of a similar failure during future tests, the feedback control system is being changed to an "average and reject" type which is inherently more reliable. A third transducer is being added to facilitate this modification.

It should be noted that the $\mathrm{GN}_{2}$ header pressure (PT-002) was lower than the PCV-449 inlet pressure (PT-904) after the valve closed, which may have resulted in reverse flow in the system.

In summary, it appears that the PCV-449 control system operated satisfactorily and that the rapid termination of primary flow was caused by a faulty pressure transducer.

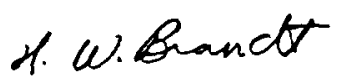

H. W. Brandt

ETS-I Operations Analysis 


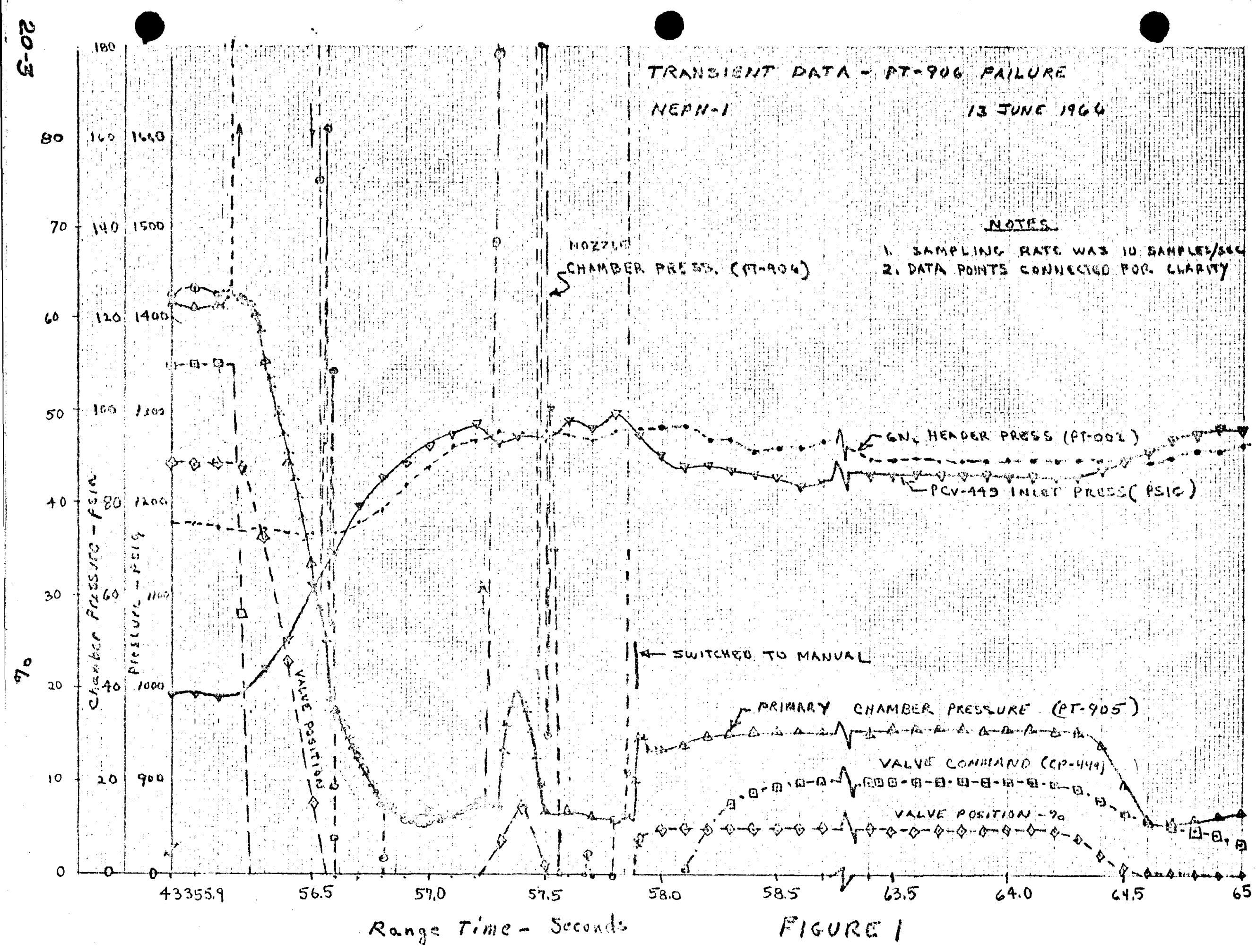


TO: $\quad$ J. H. Ransthaler

DATE: 23 June 1967

FROM: $\quad$ R. Cooper, NRO/E. Johnson, NTO

SUBJECT: Data Systems Evaluations

\section{SUMMARY}

The overall ETS-1 IEC effort, transducer through data distribution, was satisfactory. IRO's reduction and data handling in support of SPEAR was not utilized so no evaluation could be made.

The digital data system (DDS) recorded a total of 4338 seconds plus calibrations, 733 seconds of which vere in the continuous recording mode; 10 records per second. There vere 285 channels recorded, 65 of which were initially discrepant. Forty-one were corrected through data reduction and 12 channels definitely failed due to hardware and two are still under investigation. This gives an overall utilization of $96 \%$ usable data.

The analog data system was satisfactory.

\section{DISCUSSION}

2.0 The planned data reduction procedure for the IIEPN test series and the results for $\mathrm{NEP}$ il-I were as follows:

2.1.0 Guick-Look Data (should be reasonably complete by post calibration +24 hours)

2.1.1 Provide real time analog recordings. These were available upon completion of the post calibration (Tuesday 3:00 p.m. or $k+0$ ).

2.1.2 Listings from the thin digital EU tapes. These vere available Wednesday 8:00 a.m. $(R+17)$.

2.1.3 Thin IU tape plots. Delayed because of the 3200 downtime. The first 60 plots were available Thursday $8: 00 \mathrm{a.m} .(\mathrm{R}+41)$ and processing continued with special request as required.

2.1.4 Long record EU tapes containing all data for off-site distribution to INRO was complete Wednesday 2:00 p.m. $(\mathrm{R}+23)$.

2.1.5 Duplication of wide-band tapes (from four recorders). Iormally these are required on $R+24$. This requirement was deleted because

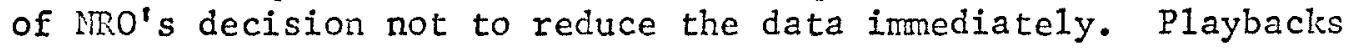
of special requests were made. Tapes vere ready Friday 10:00 a.m. $(n+67)$. On future tests these tapes will be ready for hand-carrying to ino with the EU tapes at $R+24$. 
2.2 Bulk data and special request data. (Should be available for distribution starting at $R+30$ and continuing as required.)

2.2.1 EU tab listings at $10 \mathrm{~s} / \mathrm{s}$. The first five of 25 passes was available Thursday 8:00 a.m. $(R+4 I)$ and completed by Friday $8: 00$ a.m. $(R+65)$.

2.2.2 P1ots. The first 60 plots vere available Thursday 8:00 a.m. $(R+41)$ and continued as requested.

2.2.3 Initial special wide-band playbacks were requested Vednesday $11: 00 \mathrm{a} . \mathrm{m} .(n+20)$ and 8 oscillograph rolls were available Thursday 10:00 a.m. $(R+43)$. Further processing continued as requested.

3.0 Breakdown of data reduction and instrumentation problems follow:

3.1 SS 1 it of the DDS lost 37.3 seconds of recording; the folloring is a description of the three failures that caused this loss of data:

Of the five tape drives (TD) available to the DDS, one TD is for recording and a second is for backup for each subsystem (SS). SS 1 il was assigned to TD's $1 \& 3$; SSth 2 vas assigned to TD's $3 \& 4$, with the fifth on stand-by in case of a failure.

SSit 1 transferred from TD 3 to TD 1 upon detecting the end of tape (EOT) mark, leaving TD 3 full of data and positioned at EOT mark. At approximately the same time SS the physical end of the tape, resulting in loss of about two seconds of data. TD 2 was assigned to record SS: 2 manually with TD 5 as backup. TD 2 immediately detected parity errors and automatically switched to TD 5, thus utilizing all five TD's as follows:

$$
\begin{aligned}
& \text { TD } 1-\text { Recording SS: } 1 \text { I } \\
& \text { TD } 2-\text { Parity errors } \\
& \text { TD } 3 \& 4-\text { Ful1 of data } \\
& \text { TD } 5
\end{aligned}
$$

At this time TD 1 detected parity errors and autonatically switched to TD 3, a full tape positioned at EOT mark, which promptly ran off its physical end, and alI data on SS非 were then being lost. TD 1 was then manually rewound and selected for recording of SSk1, resulting in loss of 37.3 seconds of data. Because of these failures, tape switching vas done manually for the remainder of the test. NTO is investigating means to eliminate this problem on future tests.

3.2 Eight hours of CDC 3200 computer reduction time was lost for this test because of failure of the hardware floating point system. As soon as the problem was isolated the Control Data engineer vas called and the computer was returned to service. 
3.3 The slope intercept program had a bad binary card from the latest compilation and computed the wrong slope and intercept for 27 channels. The card has been cinanged and the channels rerun.

3.4 Seven channel ECR's vere not included in the channel data log before the data reduction cards were made; however, the corrections were made for the $10 \mathrm{~s} / \mathrm{s}$ EU tab listings. Real time oscillograph in $_{3}$ recording was badly torn during the test; hovever, it was processed and the data was usable.

3.5 SPL DATA - KVT 829, 830, 831, 832 Accoustic Channels (tro mounted in ETC and two on TV bunkers) appeared to be operating satisfactorily during test and subsecuent playback from analog tape showed data vas recorded. Detailed analysis will be accomplished at MRO.

3.6 Anemometer Data - A playback on oscillograph from analog tape of measurements $\mathrm{Kil} 600 \mathrm{w}, \mathrm{x}, \mathrm{y}-601 \mathrm{w}, \mathrm{x}, \mathrm{y}$ (18 measurements) indicated that all channels of vind velocity-direction vere valid and somewhat as expected. Detailed evaluation will be done at a later date.

3.7 PT627 - Appears that plumbing may be reversed with PT633. Under investigation.

3.8 TT534 - No data. Post test checks showed that transducer was misterminated.

3.9 PT204, 209, 226 - These three pressure transducers vere locked out and reading full scale throughout test. All three are 0 - 100 psia transducers mounted on $\mathrm{H}_{2} \mathrm{O}$ system and pressurized in excess of 200 psia.

3.10 PT239 - Duct steam header pressure - Transducer pressure port or sense line appeared plugged. Pressure variations did not follow those of PT925 which monitors same pressure. Electrical calibrations were o.k. Problem is being investigated.

3.11 FTO32 - Duct $\mathrm{H}_{2} \mathrm{O}$ supply pressure total - Channel was extremely noisy during test. No data was received because transducer was intentionally bypassed. Transducer may be replaced.

3.12 PT290, 291, 292, $293 \& 800$ - Data was somewhat contradictory with PT874 and 875. The sensing lines were found to have leaked and have since been repaired.

3.13 PT223 \& 224 appear to have both a data reduction and a hardware problem. Presently under investigation. 


\subsection{Sacramento Data Reduction}

The NEPN-I data were planned to be plotted in Sacramento. Tapes were transmitted but the data vere not reduced because of budget limitations. Sacramento will produce power spectral density and other data for follow-on analysis.

\section{RECORMENDATIOITS}

A. A complete demonstration of the Sacramento data reduction system should be made as soon as possible.

B. The tape situation which resulted in the loss of 37 seconds of data should be fully investigated and corrected.

R. Cooper, R.RO

E. Johnson, NTO 